University of Louisville

ThinkIR: The University of Louisville's Institutional Repository

Electronic Theses and Dissertations

8-2003

\title{
The influence of teachers' efficacy and beliefs on mathematics instruction in the early childhood classroom.
}

Elizabeth Todd Brown 1948-

University of Louisville

Follow this and additional works at: https://ir.library.louisville.edu/etd

\section{Recommended Citation}

Brown, Elizabeth Todd 1948-, "The influence of teachers' efficacy and beliefs on mathematics instruction in the early childhood classroom." (2003). Electronic Theses and Dissertations. Paper 160.

https://doi.org/10.18297/etd/160

This Doctoral Dissertation is brought to you for free and open access by ThinkIR: The University of Louisville's Institutional Repository. It has been accepted for inclusion in Electronic Theses and Dissertations by an authorized administrator of ThinkIR: The University of Louisville's Institutional Repository. This title appears here courtesy of the author, who has retained all other copyrights. For more information, please contact thinkir@louisville.edu. 
THE INFLUENCE OF TEACHERS' EFFICACY AND BELIEFS

ON MATHEMATICS INSTRUCTION

IN THE EARLY CHILDHOOD CLASSROOM

By

Elizabeth Todd Brown

B.S. Drake University, 1970

M.A. University of Louisville, 1995

\author{
A Dissertation \\ Submitted to the Faculty of the \\ Graduate School of the University of Louisville \\ in Partial Fulfillment of the Requirements \\ for the Degree of \\ Doctor of Philosophy \\ Department of Teaching and Learning \\ University of Louisville \\ Louisville, Kentucky
}

August 2003 
Copyright 2003 by Elizabeth Todd Brown

All rights reserved 
The Influence of Teachers' Efficacy and Beliefs on Mathematics Instruction in the Early Childhood Classroom

\author{
By \\ Elizabeth Todd Brown \\ B.S. Drake University, 1970 \\ M.A. University of Louisville, 1995 \\ A Dissertation Approved on
}

July 23,2003

by the following Dissertation Committee

Dissertation Director 


\section{DEDICATION}

This dissertation is dedicated to my late father and grandmother

Robert R. Dunlap and Elizabeth Brownley Smith

who gave me an invaluable spirit and love of education. 


\section{ACKNOWLEDGEMENTS}

This dissertation represents a milestone in my journey of learning and teaching. I believe to accomplish a "terminal degree" you need to be surrounded by people that are committed and share your love of learning. I would like to acknowledge the people that have shared my journey in research and education.

First, my husband Ron is a large part of the reason I am even writing this acknowledgement. Three years ago he encouraged me to pursue the dream of a $\mathrm{PhD}$. He has been my foundation, guidance counselor, and coach in the journey. Along with the cheerleading section of daughter Beth, son Andy and daughter-in-law Amanda, they have worked in concert with Ron to keep me focused on the prize. Their confidence in me and unconditional love has been my motivation.

Second, my dissertation chair, colleague and friend Dr. Karen Karp has been an inspiration and guiding force in my life for ten years. Her vision for equity in mathematics, her determination to make a difference in her field and her talent for teaching teachers has been my role model during this journey. Dr. Karp has been an outstanding mentor in her guidance and suggestions for professional development and experiences that have facilitated the completion of this dissertation. She has been magnanimous with her time, talents and resources. This educational, learning journey 
would have been far more challenging without a friend, like Karen, to share the joys and celebrations along the way.

The other members of the committee have contributed to my development in considerable ways. Dr. Victoria Molfese, director of the Early Childhood Research Center, has provided support for me to work on research projects that became the backbone for my own research. Her expertise in research design and analysis has been invaluable. She has been generous with providing feedback on the various drafts and her door has always been open for "quick, quality conferences."

Dr. Joseph Petrosko has supported my development as a quantitative researcher. His guidance and mentoring of the research design and subsequent procedures for data collection and data entry facilitated a smooth journey. Dr. Petrosko, as well as Dr. Ann Larson and Dr. William Bush, have been generous with dedicating time to read multiple drafts and adding their knowledge and suggestions along the way. 


\begin{abstract}
THE INFLUENCE OF TEACHERS' EFFICACY AND BELIEFS ON MATHEMATICS INSTRUCTION IN THE EARLY CHILDHOOD CLASSROOM
\end{abstract}

\author{
Elizabeth Todd Brown
}

July 23, 2003

This dissertation was a correlational study conducted with a population of pre-k educators from a large Midwestern, metropolitan school district. The purpose was to examine if relations existed among early childhood teachers' sense of self efficacy, their beliefs about the importance of mathematics and teachers' mathematics instructional practices. There is strong reason to believe that teachers' mathematics beliefs and conceptions about the subject matter and its teaching play a vital role in their effectiveness as mediators between the subject and the learner. Examining teachers' efficacy and beliefs can inform educational practice and differentiate between successful and less successful instructional practices in teaching mathematics in the early childhood classroom. The research and observations of what early childhood teachers know and believe they are able to do has a profound effect on the way they teacher and on ultimately their students mathematical literacy development.

Data were collected on teacher efficacy and teacher beliefs about the importance of mathematics with two self-report questionnaires. The hypothesis that the teachers higher in efficacy will rate the importance of mathematics higher on the Teacher Belief 
Scale than the teachers with lower efficacy was found to be true with this sample, but the correlation was weak. The level of efficacy of the early childhood teachers in this sample confirmed that in assessing their capabilities they rate themselves high in instructional strategies, classroom management and student engagement. The early childhood teachers did not rate their mathematics beliefs as high as their efficacy. The belief rating may reflect the lack of consensus among early childhood teachers that mathematics is important for preschool children.

Observations of mathematics instructional practices were conducted with twenty teachers. It was hypothesized that the combination of high Teacher Efficacy and high Teacher Mathematics Beliefs would show alignment with the presence of standardsbased Mathematics Instructional Practices. The results were not statistically significant. No correlation signals a need for more research to explore what other personal or external factors relate to mathematics instructional practices in the early childhood classroom. The research will inform pre-k teachers about effective instructional strategies and knowledge needed to launch early childhood students on a developmentally appropriate pathway to mathematical literacy. 


\section{TABLE OF CONTENTS}

PAGE

ACKNOWLEDGEMENTS ..................................................... iv

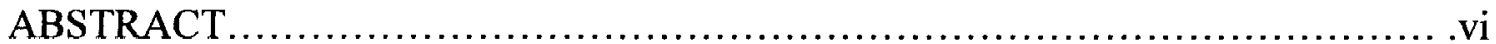

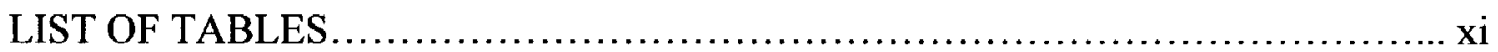



CHAPTER

I. INTRODUCTION AND STATEMENT OF THE PROBLEM.......... 1



Theoretical Rationale ............................................. 7

Statement of the Problem........................................ 12

Purpose ............................................................... 15

Significance.................................................... 17

Research Questions................................................... 17

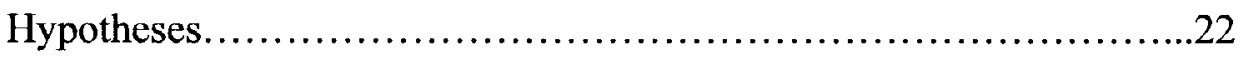



Conceptual Model................................................. 24





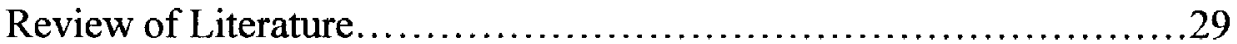


Theoretical Foundations............................................30

Research on Teacher Efficacy.....................................34

Research on Teachers' Beliefs....................................... 48

Research on Young Children and Mathematics......................... 64

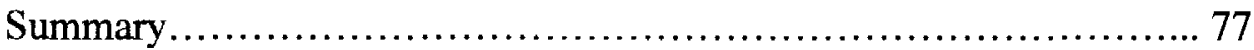

III METHODS AND PROCEDURES ....................................79

General Perspective................................................. 79

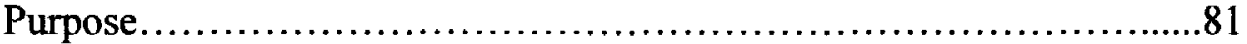

Research Context..................................................... 81

Research Participants................................................82

Data Analysis.................................................... 93

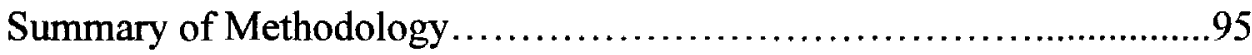

IV. RESULTS ...................................................... 97

Results........................................................ 97

Descriptive Statistics........................................... 98

Correlations..................................................... 101



V. DISCUSSION, LIMITATIONS AND IMPLICATIONS ................121

Discussion.................................................... 110

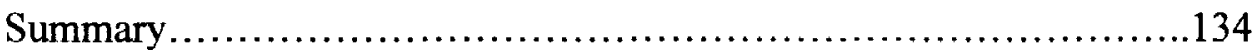

Limitations..................................................... . .

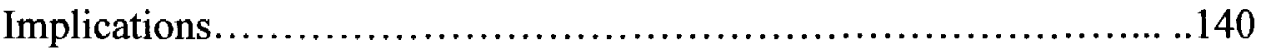


Summary

REFERENCES ....................................................... 150

APPENDICES ............................................................ 166

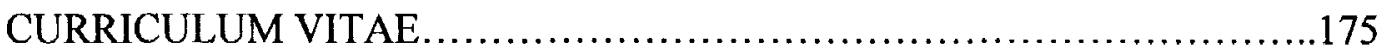




\section{LIST OF TABLES}

TABLE

PAGE

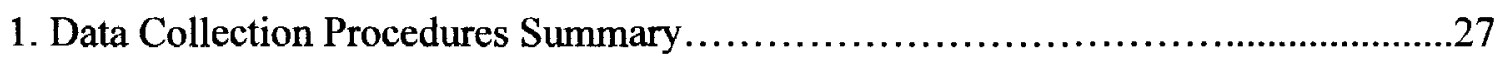

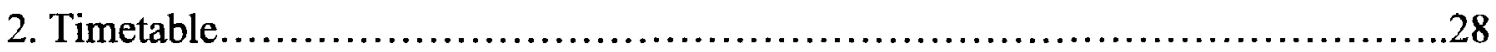

3. Characteristics of Sample Population Full Data Set and Sub Group Observation Sample .......................................................................

4. Variable used in Correlational Analysis........................................95

5. Means, Standard Deviations, and Ranges for Teacher Efficacy and Beliefs about

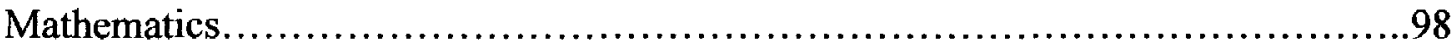

6. Correlations Among Subscales for Teacher Efficacy and Beliefs about Mathematics

7. Means, Standard Deviations of Teacher Efficacy and Teacher Beliefs about the importance of Mathematics for Sub Group and Full Data Set....................106

8. Means, Standard Deviations, and Ranges for Standards Observation Form

9. Intercorrelations Among the Standards Observation Form Categories of Teacher Mathematics Instructional Practices.

10. Correlations Among Teacher Beliefs about the importance of Mathematics, Teacher Efficacy and Mathematics Instructional Practices.

11. Means for Sub Group Observed in Teacher Efficacy and Beliefs about the importance of Mathematics and Mathematics Instructional Practices.

12. Correlations Among the High/High and Low/Low groups for Teacher Efficacy, Beliefs About Mathematics and Mathematics Instructional Practices with and without Outliers.

13. Classroom Demographics Frequencies.

14. Standards Observation Form Categories. 


\section{LIST OF FIGURES}

FIGURE

PAGE

1. Conceptual Model of the influence of Teachers' Efficacy and Beliefs about the importance of mathematics has on the Mathematics Instructional Practices in the Early Childhood Classroom..

2. Scatterplot of Overall Teacher Efficacy Scores and Teacher Beliefs about the importance of mathematics scores.

3. Scatterplot of Quadrants of High and Low Teacher Efficacy and Teacher Belief Scores of Individual Teachers; Numbers Identify Teachers in Sub Group Observed.105

4. Scatterplot of Teacher Belief Scores and Mathematics Instructional Practices Scores of a Sub Group of Early Childhood Teachers.

5. Scatterplot of Teacher Efficacy Scores and Mathematics Instructional Practices Scores of a Sub Group of Early Childhood Teachers.

6. Scatterplot of Teacher Belief Scores and Teacher Efficacy Scores of a Sub Group of Early Childhood Teachers.

7. Conceptual Model of the influence of Personal and External Factors on the Mathematics Instructional Practices in the Early Childhood Classroom. 


\section{CHAPTER I}

\section{RATIONALE}

The landmark educational reform act No Child Left Behind (USDE, 2002) embodies key principles that argue in favor of investing more in teachers and in teaching to improve public schooling in America. In this act the federal government is advocating for a highly qualified teacher for every child by $2005-06$. Supported by research the Department of Education points out that it takes "highly qualified" teachers to help students learn and achieve at high levels. The federal guidelines state, "The NCLB Act requires states to ensure that all teachers of core academic subjects are highly qualified which means they have state certification, hold a bachelor's degree and have demonstrated subject area competency" (NCLB, 2002, p. 8). One piece of research suggests differences in teacher effectiveness have been found to be the dominant factor affecting student academic gain (Sanders and Rivers, 1996). Effective teachers can help students learn in different ways and know how and why their students learn better one way than another. Researchers have found that often the most disadvantaged students are taught by minimally qualified teachers. This is perhaps more true in the ever increasing population of pre-kindergarten teachers working in public school pre-k programs. For the young children who are living in circumstances that place them at greater risk for school 
failure these early childhood teachers essentially combine care and education to provide children's initial formal cognitive stimulation (Bowman, Donavan and Burns, 2001).

The No Child Left Behind act requires elementary school teachers to pass a test of reading, mathematics and other areas of the curriculum, but this is not currently required for early childhood teachers. Compared to elementary and secondary teachers, early childhood teachers have fewer educational opportunities to prepare through education for their roles, acquire ongoing training and advance along a career path. Our nation has no uniform preparation requirements or licensure standards for pre-kindergarten teachers (Carnegie Corporation Initiative, 2002).

Many factors affect the quality of early education including facilities and adult to-child ratio, but no factor is more important than the preparedness, competence and commitment of the teacher (Carnegie Corporation Initiative, 2002; Darling Hammond, 2000). Currently, to be a lead early childhood teacher in Kentucky a person must have earned the Interdisciplinary Early Childhood Education certificate, a four year certification process. Previous to 2002 , the requirement to be a lead teacher was to possess an Associate of Arts or Child Development Associate degree (Kentucky Department Education, 2002). The National Research Council's Committee on Early Childhood Pedagogy (NRC, 2001) recommends that in every early childhood program the students should have a teacher who has a bachelor's degree in some aspect of child development or special education. If the ultimate goal is the improvement in academic growth of student populations, the improvement for student learning must begin with the improvement of the effectiveness of teachers (Sanders and Rivers, 1996). 
The No Child Left Behind Act mandates that certified elementary and secondary teachers be highly qualified teachers of reading. Funds are available to help prekindergarten and elementary teachers strengthen old skills and gain new ones in effective reading instructional techniques. The NCLB Act specifically spells out that the goal is to prevent reading failure with high-quality early education for young children. It is articulated in the NCLB Act that many programs serving young children have not adequately addressed the importance of early reading skills. The Center for Family Literacy (2003) reports that research is clear about the quality of childcare and its lasting impact on children's ability in language and reading skills. A strong argument can be made that early mathematics skills are as critically important for a high-quality education for young children as reading skills. The joint statement of the National Association of the Education of Young Children and National Council of Teachers of Mathematics (2002) affirms that a high-quality, challenging and accessible mathematics education for 3- to 6-year-olds is vital for future mathematics learning. Currently in Kentucky the preschool guidelines recommend a program that focuses on the child's physical, intellectual, social and emotional development, including interpersonal, intrapersonal, and socialization skills (Kentucky Department of Education, 2003). The recommendations of the NAEYC and NCTM to offer more mathematical experiences for pre-k students will shift the focus for Kentucky teachers to prepare pre-kindergarten students for school readiness for mathematics.

The focus of this research project is a study of what pre-kindergarten teachers report about their own teaching efficacy and what they believe about the role of 
mathematics in the pre-kindergarten curriculum. The study also reports the ways these teachers interact with their students during mathematics instruction.

The research on K-12 teachers' mathematical knowledge has been narrow and until recently even less is known about the ever-increasing population of pre-kindergarten teachers (Baroody, 1987). "There is a great disjunction between what is optimal pedagogically for children's learning and development and the level of preparation that currently typifies early childhood educators" (Bowman et al., 2001, p. 311). Evidence suggests that early childhood teachers' memories of their early schooling impact their motivations, expectations, and values in their classrooms (Hollingsworth, 1989). "There is strong reason to believe that in mathematics, teachers' conceptions (their beliefs, views and preferences) about the subject matter and its teaching play an important role in affecting their effectiveness as the primary mediators between the subject and the learners" (Thompson, 1984, p. 105). The Rand Mathematics Study Group (Rand, 2002) recommended a research agenda that will explore what knowledge is needed and the means of helping teachers acquire, apply and use this information. The progress of helping future generations of students become mathematically proficient will need study and analysis of mathematical practices and the content knowledge needed for teaching.

Over the last three decades three major trends have focused public attention on pre-kindergarten schooling. First, the unprecedented rise in the proportion of women participating in the labor force created an increased demand for quality child care. According to the National Center for Education Statistics, in $199567 \%$ of 3-year-olds and $77 \%$ of 4-year-olds spent time in non-parental care (Hofferth, Shauman, West and Henke, 1998). This is an increase from 1965 when only $28 \%$ of all 4-year-olds 
participated in pre-kindergarten programs (McDill and Natriello, 1999). Second, there has been a shift in the attitudes of parents and professionals about the need to provide cognitive development and education in the pre-kindergarten years. The focus of prekindergarten programs for the previous two decades was on socialization and emotional development. The third factor is the accumulation of research about pre-kindergarten children's capabilities as learners. The National Academy Press reported in Eager to Learn the potential effect of good early educational experiences on later learning and school performance (Bowman et al., 2001). A significant finding from the body of research is that pre-kindergarten programs can be particularly important in enhancing school readiness for children from low-income and educationally disadvantaged families. With more parents relying on child care and pre-kindergarten programs, the importance of early learning of mathematics and literacy in early childhood programs is a timely national educational issue.

The study of early childhood development includes a broad range of behavioral and social science research on learning and development between the ages two and five (Bowman et al., 2001). In 1997 the National Research Council established the Committee on Early Childhood Pedagogy (NRC, 2001) to review the research, form the knowledge base, and develop implications for early childhood education. The committee supported the belief that children come into this world ready to learn. In the research it was noted that the pace and inclination for the early learning depended on the extent of each child's encounters and engagement with supportive environments. Learning for pre-kindergarten children involves constructing knowledge and integration of new ideas and concepts into their existing understandings (Kamii, 2000; Mix, Huttenlocher and Levine, 2002; and 
Smith, 2001). Recognition of the importance of the early childhood years has heightened interest and support for increased emphasis on early basic skill instruction. The National Research Council Committee on Early Childhood Pedagogy pointed out that the interaction between teacher and child is the most critical feature of early childhood education (Bowman et al., 2001). Young children come to pre-kindergarten and caregivers with many differences in cognitive, social, and physical skills. Recent research provides information about the best practices for providing early basic skills instruction to address the differences of children on such variables as gender, race, ethnicity, language and social class. "The importance of teacher responsiveness to children's differences, knowledge of children's learning and capabilities... all point to the centrality of teacher education and preparation (Bowman et al., 2001, p. 8)."

At the core of the effort to promote the development of quality early childhood programs in literacy, mathematics, and social-emotional skills is the education and licensure of those who work with the pre-kindergarten children. The National Association for the Education of Young Children (NAEYC, 1996) placed the critical role of the teacher in supporting children's development and learning at the top of their list of fundamental principles (Bredekamp and Copple, 1997). The shift to a belief that the early childhood program should provide cognitive development and education has created a "mismatch between the preparation of the average early childhood professional and the growing expectations of parents and policy makers" (Bowman et al., 2001, p. 261). In a large-scale study conducted by researchers from several universities, the Cost, Quality, and Child Outcomes Study Team (Helburn, 1995) found an inadequate level of education and training for early childhood staff. The Florida Child Care Improvement 
study (Howes, Smith and Galinsky, 1995) yielded classroom ratings of global quality and teacher effectiveness (e.g., sensitivity, responsiveness, positive initiations, promotion of positive peer interaction and decrease in negative management). The ratings as measured by the Early Childhood Environmental Rating Scale (Harms, Clifford and Cryer, 1998) were higher in classrooms where the teachers had a least an Associate degree in child development; the highest scores were obtained from teachers with Bachelor of Arts (Bowman et al., 2001). The knowledge, skills and preparations of teachers are important factors in creating an environment supportive of learning in young children (Kajac, Bloom, Talan, and Clark, 2001).

Theoretical Rationale

Psychology is concerned with discovering principles about human behavior in order to learn how to structure environmental influences and link cognitive activities to promote human adaptation and change (Bandura, 1986). Most human behavior is determined by multiple interacting factors. The issue is often whether the individual is capable of human agency or is pushed by an inborn drive or pulled by anticipated benefits. The Social Cognitive Theory (Bandura, 1986) and Social Cultural Theory (Vygotsky, 1978) present theoretical approaches to human performance. The focus of this study was to examine human performance of teachers related to their sense of efficacy, beliefs about mathematics to their instructional practices. The Social Cognitive Theory encompasses sets of factors that regulate and motivate established cognitive, social and behavioral skills. The triadic-reciprocal model describes three major classes of determinants (Bandura, 1986). The mutual action among interacting influences of an individual's behavior, internal personal factors (e.g., conceptions, beliefs, self- 
perceptions, cognition) and environmental events are determinants of human behavior (Bandura, 1978).

The determinant of human behavior that is examined in this study is self-efficacy. In the sociocognitive view, choice behavior, effort and persistence are extensively regulated by beliefs of personal efficacy rather than by drive (Bandura, 1986). Efficacy beliefs are developed not only by personal and vicarious experiences, but also evaluations and feedback from significant others. When individuals perform poorly in a setting, this can come to activate a sense of incompetence that impairs future performance in those contexts. Once individuals develop that mind set, they act on their established self-beliefs without re-evaluating their capabilities. The self-beliefs of teachers affect their thoughts about teaching certain subjects to certain students in specific settings (Tschannen-Moran, Woolfolk and Hoy, 1998). There is strong reason to believe that in mathematics, teachers' beliefs and conceptions about the subject matter and its teaching play a vital role in their effectiveness as mediators between the subject and the learner (National Research Council, 2001; Ma, 1999; and Thompson, 1984).

Human intelligence develops through interaction with the world in the form of social interaction and experience. The Vygotskian social cultural theory espouses that social interaction leads to continuous step-by-step changes in children's thoughts and behaviors that may vary from culture to culture (Woolfolk, 1998). The theory suggests that development of cognition is mediated by natural maturation and cultural development. The three cultural tools that are the result of the interaction between children and adults are imitative learning, instructed learning and collaborative learning. The Vygotskian perspective states, "...for a child to acquire these tools en route to 
higher order mental functioning the child has to be helped by knowing individuals, teachers and parents" (Bowman et al., 2001). A central premise of Vygotsky's theory is that if a child cannot do something alone, he or she may be successful with a more cognitively aware person who facilitates through modeling and assistance (Boehm and Weinberg, 1997).

One of the key principles of the social-cultural theory is the zone of proximal development (ZPD). The environment that is created by the adults' pedagogy promotes learning processes that lead to cognitive development of children. The concept of ZPD is accomplished when a child is successful with a task that he/she could not do alone, when helped by a skilled person. Vygotsky described the ZPD as the difference between actual developmental level and potential development level as determined by individual problem solving. The zone of proximal development is crucial to understanding the child's readiness to benefit from instruction (Moll, 1994). The research supports the notion that in order to substantially alter developmental outcomes in early childhood environments, the adults must attend to children's cognitive, social-emotional development simultaneously. A central premise of Vygotsky's theory is that if a child cannot do something alone, he or she may be successful with a more cognitively aware person who facilitates through modeling and assistance (Boehm and Weinberg, 1997). The adult or teacher's ability to recognize the zone of proximal development and provide the scaffolding is directly related to that individual's belief in his/her own effectiveness to perform these behaviors.

Researchers of teacher effectiveness have studied the relation among beliefs, attitudes and behaviors. Bandura (1977) suggested that people develop specific beliefs 
about their own coping abilities based upon life experiences. The two cognitively-based sources of motivation for teacher efficacy described by Bandura $(1977,1997)$ are outcome expectations and efficacy expectations. Behavior is a result of what desirable outcomes (outcome expectancy) teachers expect and teachers' belief in their own ability to perform the behaviors (self-efficacy). The stronger the perceived teacher efficacy the more persistent the teacher efforts (Bandura, 1986). The outcome expectations are teachers' beliefs about the effects that specific teaching actions have on students (Wheatley, 2001). The efficacy expectations are teachers' beliefs about their own ability to execute specific teaching actions. These beliefs/perceptions ultimately guide individual behaviors. There is not a simple relation between outcome expectations and efficacy expectations.

The relation between outcome and efficacy is often contingent on the individual's reliance on her/his efficacy beliefs in deciding which course of action to pursue and how long to pursue it. Bandura (1986) hypothesized that self-efficacy beliefs mediate the effect of other determinants, such as gender, past experience and performance. Once people develop a mind-set about their efficacy, they often act on their established selfbeliefs and are quick to take advantage of opportunity and rarely reappraise their capabilities. Ross (1994) found that teacher efficacy was increasingly recognized as a variable influencing teacher practice and student outcomes. Conversely, inefficacious people are less apt to take advantage of enabling opportunities and are easily discouraged by institutional impediments. Bandura (1986) noted in his work with teacher efficacy that self-efficacy is the strongest predictor of motivation and beliefs. The individual's efficacy beliefs are instrumental in defining tasks and selecting cognitive tools with which to 
interpret, plan and make decisions that individuals make throughout their lives (Bandura, 1986; Nespor, 1987). "Teacher efficacy is a simple idea with significant implications" (Tschannen-Moran and Woolfolk Hoy, 2001, p. 2). Identifying Pre-k teachers' efficacy judgments about their capabilities to affect student outcomes, student attitudes and student achievement in early mathematics can be of value in better educating and equipping early childhood teachers for the complex tasks of guiding early learners on the pathway to mathematical literacy.

"Virtually all children like mathematics. They do mathematics naturally, discovering patterns, and making conjectures based on observations. Natural curiosity is a powerful teacher, especially for mathematics" (National Research Council, 1989, p. 43). Research supports that children begin learning mathematics well before they enter school (Baroody, 1992; Fuson, 1992; Gelman and Gallistel, 1978; Ginsburg, 1983; Huttenlocher, 1994; Mix, Huttenlocher and Levine, 2002; Starkey and Cooper, 1980; Sophian, 1995; and Wynn, 1992). Greenes (1999) points out that young children do not have to be protected from the study of mathematics or made ready to learn. Children are positively disposed to do and understand mathematics when they first encounter it.

Although children come to the early childhood program with mathematical knowledge, most of the mathematics they know is learned in school and therefore depends on who teaches them. Ziechner and Tabachnick (1981) suggest that the thousands of hours that prospective teachers spend as pupils in the classroom shape their beliefs. "These perspectives serve as culturally based filters to help make sense of the program content, their roles, their observations of classrooms at work, and their translation of program content into teaching and learning activities in classrooms" 
(Hollingsworth, 1989, p. 162). In order to facilitate pre-kindergarten children's mathematical development the pre-kindergarten curriculum, and more importantly the teacher, must intricately weave the mathematics content learning into activities that the young children encounter throughout the day. It is during these early years that foundations are established for habits of reasoning that upon which later achievement will depend on (Kessel, Epstein and Keynes, 2002). Learning to read and develop mathematical proficiency both rest on a foundation of preliminary concepts and skills. Reform mandated by the National Council of Teachers of Mathematics (NCTM, 1989) developed K-12 standards for teaching and learning mathematics. NCTM (2000) published Principles and Standards for School Mathematics with revised standards for pre- kindergarten through grade 12 with a specific focus on PreK-2. The research as well as observations of teachers' practices all indicate that to improve the mathematical environment for children at all levels depends on the capabilities of the teacher.

Statement of the Problem

Research on teacher effectiveness indicates that teachers' implicit beliefs bout subject matter, students, their roles and responsibilities influence their instructional teaching actions (Bowman et al., 2001; Lortie, 1975). Tschannen-Moran, Woolfolk and Hoy (1998) contend that teachers' beliefs about their efficacy are constructed from personal experience, their expectations about teaching and their knowledge of the subject matter. Their teaching efficacy also influences other professional behaviors such as willingness to work and openness to new ideas. "Children acquire the foundations of knowledge and the dispositions to learn during the early childhood years. Teacher beliefs 
are the heart of this socialization process and help set the climate for learning" (Vartuli, 1999, p. 490).

Hollingsworth (1989) found that when an educational practice is not consistent with the teacher's stated beliefs, that teacher has more difficulty implementing the proposed innovation. Research on the relation between teachers' stated beliefs and observed teaching practices has been inconsistent. Guskey (1987) concluded that more efficacious teachers expressed greater confidence in teaching abilities and liked teaching more. Tschannen-Moran, Woolfolk and Hoy (1998) also found that lower efficacy led to less effort and giving up easily. Spodek (1987) found that early childhood education teachers generated a greater number and variety of theories about educational decisions than kindergarten and first grade teachers. The early childhood teachers supported more play, and Spodek noted that their decisions were more often based on their personal practice rather than knowledge about child development and learning theory. The research indicates this made identifying a common core of beliefs difficult. Early childhood and kindergarten teachers' beliefs were found to be consistent with observations of practice conducted by Charlesworth, Hart, Burts, Mosely and Fleege (1993). A study by Hyson, Hirsch-Pasek and Rescorla (1990) found a direct correlation between the developmental appropriateness of the early childhood program and the selfreported educational attitudes of the staff. The observational instrument used by the researchers was able to identify differences in teacher instructional practices that were significantly related to differences in children's abilities and behavior. A causal relation could not be identified with the data collected. 
Knowledge about what constitutes early childhood teachers' beliefs about mathematics and whether those beliefs are related to the pedagogical process are limited. Therefore, the design of this study examines the influences of early childhood teachers' efficacy, their beliefs about early childhood mathematics and subsequent classroom instructional practices. This study extends the research on self-efficacy and teacher beliefs to new populations, specifically early childhood education contexts, and target behaviors focused on mathematics instruction.

The National Research Council reported in Adding it $U p$ (2001) that most U.S pre-kindergarten children come to school with an interest and motivation to learn mathematics. The challenge to educators and parents is to help maintain that productive disposition. Encouraging a positive disposition, along with relating mathematics to everyday life and engaging in the processes of mathematical inquiry are the three recommendations from Adding it $U p$ for developing mathematical power in young children today (Baroody, 2000). Ginsburg (1983) conducted research on early childhood "free play" and noted that while 3- and 4-year-old children were engaged in mathematical explorations and applications in an early childhood setting there was very little adult involvement in explicit teaching or indirect assistance to integrate the experience and the meaning of the language of mathematics. Likewise the National Institute of Health and Development (Freidman and Haywood, 1994) conducted research on early child care settings. They concluded that there are significant dilemmas for extending mathematical instruction into the pre-kindergarten years. The most significant hindrance to quality mathematical teaching and learning in the pre-kindergarten years is the severe shortage of well-prepared instructional staff (Carnegie Corporation, 2002). Not only do the pre- 
kindergarten teachers lack education in early childhood development they often have limited experiences and background in the support and delivery of mathematical instruction and limited content knowledge of mathematics (Carnegie Corporation, 2002).

\section{Purpose}

In response to the need for highly qualified teachers for all children, the focus of this study is to explore teacher efficacy and teacher beliefs about mathematics for early childhood students and the influences of these on mathematics teaching in the early childhood classroom. Effective teaching of mathematics is more likely when teachers have a belief that their teaching actions will have a positive effect on student achievement. "Teachers' beliefs, knowledge, judgments, thoughts, and decisions have a profound effect on the way they teach as well as on students' learning in their classrooms" (Peterson et al., 1989, p. 2). Teachers should understand that their beliefs and knowledge affect their instructional behaviors.

Early childhood teachers face complex environments with many interactions going on among children, adults, materials and tasks. Teachers respond to this complex environment by drawing on their own experiences, priorities and beliefs to deliver the curriculum. The teacher's beliefs in the ability to successfully execute specific mathematical teaching actions are influenced by past stimuli. Research on pre-service teacher beliefs about mathematics teaching and learning noted that those beliefs are shaped during teachers' own schooling and their own experiences as students of mathematics (Ball, 1988; Jackson and Hartounian, 1986). One purpose of this study is to discover if teachers' beliefs about mathematics in the early childhood curriculum 
influence the teachers' adoption of novel instructional practices that are needed to engage today's young mathematicians in successful learning situations.

Teacher efficacy has also been identified as a variable accounting for individual differences in teaching effectiveness (Gibson and Dembo, 1984). Research on teacher efficacy has found that highly efficacious people take advantage of opportunity and problem solve to work with and around institutional constraints (Tschannen-Moran and Woolfolk Hoy, 2002). On the other hand inefficacious people are less apt to make use of opportunities and are discouraged by institutional hindrances. The body of research notes that teacher efficacy is a complex and multidimensional construct. Efficacy beliefs are affected by school context-specific factors, such as age level and ability of the population of students, as well as classroom management issues (Guskey, 1987).

What early childhood teachers know and believe they are able to do is one of the major influences on the learning and development of pre-kindergarten children. Bandura's Social Learning Theory (1986) suggests that teachers who have confidence in their own teaching abilities and believe that student learning can be influenced by their effective teaching exhibit different types of teaching behaviors, such as more feedback to their students, than teachers who have lower expectations (Gibson and Dembo, 1984). One purpose of this study was to investigate the relation of a teacher's efficacy to that teacher's orchestration of students' learning activities in their classrooms. Are the instructional practices of a teacher identified with higher teacher efficacy significantly different from a teacher lower in teacher efficacy?

Early childhood teaching practices should provide an effective experience for young learners to build the vital foundation for life-long mathematical learning. Issues 
that threaten the early childhood program quality include the varied educational requirements for early childhood teachers, the teachers' past educational experiences in mathematics and the high turnover rates of teachers of young children. At the onset of this study it was hypothesized that many early childhood teachers have had less than successful mathematical experiences and may doubt their own confidence in their own content knowledge and ability to teach mathematics. The research examined the relation between teacher efficacy, teacher beliefs about early mathematics and actual mathematics instructional practices. The following research questions were designed to better understand the nature of efficacy, beliefs about mathematics and the instructional practices of teachers of pre- kindergarten children in public school settings.

\section{Research Questions}

1. What is the relation between the measures of teacher efficacy, measures of teacher beliefs about mathematics?

2. What is the degree of the relation among the measure of teacher efficacy and of teacher beliefs about the importance of mathematics and mathematical instructional behaviors of teachers?

\section{Significance}

There are questions about why research should examine teacher efficacy and teacher beliefs about the importance of developmental skills and abilities in mathematics in the early childhood environment. Woolfolk and Hoy (1990) noted that the research reveals few consistent relations between teacher characteristics, such as expectations, establishing and maintaining order in the classroom, and student learning. An exception to the rule is teachers' sense of efficacy and teacher beliefs as determinants of teaching 
behavior. Theory supports the notion that teachers' efficacy beliefs will transfer from one context to another if the teacher perceives similarities in tasks and resources (Bandura, 1977; Tschannen-Moran et. al, 1998). From the research literature, it appears that we do not know if the effect of the individual teacher's efficacy and beliefs can override the effects of professional development learning experiences and the tasks and resources often available with a school district's curriculum (Darling-Hammond, 1998; Cassidy et al., 1995; Hollingsworth, 1989; Howes et al., 1995). This study attempts to provide a better understanding of the relation between teacher efficacy and teacher beliefs about the importance of mathematics and differentiate between successful and less successful instructional practices in teaching mathematics in the early childhood classroom.

Investigating teachers' sense of efficacy and their beliefs about the importance of developmental skills and abilities in mathematics education, specifically, in early childhood settings has a number of implications for researchers. There are lessons to be learned from studies of early childhood education abroad (Sheridan and Schuster, 2001). If early childhood teachers are to develop a professional orientation based on knowledge, reflection and analysis similar to exemplary programs in other countries then policy makers need to explore the factors that help early childhood teachers be successful (Bowman et al., 2001). It is important to examine teaching environments to help teachers reflect on teaching practices. Vartuli (1999) suggests that the one promising area of future research in teaching practices is the comparison of teacher self-reported beliefs and observed practices using the same and different instruments. To this end, this project 
combines early childhood teachers' espoused efficacy and beliefs with an observational rating of the presence of mathematics instructional practices in their classrooms.

Early childhood teachers are being mandated to promote higher level achievement for all children, and this has implications for teacher educators. As at any education level, early childhood teachers in the United States reflect a diverse level of professional training, varied philosophical beliefs and life experiences, and different pedagogical approaches. These beliefs and approaches may be deeply entrenched from the experiences that early childhood teachers had as students. Successful reform in the early childhood environment requires profound teacher learning and change. Typically, teachers solve instructional problems by relying on their own beliefs and experiences (Ashton and Webb, 1982; Hoy and Woolfolk, 1990). The research on teacher beliefs (Pajares, 1992) advocates that pre-service and inservice education should directly address teachers' prior experiences and memories in order to affect change. Cassidy, Buell, PughHoese and Russel (1995) found coursework may increase a teacher's knowledge, but that increased knowledge may not be reflected in classroom practice. Researchers argue that the prospective teachers' perceptions may be shaped by beliefs that may be beyond the influence of teacher educators (Nespor, 1987; Richardson, 1996). Teachers filter information through their own personal belief systems and form their own distinctive pedagogies. Teacher educators need information about teacher beliefs in order to provide professional development to give early childhood teachers opportunities to integrate and differentiate old and new knowledge (Posner and Gertzog, 1982). University early childhood program developers may find this information useful in evaluating the type of mathematics methods courses that would best prepare pre-service or graduates to be 
effective teachers of early childhood mathematics. Teachers need to learn about presenting opportunities for mathematics to develop in the context of play, which enable them to teach mathematics effectively (Ball, 1988).

Authors from the fields of early childhood education and mathematics education have published materials that represent broad professional consensus about the curriculum, instruction and assessment that support the early childhood and mathematics communities. In a joint position statement the National Association for the Education of Young Children (NAEYC) and the National Council of Teachers of Mathematics (NCTM) affirm, "A high quality, challenging, and accessible mathematics education for three- to six-year-old children is a vital foundation for future mathematics learning" (Clements, Sarama and DiBiase, 2002, p. 24). The U.S. Department of Education Early Childhood Longitudinal Study reported, "Children who bring certain knowledge and skills to kindergarten are likely to be at an advantage in classroom learning compared to their peers who do not possess these resources (United States Department of Education, National Center for Education Statistics, 2002, p. 25). The trend discovered in the study's data showed that children who entered kindergarten recognizing basic numbers and shapes and who understood the mathematical concept of relative size were more likely to acquire specific mathematics skills later on. The knowledge that early mathematics for young children may have long-lasting outcomes is not yet in the hands of early childhood teachers to effectively guide their teaching (NAEYC, NCTM, 2002)

The challenge for many early childhood teachers is how to provide for children's deep and sustained interaction with key mathematical ideas and mathematical language with their own personal philosophies of how children learn mathematics. Many early 
childhood teachers have been educated to use an integrated approach for strengthening childrens' early reading skills, but not in planning mathematics activities. The integrated environment they use for language development can provide the early childhood teacher with an opportunity to firmly yet patiently support young children in developing independence to explore and manipulate mathematical ideas with natural interest as they use it to make sense of their physical and social worlds (NAEYC, 2002). For example, Howes, Smith and Galinsky (1995) found play and positive interactions with teachers predicted more complex cognitive activities in child care centers. Teachers should focus on the big ideas of mathematics and connections and sequences to be able to pose questions that help children clarify and extend their development of new knowledge. Teachers can use the child's response to help them assess what trajectory or learning path the child is on in order to promote progress. The more knowledgeable teachers are about the trajectory or path of learning and how to teach developmentally appropriate and challenging mathematics content, the better equipped they will be to construct a solid curriculum base for what children should know and be able to do at any given level (Howes et al., 1995). This knowledge will help teachers provide a variety of instructional strategies in meaningful child-centered contexts and opportunities for active participation to help all children learn and apply mathematical ideas.

The results of this study have the potential to focus attention on how the mathematical needs of 3- and 4-year olds are currently not being addressed well. This may inadvertently be a contributor in addressing the ever growing gap in mathematics achievement between white and African Americans and children of poverty. Policy makers for early childhood programs need specific data to help guide them in evaluating 
the type of professional development that will provide early childhood teachers with the essential tools to create a rigorous mathematical curriculum for 3- and 4-year olds. There may be a mismatch among what early childhood teachers believe about the importance of mathematical literacy, district curriculum demands, and program constraints. This study could provide a model for the process for change.

Hypotheses

The research in the study focuses on the relation among teacher efficacy and teacher beliefs about the importance mathematics in their instructional practices in early mathematics. For statistical investigation of the research questions the following hypotheses are noted:

1. What is the relation between the measures of teacher efficacy, measures of teacher beliefs about mathematics?

Hypothesis: Teacher efficacy and teacher beliefs influence teachers' mathematics instructional practices. Teachers higher in efficacy will rate the importance of mathematics higher on the Teacher Belief Scale than the teachers with lower efficacy.

2. What is the degree of the relation among the measures of teacher efficacy and of teacher beliefs about the importance of mathematics and mathematical instructional behaviors of teachers?

Hypothesis: The combination of high teacher efficacy and high teacher beliefs about the importance of mathematics will show higher levels of alignment with standards- based mathematics instructional practices than either high teacher efficacy or high teacher beliefs alone. 


\section{Definition of Terms}

Terms central to this study are defined as follows:

Teacher efficacy- A teacher's efficacy belief is a judgment of his or her capabilities to bring about desired outcomes of student engagement and learning, even between those students who may be difficult or unmotivated as measured by the teacher efficacy scale (Armor, et. al., 1976; Bandura, 1977).

Outcome expectancy- The outcome expectation is an individual belief/perception that guides individual behaviors and affects what that person tries to achieve and the degree of effort he/she puts into performance (Bandura, 1977).

Efficacy expectancy- The efficacy expectation is an individual's belief/perception about his/her own abilities (Bandura, 1977).

Personal efficacy- The teacher's belief in his/her own teaching ability to overcome the effects of outside influences on student achievement (Soodak and Podell, 1996). Teacher beliefs-'s Teacher Belief Study (Richardson, 1996; TBS, 1987) describes a person's belief system as consisting of propositions or assumption, concepts and arguments by those who hold them. These belief systems include affective feelings and evaluations and memories of personal experiences and assumptions that Nespor describes as being "not open to outside evaluation or critical examination in the same sense that the components of knowledge systems are" (p. 321).

Developmentally appropriate practices- The outcome of a process of teacher decision making about what teachers know about how children develop and learn; what teachers know about the individual children in their group and; teacher knowledge of the social and cultural contexts in which children live and learn (Bredekamp and Copple, 1997). 
Child centered- An environment where young children actively learn from observing and interacting with other children and adults. Children need to form their own hypotheses and keep trying through social interaction, physical manipulation and their own thought processes (Bredekamp and Copple, 1997; Piaget, 1952) for meaningful learning to take place.

Early childhood students- The terminology is used in the literature for pre-kindergarten through third grade children. This study primarily identified children in pre-kindergarten programs from age 2-years-old to 5-years-old (Bredekamp and Copple, 1997).

\section{Conceptual Model for the Study}

Teacher efficacy, teacher beliefs about the importance of mathematics, and teacher instruction practices in mathematics are the three major constructs of this study.

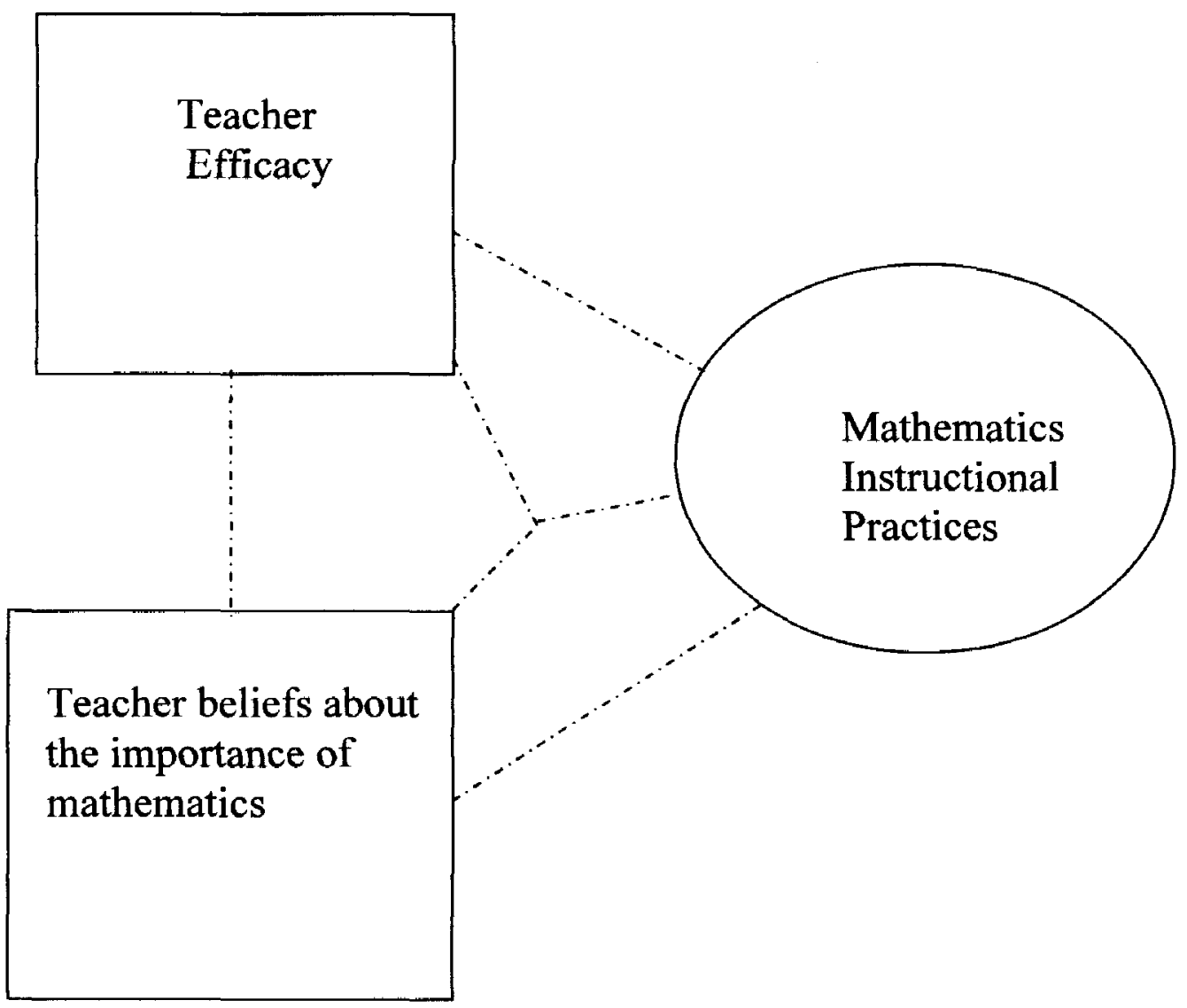


The conceptual model suggests that teacher efficacy and teacher beliefs about the importance of mathematics influence mathematics instructional practices. Research reveals (Woolfolk and Hoy, 1990) few consistent relations between teacher characteristics, such as expectations, establishing and maintaining order in the classroom, and student learning. An exception to the rule is teachers' sense of efficacy and teacher beliefs as determinants of teaching behavior, therefore these were two key pieces of the model. However, what is not known is the relation with mathematics instructional practices in the early childhood classroom. Prior to the onset of this research it was hypothesized that the combination of Teacher Efficacy and Teacher Beliefs about the importance of mathematics would show higher levels of alignment with standards-based mathematics instructional practices than either teacher efficacy or teacher beliefs alone.

\section{Summary}

The National Research Council (2001) reports in Eager to Learn that good early educational experiences have the potential effect on later school performance. Many factors affect the quality of early education, facilities, adult-to-child ratio, but the preparedness and competence and commitment of the teacher are critical. The National Association for the Education of Young Children (1996) considers the teacher's role in supporting children's development as one of their top fundamental principles. Identifying pre-k teachers' efficacy judgments about their capabilities to affect student outcomes, pre-k teacher beliefs about mathematics in the pre-k curriculum and teachers' instructional practices in early mathematics has implications to inform other educators of the significance of mathematical literacy for 3-and 4-year olds. Pre-k teachers often lack 
education in early childhood development and have limited experiences and background support and delivery of mathematical instruction and limited content knowledge of mathematics. The focus of this research was to study what pre-kindergarten teachers reported about their sense of teaching efficacy and what they believed the role of mathematics was the early childhood curriculum. A sample of teachers was observed to examine relations among efficacy, beliefs and practices. 


\section{Table 1}

Data Collection Procedures Summary

\begin{tabular}{|c|c|c|}
\hline Information Sought & Data Collection technique & Sources of data \\
\hline $\begin{array}{l}\text { 1. What is the relation } \\
\text { between the measures of } \\
\text { teacher efficacy, and } \\
\text { measures of teacher beliefs } \\
\text { about mathematics? }\end{array}$ & $\begin{array}{l}\text { Teachers' Sense of Efficacy } \\
\text { Scale } \\
\text { Teacher Beliefs about } \\
\text { Mathematics- The Child } \\
\text { Development Project - } \\
\text { Early Childhood Research } \\
\text { Consortium } \\
\text { The Standards Observation- } \\
\text { Mathematics Instructional } \\
\text { Practices }\end{array}$ & $\begin{array}{l}\text { Pre-school lead teacher } \\
\text { Pre-school lead teacher } \\
\text { Pre-school lead teacher and } \\
\text { classroom }\end{array}$ \\
\hline $\begin{array}{l}\text { 2. What is the degree of } \\
\text { relation among the measure } \\
\text { of teacher efficacy, and of } \\
\text { teacher beliefs about the } \\
\text { importance of mathematics } \\
\text { and mathematics } \\
\text { instructional behaviors of } \\
\text { teachers? }\end{array}$ & $\begin{array}{l}\text { Teacher Beliefs about } \\
\text { Mathematics-The Child } \\
\text { Development Project - } \\
\text { Early Childhood Research } \\
\text { Consortium }\end{array}$ & $\begin{array}{l}\text { Pre-school lead teacher and } \\
\text { classroom }\end{array}$ \\
\hline
\end{tabular}




\section{Table 2}

\section{$\underline{\text { Timetable }}$}

$\begin{array}{lllllllllll} & \mathrm{J} & \mathrm{F} & \mathrm{M} & \mathrm{A} & \mathrm{M} & \mathrm{J} & \mathrm{J} & \mathrm{A} \\ \text { Entrance } & \mathrm{X} & & & & & & & \end{array}$

\section{TSES}

Child Development

Project-Teacher

Rating Scale

X

Identification

of sample

$\mathrm{X} \quad \mathrm{X}$

Observations

$\mathrm{X} \quad \mathrm{X} \quad \mathrm{X}$

Analysis of

data

$\begin{array}{llllll}X & X & X & X & X & X\end{array}$

Final report

X $\quad \mathrm{X}$ 


\section{CHAPTER II}

\section{REVIEW OF LITERATURE}

First, whenever educators have spent considerable time with young children and seriously observed them in naturalistic settings, they have witnessed the children engaging in sophisticated mathematical activities in a joyful manner.

$$
\text { Robert Balfanz (1999, p. 9) }
$$

This chapter reviews the extant research concerning teachers' efficacy and teachers' beliefs about the importance of early mathematics education and learning as a factor of instructional practices. Philosophical principles and belief systems guide teacher expectations about the decisions they make in their classrooms (Vartuli, 1999). Teachers' decisions are often rooted in their own personal practical knowledge rather than the knowledge about child developmental and learning theory. They often teach content according to the values they hold of the content itself. Bandura (1977) hypothesized that teachers develop a specific belief about their own coping abilities and expect certain behaviors to produce desirable outcomes. Bandura called this self-efficacy.

The studies reviewed for this research approached teacher beliefs and selfefficacy from several different view points. Studies have examined teacher beliefs about student achievement and failure (Clark and Peterson, 1986), teacher beliefs about developmentally appropriate practices (Cassidy et al., 1995; Charlesworth et al., 1993; Isenberg, 1990; Kowalski, Pretti-Frontczak and Johnson, 2001) and teacher locus of 
control (Guskey and Passaro, 1994; Rose and Medway, 1981). The studies about teacher self-efficacy have also related to student outcomes and achievement (Armor, ConroyOseguera, Cox, King, McDonnell, Pascal et al., 1976; Soodak and Podell, 1996). Studies show that teachers with a higher sense of efficacy show more enthusiasm for teaching and demonstrate more persistence when things do not go smoothly (Ashton and Webb, 1986; Guskey, 1987). Assimilating these studies to relate to teacher beliefs and selfefficacy about mathematics in the early childhood classroom is the focus of this review. The research is organized in four categories; Theoretical foundations, research on teacher efficacy, research of teacher beliefs and research on mathematics for young children. The selected research provides the most important correlates of teachers' sense of self efficacy and content-specific beliefs about early mathematics instruction.

\section{Theoretical Foundations}

\section{Social Learning Theory}

The foundation for the work with efficacy and beliefs began with the Social Cognitive Theory that originated in the discipline of psychology stemming from the Social Learning Theory (SLT) that dates to the 1800 s. Social Learning Theory questioned the behaviorist view of stimulus-response-reinforcement pathway approach that explained human behavior as being influenced by individual differences and how the individual perceived events as being personally or externally determined. The ongoing debate was whether there was a mediating factor between the stimulus and the response that regulated behavior. Miller and Dollard published Social Learning and Imitation (1941) and contributed the notion that behaviors could be learned through observation and imitation. The organism did not have to directly experience a stimulus-response- 
reinforcement chain. This expanded Social Learning Theory to include the relation between environment and behavior. The unidirectional approach of the behaviorist was expanded to assert that there is a mediator (human cognition) that puts the individual in control of behavioral responses. The introduction of human cognition as a mediator expanded the knowledge of cognitive theory (Bandura, 1982).

Rotter's Social Learning Theory (1966) explained that the probability of a given behavior in a particular situation is determined by two variables. The two variables, 1) the expectancy (probability) and 2) the reinforcer (behavior) presuppose the existence of a hierarchy of responses that occur in different situations with varied probability based on how reinforcing the consequences are to individuals. Rotter (1966) explained behavior in a bi-directional manner, placing more emphasis on the influence of the environment than on learning experiences. Much of this research was concerned with how behavior was influenced by individual differences in experiences and how events were perceived as being internally or externally determined. Rotter's conceptual scheme was more focused on causal beliefs about the relation between action and outcomes rather than with personal efficacy. “Although Rotter's theory was adequate for predicting the occurrence and modification of previously learned response patterns, it has had relatively little impact on theories of social behavior"(Bandura and Walters, 1963). Social Cognitive Theory is a subset of the social learning principles that began with Rotter's work but with more emphasis on cognitive variables.

\section{Social Cognitive Theory}

Albert Bandura led efforts on cognitive Social Learning Theory development in his book Social Foundation of Thought and Action: A Social Cognitive Theory (1986). 
Bandura's Social Cognitive Theory defines human behavior as a triadic interaction of personal factors, behaviors and the environment $(1977,1986)$. Social Cognitive Theory upholds the behaviorist view that the individual's assessment of the event can mediate the occurrence of behavior. However, Social Cognitive Theory adds that one's mind is an active force that influences actions. Bandura did not view all sources of influence as having equal strength. The contributions of personal factors, behaviors and environment would differ based on the individual and what behaviors are in the individual's repertoire and the situation in which the behavior occurs. The individual's response would involve their system of self regulation, an internal control that oversees what behavior is performed and the self-imposed consequences of that behavior.

Bandura described the self-regulatory system as an individual's referee for external influences. The self-regulatory system allows the individual personal control. The importance of this capability is reflected in how the individual gradually substitutes internal controls for external controls of behavior (Bandura, 1977, 1986, 1997). Three factors appear to establish the degree of self-motivation: a person's self-efficacy, feedback, and anticipated time to goal achievement. These factors operate together in the management of a person's course of action, the level of effort they exert, their persistence when faced with barriers and the level of accomplishment they realize in all contexts.

Examining one of these factors, self-efficacy, has become a central focus of Bandura's research. Two cognitively-based sources of motivation or self-efficacy proposed by Bandura are efficacy expectations and outcome expectations. The efficacy expectation is an individual's belief/perception about his/her own abilities. These beliefs/perceptions ultimately guide the individual behaviors (outcome expectancy), 
affect what a person tries to achieve, and the degree of effort he/she puts into performance (Bandura, 1977). The person's self-efficacy develops from one's own history of achievement. For example, in mathematics, a person's observation of others' successes and failures and the persuasion of others may affect that individual's own development in mathematics. Another strong influence is social comparison of one's own performance to peers or siblings' performance. Bandura (1986) hypothesized that selfefficacy thinking mediates the effect of other determinants, such as gender, past experience and performance.

For example, people high on both self-efficacy and outcome expectancy would be more decisive about ways to circumvent institutional constraints and experiment with innovative methods of instruction (Guskey, 1987). They would act more quickly with confidence in a given area and work longer with a student who is struggling (Gibson and Dembo, 1984). A person low on both variables would be more likely to give up earlier on new instructional methods if outcomes were not reached quickly and be discouraged by struggling students. Self-efficacy acts a cognitive mediator of behavior. Self-efficacy affects whether a person initiates a specific behavior and how long she/he persists on attempts to achieve that behavior (Bandura, 1977, 1986). Teachers are expected to manage an array of social and academic processes in their classrooms. Teachers' beliefs concerning the efficacy of their efforts may be determinants of the quality and persistence of those efforts.

School experiences are considered a strong source of shaping a person's selfefficacy. During years of schooling children are developing their cognitive competence, knowledge and problem solving skills. Teacher efficacy relates to the extent that a 
teacher feels efficacious in a variety of teaching situations rather than a narrowly defined range of situations (Jackson, and Haroutunian, 1989). The teacher's beliefs in how competent he or she is to teach students are related to that teacher's own self-efficacy. Bandura stated that self-efficacy thinking is the strongest predictors of motivation and beliefs. He found that teachers with strong self-efficacy felt competent to persist longer whereas those with weaker self-efficacy did not feel as competent (Bandura, 1977, 1986).

Several psychological measures of teacher efficacy have grown out of Bandura's work. More recent research has focused on: (1) measurements of teachers' self beliefs as determinants of teaching behaviors (Armor et al.,1976; Ashton and Webb, 1982; Bandura, 1977, 1997; Berman, McLaughlin, Bass, Pauly and Zellman, 1977; Gibson and Dembo, 1984; Guskey and Passaro, 1994; Rose and Medway, 1981; Rotter, 1966; Tschannen-Moran and Woolfolk Hoy, 1998 and Woolfolk and Hoy, 1990); (2) measurements of context specific teacher self efficacy (Bandura, 1997; Riggs and Enochs, 1990; Soodak and Podell; 1996 and Tschannen-Moran and Woolfolk Hoy, 2001); and (3) measurements of teacher self efficacy with factor analysis (Brouwers and Tomic, 2001; Henson, Kogan and Vacha-Haase, 2001; Pontius, 1998). The following is a brief review of three main areas of empirical research on teacher efficacy.

\section{Research on Teacher Efficacy}

The study of teacher efficacy is nearly three decades old with the work of Rotter's locus of control theory (1966) and Bandura's social cognitive theory (1977) influencing the studies that have been conducted. A review of teacher efficacy studies presents a mixed construct of what is known about measurement of teachers' self beliefs as 
determinants of teaching behaviors. The construct of teacher efficacy may be "messy" but it is an important area of educational research (Pajares, 1992).

As a construct in psychology, teacher efficacy was introduced in two Rand Corporation evaluations (Armor et al., 1976; Berman et al., 1977). Researchers in the first investigation included two forced choice items in a large study of teacher characteristics about teaching reading to minority students in an urban context (Armor et al., 1976). The second study incorporated the two items to measure teacher efficacy in the continuation of federally funded innovations at the end of the grant. The items were designed to consider teacher efficacy as the extent to which teachers believed that controlling the reinforcement of their actions lay within them or the environment. The first item, "When it comes right down to it, a teacher really can't do much because a student's motivation and performance depends on his or her home environment" (Woolfolk and Hoy, 1990, p. 82) measured General Teacher Efficacy (GTE). The second item, "If I try really hard, I can get through to even the most difficult or unmotivated students" (Woolfolk and Hoy, 1990, p. 82) measured Personal Teacher Efficacy (PTE). Each item generated a score based on the teacher's level of agreement on a 5-point Likert scale from strongly agree to strongly disagree. The sum of the two scores was called teacher efficacy (TE). The teachers' beliefs in their own capabilities proved to be significantly related to the success that teachers had in teaching reading to minority students in an urban context (Armor et al., 1976). In the second study Rand researchers found that teacher efficacy had a strong positive link to the percent of project goals achieved and to the amount of change in the teachers' instructional practices resulting from participation in federally funded programs and to the continuation of federally funded innovations (Berman et al., 1977). The 
success of the Rand studies promoted more interest in research to measure teachers' discernment of their capabilities to influence the achievement of their students.

Rose and Medway (1981) developed an instrument with a forced-choice scale to specifically measure elementary school teachers' perceptions of control in the classroom. The control beliefs were defined as fewer disciplinary commands given to students, lower rates of inappropriate student behavior, and higher rates of student self-directed activity. The items on the teacher locus of control (TLC) instrument asked 45 elementary school teachers to assign responsibility for student success or failure by choosing between two competing explanations for a described situation. Fourteen items described situations of student success an attribute the positive success to the teacher $(\mathrm{I}+)$ and fourteen described student failure an assigned responsibility outside (I-) of the teacher, usually to the student. Separate scores were provided for the teacher beliefs in internal responsibility for student success $(\mathrm{I}+)$ and failure (I-). Rose and Medway found that classroom teachers who scored higher in positive outcome $(\mathrm{I}+)$ displayed classroom characteristics of fewer disciplinary commands to students, lower rates of student inappropriate behaviors and higher rates of student self-directed activity. The teachers with the higher ratings in I+ took a more active role in the instructional process than teachers with a higher I- rating. This measurement method was not widely used and did not reappear in this search of the literature.

The Webb Scale (Ashton and Webb, 1982), as did the teacher TLC instrument, used a forced-choice format. The 7 items asked participants to determine if they agree most strongly with the $1^{\text {st }}$ or $2^{\text {nd }}$ item. The intent of this instrument was to expand the measure of teacher efficacy and to reduce the problem of social desirability bias. For 
example, (A) A teacher should not be expected to reach every child; some students are not going to make academic progress or (B) Every child is reachable; it is the teacher's obligation to see to it that every child makes academic progress. The study found that teachers who scored higher on the Webb Efficacy Scale had fewer angry or impatient interactions in their teaching.

The Ashton vignettes (Ashton, Buhr, and Crocker, 1984) were a series of teaching situations that a teacher might encounter and have to make judgments as to their effectiveness about motivation, discipline, academic instruction, planning, evaluation and working with parents. The research tested teacher judgments with self-referenced vignettes on how the teacher would perform on a scale from extremely effective to extremely ineffective and with norm-referenced vignettes which asked teachers to make a comparison to other teachers from judgments of much less effective than most teachers, to much more effective than most teachers. The norm-referenced vignettes were significantly related to the two Rand items, which were 1) When it comes right down to it, a teacher really can't do much because a student's motivation and performance depends on his or her home environment and 2) If I try really hard, I can get through to even the most difficult or unmotivated students. The self-referenced vignettes did not relate to the two Rand items. The Ashton et al., (1984) design of using teaching situations vignettes to measure teacher efficacy did not appear in current studies reviewed.

Gibson and Dembo (1984) developed the Teacher Efficacy Scale (TES) to address the relation between teacher efficacy and classroom behaviors. They applied Bandura's theory (1986) about efficacy expectations and outcome expectations to teacher interviews and analyses of previous studies to develop a 30 -item instrument. The factor 
analysis revealed two factors that Gibson and Dembo linked to Bandura's two expectancies of Social Cognitive Theory. The first factor was Personal Teaching Efficacy (PTE) that a teacher's sense of personal responsibility in student learning and/or behavior corresponded with Bandura's expectancy expectation dimension. The second factor represented a teacher's sense or belief that bringing about change for students is limited by factors external to the teacher. The factor titled General Teaching Efficacy (GTE) corresponded with the Bandura's outcome expectancies. The study also employed a limited classroom observation with a teacher-use-of-time measure. The measure of eight elementary teachers recorded the proportion of time the teacher spent on activities relating to teaching and academic learning. The data indicated that teachers with higher efficacy achieved higher student engagement rates than teachers low in efficacy in keeping other students engaged while instructing small groups. This instrument has been used and inconsistencies have been found on items loading on both factors which raise questions about whether there are only two discrete factors (Tschannen-Moran and Woolfolk-Hoy, 2001). Even though the meanings of the two factors and the instability of the factor structure have been problematic it is the most often used teacher efficacy instrument to date.

Guskey (1987) expanded the measure of teacher efficacy by looking at teacher responsibility for student outcomes. Guskey's exploratory study investigated the relation between selected teacher perceptions, past teacher attitudes and the implementation of new instructional practices. He developed a 30 item instrument, Responsibility for Student Achievement (RSA), to measure teacher efficacy by asking participants to give a weight or percentage to each of the 2 choices of how the teacher assumed responsibility 
for student successes and failures. An example from the study is: when your students seem to be having difficulty learning something, it is usually (a) because you are not willing to work at it or (b) because you weren't able to make it interesting for them. The two subscale scores were: assumed responsibility $(\mathrm{R}+)$ for student achievement and responsibility for student failure (R-). Guskey reported a strong intercorrelation with the Rand Teacher Efficacy (Armor et al., 1976)) findings that measures of teacher efficacy were strongly and consistently related to the teachers' overall responsibility for student success $\mathrm{R}+$ and student failure $\mathrm{R}-$. The results suggest that personal teaching efficacy (PTE) defined by the Rand research results might be divided further into responsibility for positive and negative student outcomes based on the RSA (Guskey, 1987). Teachers with instructional practices that were more aligned with the mastery learning process rated their beliefs in mastery learning strategies more important and easier to implement than teachers with practices that were different who saw the mastery learning strategies as harder to implement and a great deal of extra work. Guskey concluded, "Assuming that teachers who express a high level of personal efficacy, like teaching, and feel confident about their teaching abilities are, indeed, highly effective in the classroom, these teachers also appear to be the most receptive to the implementation of new instruction practices (Guskey, 1987, p. 12). He also believes that teachers assume responsibility for positive results more than negative results.

The concept of efficacy that were measured with the Gibson and Dembo (1984) and Guskey (1987) scales have been used with practicing teachers. However, Woolfolk and Hoy (1990) examined prospective teachers' sense of efficacy in order to clarify the concept of efficacy using the Gibson and Dembo scale and Guskey's findings. They 
investigated whether the structure of teacher efficacy is the same for prospective and experienced teachers. This study also explored the nature of prospective teachers' beliefs about efficacy toward discipline, order, control and motivation.

Woolfolk and Hoy used a version of the Gibson and Dembo general teaching efficacy (GTE) 1984 scale. They identified 20 items through factor analysis with reported reliability of alpha $=.77$ for Personal Teaching Efficacy and .72 for General Teaching Efficacy. The results of the study indicate that prospective teachers who expect to be good at their jobs anticipate being loyal to the school organization. Their results supported the earlier research with two independent efficacy dimensions for prospective teachers. Furthermore, their results also agreed with Guskey's findings that personal efficacy could be divided into responsibility for positive and negative student outcomes. The authors stated, "In other words, they have positive attitudes about being controlled themselves, but negative feelings about controlling their students (Woolfolk and Hoy, 1990, p. 90). Woolfolk and Hoy posit that to draw conclusions about teacher efficacy, a clear definition of efficacy must be established in each study.

The investigation of teacher efficacy beliefs can provide a more complete understanding of teacher behavior. Riggs and Enochs (1990) wanted to find out if efficacy could be measured specifically in relation to teaching science. They utilized the Gibson and Dembo (model to develop an instrument titled the Science Teaching Efficacy Belief Instrument (STEBI). The results were consistent with the two factors in the Gibson and Dembo (1984) measure. Riggs and Enochs relabeled Personal Efficacy as personal science teaching efficacy (PSTE) and Outcome Efficacy as science teaching outcome expectancy (STOE). The results of the study validated the STEBI as a reliable tool for 
examining elementary teachers' beliefs about science teaching and learning. The researchers found that teachers with low PSTE had a tendency to rate themselves as low in self-efficacy belief regardless of the science content or activity. The findings show that the teacher participants rated the items that contend with themselves more consistently than the external factors they did not feel they could control. The researchers interpreted this to mean that it is easier for teachers to evaluate their own behaviors than to determine the possible outcomes dependent on what they view as external factors.

The research to this point in this review of the literature has focused on investigating the existence of teacher efficacy consistent with Bandura's original Social Cognitive Theory (1986). Recently, Soodak and Podell (1996) introduced the idea of another dimension of teacher efficacy. These researchers accepted the factors identified by Bandura as "efficacy expectations" and "outcome expectations". They also wanted to find out what role outside influences, like the student's home environment, had on shaping teacher efficacy beliefs. They used a modified version of the Gibson and Dembo (1984) Teacher Efficacy Scale as their instrument to measure teacher efficacy beliefs. Unlike the Gibson and Dembo findings three uncorrelated factors emerged. Similar to previous research with the Gibson and Dembo (1984) scale, Personal Efficacy and Outcome Efficacy emerged. The third factor, Teaching Efficacy represented the belief about one's profession and that one's teaching can overcome the effects of outside influences. Soodak and Podell argued that this was not the same as either the Guskey (1984) or Woolfolk and Hoy's (1990) two-factor findings. Both factors relate to teacher beliefs about their own value. These authors raised the issue of whether the third factor Teacher Efficacy is part of Bandura's "effective expectancies" or "outcome 
expectancies" descriptions of self-efficacy. Importantly, the findings suggest that for future research with teacher efficacy one must take into account whether low efficacy is related to the teachers' lack of confidence or the sense teachers have about their abilities to impact their students beyond other outside influences.

Researchers Tschannen-Moran and Woolfolk Hoy, in collaboration with eight graduate students, proposed a new measure of teacher efficacy for use in exploring the frequent activities in a teacher's work life (1998). The study was conducted after an extensive review of the existing measures of teacher efficacy. The researchers wanted to, "identify the factors that both facilitate and impede teaching in a particular context" (Tschannen- Moran and Woolfolk Hoy, 2001, p. 795). The results were examined for more information about the unresolved issues in the measurement of teacher efficacy about to what extent teacher efficacy is specific to given contexts and the extent that efficacy beliefs are transferable across contexts. As a result of the work on the factor structure, the researchers in the study developed a teacher efficacy instrument named the Ohio State Teacher Efficacy Scale (OSTES). The instrument differed from previous measures of teacher efficacy in that it had a unified stable factor structure that assessed a range of capabilities that teachers deem important to good teaching. The three factors that consistently emerged from the collected data were efficacy for student engagement, efficacy for instructional strategies, and efficacy for classroom management. The OSTES was used in three studies with preservice and inservice teachers who were registered in classes at three universities. The instrument was originally 52 items and through subsequent testing resulted in an instrument with a long form of 24 items and a short 
form of 12 items. The three subscales had a moderate positive correlation that suggested that the items would measure the underlying construct of efficacy.

The OSTES was validated by assessing the correlation with other existing measures. The short and long forms of the OSTES were positively related to the two item Rand measure (Armor et al., 1976), Hoy and Woolfolk's version of TES (1990), and the Gibson and Dembo (1984) TES instrument. The OSTES instrument attempted to address the issue that teachers do not feel equally efficacious in all teaching situations. Tschannen-Moran, Woolfolk Hoy and Hoy (1998, p. 228) suggest, "In assessing their level of efficacy a teacher is judging personal capabilities such as skills, knowledge and strategies or personality traits balanced against personal weaknesses and liabilities in this particular teaching context. The on-going work is to design an instrument that measures the teacher's optimal level of specificity in a particular teaching context." TschannenMoran, Woolfolk Hoy and Hoy (1998) posit that the earlier teacher efficacy measures were too general or too specific and that often resulted in surrendering the external validity and practical relevance.

Pajares (1992) noted that the construct of self-efficacy may be "messy" but it is an important area of educational research. Bandura's theory of efficacy expectations and outcome expectations laid a foundation for the investigation of teacher efficacy (1986). The early research in this area identified that teachers believed that controlling the reinforcements of their actions lay within them or the environment. The results of preceding studies supported the earlier research with the two consistently identified independent efficacy dimensions for teachers. More recently a third factor, teaching efficacy, a belief in one's profession and that teaching can overcome outside influences 
has been introduced. As the research continues, the factors that facilitate and impede effective teaching yet still be there to discover.

\section{Measuring Teacher Efficacy}

The research in teacher efficacy has been a subject of debate over the meaning of teacher efficacy and the optimal method of measuring the construct. Henson writes, “Unfortunately researchers' interpretations of the Bandura (1977) and Rotter (1966) theories have significantly muddied the efficacy waters as regards the theoretical formulation of teacher efficacy and the psychometric attempts to measure the construct" (2002, p. 138). Even with the measurement challenges, teacher efficacy has still emerged as a worthy variable in educational research. Teachers' self-beliefs as determinants of teaching behavior are a simple yet a powerful idea to investigate. Following is a brief review of studies conducted to explore reliability issues with measuring teacher efficacy.

As was stated previously, teacher belief in his/her ability to perform a given behavior is influenced by the teacher perception of the difficulty of the behavior (Bandura, 1977). The investigation by Pontius (1998) utilized two teacher efficacy scales to compare and look for a correlation in teacher self-efficacy beliefs in the teaching of science. The two measurement scales used were adaptations of the Teacher Efficacy Scale developed by Gibson and Dembo (1984), the Woolfolk and Hoy (1990) teacher efficacy scale and the Science Teaching Efficacy Belief Instrument, Form B (STEBI) developed by Riggs and Enochs (1990). The self-efficacy instruments were modified to increase the validity for use with pre-service teachers. The results reported that prospective teachers with high teaching efficacy tended to have lower science teaching efficacy and those with high science teaching efficacy tended to have lower teaching 
efficacy. The Teaching Efficacy Scale and the Personal Science Teaching Efficacy Scale were -0.325 and was significant at $p=.01$ level. The Teaching Efficacy Scale and the Science Teaching Outcome Expectancy Scale was --0.08 but not statistically significant at $p=.05$ level. The result of the correlation analysis was negative and came as a surprise. The hypothesis that teaching behaviors required for teaching science would be similar to behaviors for other subjects did not appear to be true in this sample of prospective teachers. Pontius suggests that the instruments did not totally correlate because they were modified from instruments with common ancestry and raised issues about whether teacher efficacy does vary from subject to subject independent of general teaching efficacy. The fact that some of the sample had taken more general methods classes before the science methods course could have also been a factor in the outcome.

This differences in general teaching efficacy and science teaching efficacy could have major implications for teaching. Pontius (1998) suggested that if teaching behaviors for science are not similar to other teaching behaviors it may be due to teacher perceptions of the fact based subject. The science teaching knowledge may be more important than pedagogical knowledge to pre-service teachers' teaching behaviors. Pontius recommended more research to investigate the validity of the scores with other pre-service populations and in other subject areas.

The measurement instruments used to assess the construct of teacher efficacy are the subject of debate. A reliability generalization study of the teacher efficacy scale and related instruments was conducted by Henson, Kogan and Vacha-Haase (2001). The purpose of the study was to examine the sources of measurement error variance 4 scales, Teacher Efficacy Scale-TES (Gibson and Dembo, 1984), Science Teaching Efficacy 
Belief Instrument- STEBI (Riggs and Enochs, 1990), Teacher Locus of Control- TLC (Rose and Medway, 1981) and the Responsibility of Student Achievement scale- RSA (Guskey, 1987). Henson et al., (2001) noted that researchers fail to cite reliability estimates for their data and often assume that estimates from prior studies or test manuals suffice for their current work. Vacha-Haase and Nilsson (1998) employed a meta-analytic method called "reliability generalization" that allows examination of the score reliability across studies. The TES, STEBI, RLC and RSA were selected based on their frequency of use in the study of teacher efficacy. The focus of the analysis was the commonalities in the four scales. Each scale had two subscales and score reliability is more appropriately examined with subscales.

The results of the Vacha-Hasse and Nilsson meta-analysis (1998) indicated considerable variance of score reliability between subscales and within some subscales. The Teacher Efficacy Scale, TES (Gibson and Dembo, 1984) and Science Teaching Efficacy Belief Instrument, STEBI (Riggs and Enochs, 1990) had similar score reliability. The subscales of personal teaching efficacy (TES) and personal science teaching efficacy (STEBI) were more reliable than outcome efficacy (TES) and science teaching efficacy (STEBI). This outcome was expected since the Science Teaching Efficacy Belief Instrument (STEBI) was modeled after the Teacher Efficacy Scale (TES). Reliability can be affected by the study characteristics, and the results of the correlational analysis of the study characteristics indicated a differential impact on the reliability estimates. Teaching experience and teaching level were negatively correlated in each of the Teacher Locus of Control, TLC (Rose and Medway, 1981) subscales. Reliability estimates were lowest for the inservice teachers and teachers other than those at the 
elementary level. The teaching content areas such as mathematics and science were unrelated to reliability estimates. Gender homogeneity was consistently negatively related to score reliability with the exception of the Responsibility of Student Achievement, RSA (Guskey, 1987). This may suggest that lower reliability may be obtained from samples that contain a large proportion of one gender. Therefore, future researchers should examine the literature for sources of measurement error variance before selecting an instrument to measure teacher efficacy.

The Vacha-Hasse and Nilsson (1992) analysis of efficacy scales targets how the variability between instruments affect their ability to yield reliable scores. The researchers concluded that it is insufficient to assume that a test yields reliable scores from data obtained in the past. It is important for substantive studies to report reliability coefficients even if the focus of the study is not psychometric. For future research exploring teacher efficacy it will be prudent to continue to examine instruments that will strengthen measurement methodologies. For example researchers should consider context more directly via observation or evaluate teacher cognition through "think aloud" so teachers can elaborate about their responses (Henson, 2002). Vacha-Hasse and Nilsson (1992) suggest a combination of methods to deepen the understanding of any relation between teacher efficacy and classroom instructional practices.

Teachers' self-beliefs as determinants of teaching behavior are a simple idea and a powerful one to investigate, but the methodology for this type of research needs to be strengthened. The variations in the instruments used to measure teacher efficacy raise issues about whether teacher efficacy varies from person to person independent of general teaching efficacy. This difference could have major implications for teaching and 
future research. The question of whether samples that contain a large proportion of one gender may lower reliability should also be addressed. If the goal is to discover the factors that hinder and aid teaching in a specific context, then a combination of methods should be considered to improve validity and practical relevance.

\section{Research on Teachers' Beliefs}

As a global construct, an individual's beliefs do not lend themselves easily to empirical investigation (Pajares, 1992). Pajares observed that when specific beliefs are carefully operationalized and methodology carefully selected it is possible to research and understand specific beliefs about reading, mathematics or the nature of science. In a review of literature, Pajares (1992) refers to beliefs as traveling in disguise as attitudes, judgments, ideology, conceptions, dispositions, implicit and explicit theories, rules of practice, perspectives, and rules of understanding. In Bandura's (1986) work with efficacy he refers to self-efficacy beliefs as the strongest predictors of motivation and action for the individual. He suggests that beliefs are the best indicators of the decisions that individuals make throughout their lives.

The challenge for this research project was to find empirical work that would help examine early childhood teachers' beliefs about mathematics. There is a scarcity of studies on teacher beliefs and even more limited groups of studies narrowed to early childhood teachers' beliefs about mathematics. Pajares (1992) notes that research about subject-specific beliefs, like reading, mathematics, or the nature of science are feasible and useful to education. Researchers must study the context-specific effects of beliefs in order to understand the relation and the nature of their effect and connections to teacher practices, teacher knowledge and student outcomes. 
Nespor's Teacher Belief Study (1987) describes a person's belief system as consisting of propositions, concepts and arguments by those who hold them. The belief systems include affective feelings, evaluations and memories of personal experiences, and assumptions that are described as "not open to outside evaluation or critical examination in the same sense that the components of knowledge systems are" (p. 321). The data from eight eighth grade teachers were collected over the course of a semester in a series of eight long and semi-structured interviews. The sample included two teachers from mathematics, English, American History and Texas history. Videotapes of the class were recorded and viewed with the teacher for the "stimulated recall" interviews. The Teacher Belief Study found that beliefs have two important uses for teachers; first, in defining a task, teachers' perceptions and orientations are presented and may be shaped by their belief systems. Secondly, beliefs involve emotions, feelings and moods. The affective and emotional components of beliefs may influence the reconstruction memory processes and representation of events. The memory processes affect how the teacher learns and how her/she uses the representation of events to teach. Nespor's findings did align with Bandura's interpretation that a person's self-efficacy beliefs are a major determinant of their actions (1997). The combination of affect and evaluation determine the energy that the teacher expends on an activity and how they expend it. Nespor concluded that beliefs are far more influential than knowledge in determining how individuals define tasks and behaviors and are stronger predictors of behavior than the influence of teacher educators.

Kagan (1992) interpreted teacher beliefs as the implicit assumptions that preservice and inservice teachers have about students, learning, classrooms and the subject 
matter. Kagan (1992) and Pajares (1992) concur that research on "teacher beliefs" is confounded with terms like teacher principles and practice which are personal epistemologies used to represent what is inside teachers' heads about subjective knowledge and beliefs. Despite the varied terminology two generalizations have emerged. First, teacher beliefs appear to be stable and resistant to change; second, the beliefs are associated with a congruent style of teaching that is evident across grade levels and different classes. Kagan clustered the studies into separate research agendas; the study of teachers' sense of self-efficacy and the teachers' content-specific beliefs. One of the most significant characteristics that emerged from this research on teacher beliefs is the uncertainties of the classroom. Teachers have to orchestrate instruction and maintain control in a highly unpredictable and complex environment. Kagan (1992) concluded, "the more one reads and studies teacher beliefs, the more strongly one suspects that this piebald form of personal knowledge lies at the very heart of teaching....as we learn more about the forms and functions of teacher belief, we are likely to come a little closer to understanding how good teachers are made" (p. 85).

The debate between early childhood educators about developmentally appropriate and inappropriate instructional practices involves teacher beliefs and instructional practices. A questionnaire was designed to measure kindergarten teachers' beliefs and practices based on the guidelines of developmentally appropriate practices of the NAEYC (Bredekamp, 1997). Charlesworth, Hart, Burts, Mosley and Fleege (1993) used a two-part questionnaire with a degree-of-importance rating scale rather than a format of agree or disagree. The Instructional Activity Scale (IAS) asked teachers to rate the frequency of availability of activities in their classrooms with a 5-point Likert scale, 1) 
almost never to 5) very often. The 34 items included participating in dramatic play, creative movement, copying from chalkboard, coloring and/ or cutting, and the use of workbooks and dittos. The Teacher Belief Scale asked teachers to rate the 36 statements with a 5-point Likert scale with 1) not at all important to 5) extremely important. An example, It is __for children to work silently and alone on seatwork. The TBS and IAS composite scores were used to separate principal component analysis.

From the analysis six reliable TBS factors and eight IAS factors emerged. A composite score for TBS Factor 1 Developmentally Inappropriate Activities and Materials was used to identify 20 teachers, 8 teachers one standard deviation above the mean and 12 teachers one standard deviation below were selected to be observed. Charlesworth et al. (1993) designed an observation instrument to measure the perceived beliefs and practices self-reported from the questionnaire that corresponded with the NAEYC guidelines. The 24 item checklist had two or more observers rate on a 5-point Likert scale from most appropriate (5) descriptors to most inappropriate (1) during a 3 hour stay in the classroom.

The results of the study reported a statistically significant positive correlation between reported beliefs and developmentally appropriate practices. Most of the teachers had beliefs that agreed with the developmentally appropriate philosophy, but through the observations it was noted that the frequency of the DAP activities varied. Whereas teachers with beliefs in line with the TBS Factor 1, Developmentally Inappropriate Activities and Materials, were more frequently observed using those types of activities. The study demonstrates that to clarify the beliefs-practices relation more work needs to be given to an observation instrument that takes into consideration specific aspects of 
instruction for example, scaffolding, classroom organization and treatment of children relative to gender and culture.

Beliefs of early childhood teachers and their principals regarding early childhood curriculum, child development and teaching strategies were examined by Spidell-Rusher, McGrevin and Lambiotte (1992). This research conducted in Texas with 500 kindergarten teachers and 167 principals utilized a 56 item questionnaire with a 5-point Likert scale. The response rate was only $37 \%$ for teachers and $31 \%$ for the principals. Three belief factors emerged from the analysis: academics, child centeredness, and activities issues. Further analysis showed that beliefs did not appear to vary according to the type of school district, job category or gender. The data indicated that these kindergarten teachers disagreed with a strong academic focus, but agreed with childcentered practices. The principals sampled reflected similar beliefs as the teachers. Female principals expressed beliefs that favor more physical, expressive activities for young children than their male counter parts. The explanation suggested for this difference was the lengthy tenure female principals had in the classroom prior to coming to administrative positions compared to the male principals. The data from this study indicated that teacher beliefs tend to be in alignment with what researchers and experts are saying are essential child-centered practices for young children, but the actual instructional practices may reflect district or administrator favored models. Another explanation for the discrepancies in beliefs and practices may also lie in the state education agency's heavy emphasis on a skill-based academics for young children. Smith (1997) designed a study to address the limited research data about preservice teacher beliefs about appropriate practice. The purpose of the study was to 
examine the patterns and stability of pre-service teachers' embracement of developmentally appropriate practices. The participants were 60 volunteer undergraduates from an urban Midwestern university in the student teaching phase of their teacher education program. The study utilized three scales. The 42 item belief scale was developed by Smith (Primary Teacher Questionnaire, 1997) and used the NAEYC guidelines (Bredekamp and Copple, 1987) relating to school-age children to design two subscales. The Developmentally Appropriate subscale consisted of 18 items that participants responded using a 4-point Likert-type scale from strongly agree to strongly disagree. An example of this is, "learning materials should be concrete and relevant to the child's life." The other subscale of 24 items endorsed a more academically focused practice. An example of this is, "learning materials should be symbolic and representational." The second scale was an adaptation of the 42 item Primary Teacher Questionnaire. The participants were to indicate with the 4-point Likert scale the degree to which their cooperating teacher agreed with the developmentally appropriate or more academically focused practices. The third measure was the Duttweiler Internal Control Index (1974). The 28 incomplete statements were completed by the subjects using a 5point Likert scale to indicate frequency. The choices range from rarely: less than $10 \%$ of the time to usually, more that $90 \%$ of the time.

Two groups, elementary and early childhood undergraduate elementary education majors, completed the two self-report scales at the beginning of the semester and the adapted Primary Teacher Questionnaire relating to their cooperating teacher at the end of the term. The pre-student teaching beliefs differed between the elementary and early childhood pre-service teachers. The mean for the early childhood pre-service teachers 
endorsed the developmentally appropriate practices while the mean for the elementary pre-service teachers endorsed a more academically focused practice. Initially the preservice teachers in both groups rated their cooperating teachers comparable with their own developmentally appropriate and academic focus scores. The results of the study indicated pre-service teacher beliefs were stable through the course of their 16 week term. There were no significant increases or decreases in pre-service teachers' beliefs about developmentally appropriate or traditional practices or the locus of control from pre to post results. This study provided evidence that pre-service teachers who start out with developmentally appropriate beliefs retained them, and pre-service teachers with an academic focus of practice also retained those beliefs. One conclusion that could be made from the results of this study is the influence teaching perspectives have on beliefs and that these beliefs may develop early and be difficult to alter. This has implications that inform efforts to change teacher practices (Jackson and Hartounian, 1989).

Stipek and Byler (1997) also used teacher report questionnaires to explore a relation among pre-kindergarten, kindergarten and first grade teachers' beliefs about childrens' learning, goals for early childhood education, school entry policies, testing and retention. The three-part questionnaire asked the 60 participants from private schools to rate seven goals for early childhood programs: social skills, independence and initiative, basic skills, cooperation, knowledge, self-concept and creativity. The next section assessed teachers' beliefs about a more academic teaching of basic skills or childcentered practices. The final section included open-ended questions on relevant issues in early childhood education such as: less academic and structured programs, parental satisfaction with programs, school readiness and delay of entry and the usefulness and 
purpose of standardized tests. Observational ratings of two and a half hours of classroom instruction were done with 47 of the teacher participants. The observation instrument, designed by Stipek and Byler (1997), had two subscales. The first scale rated events occurring in the classroom like work versus play with (a) clearly distinguished, (b) occasionally distinguished and (c) not clearly distinguished. The second subscale reflected the social climate of the classroom and the range of scores one to four represented (a) highly critical, (b) moderately critical, (c) moderately accepting, (d) highly accepting.

The results of the questionnaires and observations showed that early childhood teachers in this study had consistent beliefs that were aligned with a more child-centered approach as seen in the cognitive development and educational literature. There was a strong negative correlation between an academic focus on basic skills and the childcentered belief scales for the early childhood (Pre-k) and the kindergarten teachers. This hints that the teachers may believe that children learn better one way or the other or perhaps a combination of the two. The observations reported associations between the early childhood and kindergarten teachers' beliefs and the practices they were implementing. Even though the practices matched the beliefs of the teachers many of the teachers claimed that they were practicing a more academic and structured program than they would prefer. The reasons the teachers gave for practicing a more structured program included parental pressure for more academics as well as school and state policies.

The first grade sample was limited and a weak non-significant correlation between basic skills and child-centered beliefs scales may have occurred because the first 
grade teachers believed that both the basic skill and child-centered approaches were appropriate in their classrooms. One of the conclusions Stipek and Byler (1997) made from the findings is that researchers need to be mindful of how the goals of early childhood educators vary. The resistance expressed by teachers about implementing different approaches to produce particular outcomes may not be a result of the lack of confidence in the approach, but lack of commitment to the outcome.

A five year longitudinal study conducted by Vartuli (1999) examined variations in reported beliefs and observed practices of Head Start through third-grade teachers. The teachers' beliefs and self-reported practices were measured by three instruments: the Early Childhood Survey of Beliefs and Practices (Marcon, 1999); the Teacher Belief Scale (TBS, Charlesworth et al., 1993); and an observation scale, the Classroom Practice Inventory (Hyson, Hirsch-Pasek, and Rescorla, 1990). The study was conducted in Missouri in the fall of $1992(n=82)$ through spring of $1997(n=79)$. The study found that teacher practices and beliefs varied across and within grade levels. Scores comparing beliefs and teaching practices were more congruent between the Head Start and kindergarten teachers when compared to scores from the first, second and third grade primary teachers.

Congruence of teacher beliefs to classroom practice was moderate for Head Start and kindergarten teachers and low-moderate for primary grade teachers. The study revealed that Head Start teachers' scores for class time set aside to learn material in a specific content area such as mathematics, science, social studies or reading were significantly lower than first, second and third grade teachers. The study measured teacher beliefs with the 34 item Teacher Belief Scale and 36 item Instructional Activities 
Scale (Charlesworth et al.,1993) and the 14 item Early Childhood Survey of Beliefs and Practices (Marcon, 1988). The TBS was used to pinpoint more specific beliefs whereas the CSBP focused on global beliefs and practices. The 36 item Classroom Practices Inventory (Hyson, Hirsh-Pasek, and Rescorla, 1990) had two parts that would reflect the instructional focus and social climate of the classroom. When comparing the two belief measures $(n=82)$, the TBS total score correlated moderately with the ECSBP: belief scale $(r=.75)$. A post-hoc comparison (Tukey-B, $\mathrm{p}<.05$ ) of the TBS revealed Head Start mean scores were significantly higher than kindergarten, first and second grade teachers' mean scores. The kindergarten mean scores were significantly higher for developmentally appropriateness than first and second grade teachers' mean scores. The results of the ECSBP indicated that the higher the score the more the beliefs were developmentally appropriate. The ECSBP also confirmed the post-hoc comparison of the TBS mean scores. The Classroom Practices Inventory compared grade level differences with an analysis of variance and significant difference resulted in a between grades comparison, $F(4,135)=37.37, p<.001$. The results confirmed what the TBS and ECSBP had shown that Head Start had significantly higher means than kindergarten, first and second grade teacher mean scores. Also the kindergarten mean scores were significantly higher than the first and second grade teacher mean scores. The higher mean scores indicated more observed developmentally appropriate practices.

The teachers in the study rated developmentally appropriate beliefs higher than they rated developmentally practices. The researchers concluded that perhaps teachers believe in appropriate practices but may be challenged about how to translate these beliefs into teaching strategies. The influences of school culture, peer pressure, and 
local/state mandates may also affect the differences between beliefs and practices. In comparing Head Start and kindergarten to first, second and third grades, as the grade level increased, the level of self-reported developmentally appropriate beliefs and practices decreased. It appeared that the older children were given less responsibility for their learning. This raised a question about the reliability of using an observation instrument designed for early childhood classrooms even with modifications for first, second and third grade classrooms. The researchers hypothesized that academic pressures that primary grade teachers feel about having their students achieve higher test scores may impact how teachers implement developmentally appropriate practices and it may be reflected in their scores on the questionnaires.

The demographic information of the teachers' years of experience were grouped as, few, 1-7; average, 8-19; and many, 20-32, and a one-way ANOVA was run. Significant differences were found with the number of years of experience and the Classroom Practices Inventory scale scores. A post-hoc comparison revealed that teachers with fewer years of experience had the highest scores on the CPI $(M=206, S D=$ 38) compared to teachers with many years $(M=172, S D=35)$. It could be stated from the comparison of data that teaching experience was not a factor in higher developmentally appropriate practice scores. The teachers with specific early childhood certification had significantly higher reported belief scores, and this correlated with their observed practices more than the teachers with elementary education certification and their observed practices. Vartuli (1999) concluded that teacher beliefs and practices varied across grade level and within grade levels. The implication for early childhood and primary teachers is awareness of how children adjust to these beliefs and practices. The 
transition for some children from a child-centered classroom to a more academically focused classroom may be great and should be planned and addressed. The research in the connections between teacher beliefs and practices (Charlesworth et al., 1993; Marcon, 1999) can be positive for more learning for children and defining the developmentally appropriate practices and strategies for teachers.

Research was conducted with an observation measure, the Assessment of Practices in Early Elementary Classrooms (APEEC) (Maxwell, McWilliam, Hemmeter, Ault and Schuster, 2001). The purpose of the observational design was to not only describe current elementary school practices but also to identify the factors that affect the practices. The focus was to attempt to understand whether teacher beliefs contributed to the observed practices beyond other classroom characteristics, like class size or education level of teacher. The study was conducted with 40 kindergarten through - third grade classroom teachers in North Carolina and 29 from central Kentucky. The primary data were scored on the basis of observation. The 16 item APPEC instrument uses the same 7point continuum as the Early Childhood Rating Scale-Revised (Harms, Clifford, and Cryer, 1998). The 16 items use two or more descriptors at the $1,3,5,7$ anchors. Teacher report may be used in some instances if the descriptor is not observed. The researchers reported interrater agreement on an average of $86 \%$ of the items. In addition to a 20 item background questionnaire the participants were also asked to complete the Charlesworth et al., (1993) Teacher Beliefs and Practice Scale-Kindergarten Version. All the items are rated on a 5-point Likert scale. Three summary scores were created from the 14 developmentally appropriate beliefs, the 9 developmentally inappropriate beliefs and the 17 developmentally appropriate practices. 
The analysis of the APPEC with a hierarchical multiple regression found that classroom characteristics, teacher characteristics and teacher beliefs accounted for $42 \%$ of the variance. The kindergarten and first grade classrooms were observed as more individualized and more developmentally appropriate than 2-and 3-grade classrooms. The teachers' years of experience was not statistically significant, but classrooms taught by teachers with master's degrees were more developmentally appropriate. Teachers who reported beliefs in developmentally appropriate practices were observed to be more developmentally appropriate than those whose beliefs were less developmentally appropriate. Like the Vartuli (1999) study, teacher beliefs predicted instructional practices independent of education level. As the grade level increased, the classrooms were less developmentally appropriate. This study demonstrated that teacher beliefs, classroom characteristics and teacher characteristics accounted for half of the variance in observed instructional practices. The teacher beliefs should be addressed and not assumed that the beliefs will change as a result of teacher training in developmentally appropriate practices.

Kowalski, Pretti-Frontczak, and Johnson (2001) examined early childhood teachers' beliefs about how important it was for young children to master socialemotional, literacy and early mathematical functions. Teachers from Head Start, public school pre-kindergarten and pre-kindergarten special education rated the importance of 54 specific items that describe the key domains of language, literacy and early mathematics that are typical for young children to learn during the pre-kindergarten years. The items use a 5-point Likert scale $(1=$ not all important, $2=$ somewhat important, $3=$ important, 4 = very important, $5=$ critically important). The key domain 
items were a combination of pre-kindergarten scales of the MAPS observational instrument, added items that reflected the recommended practices in early childhood education (Bredekamp and Copple, 1997) and developmentally inappropriate distracter items were included in each key domain to ensure that teachers evaluated each item case by case. The response rate of $74 \%$ of the Head Start, pre-kindergarten, special education and public pre-kindergarten educators provided scale reliability with calculated Cronbach's alpha, 0.81 for social-emotional, 0.85 language and literacy and 0.88 for early mathematics. The results of a 3 (teacher) $\times 3$ (scale) ANOVA, with scale treated as repeated measure showed, 'there were no significant differences in teachers' mean ratings of the items on the language and literacy and early math scales" (p. 11). Post-hoc comparisons indicated that teachers rated the items related to mastery of social-emotional skills $(M=3.83)$ as being the most important compared to language and literacy $(M=$ 2.9) and early mathematics $(M=2.9)$. The analysis indicated Pre-kindergarten Special educators rated social-emotional skills significantly higher than Head Start teachers, although the beliefs of the three groups were found to be more similar than different. A correlational analysis indicated a positive correlation between level of teacher education and mean score on the social-emotional scale, $r=.447, \mathrm{r}^{2}=0.19 p<.05$. As the teachers' level of education increased they placed greater importance on social-emotional skills and abilities.

Early childhood scholars (Bredekamp and Copple, 1997; Copley, 1999; Clements, Sarama and DiBiase, 2002 and Ginsburg, 1983) advocate for active, involved teaching behaviors that facilitate a child-interest centered curriculum based on play. Not all teachers hold personal beliefs that match this model. Wilcox-Herzog (2002) examined the 
link between early childhood teachers' beliefs and their perceived ability to practice their beliefs. The research about beliefs and actions does not always account for the factors that influence the relation between them. For example, when the sample includes early childhood teachers with varied training or training that did not address the framework being researched, there could be irregularities in reporting significance between beliefs and actions. The purpose of the Wilcox-Herzog (2002) study was to examine the early childhood teacher belief-action relation with more specific measurements. The classrooms were videotaped for two half-hour sessions during free choice time when children were able to self-select activities like library, blocks, art and manipulatives. Following the final taping the teachers completed the self-report questionnaire. The teacher belief statements were developed by adapting categories from other observational instruments relating to teacher-child interactions. The 8 teacher sensitivity statements came from The Arnett Classroom Interaction Scale (Arnett, 1989) and measure how warm caregivers are in their interaction, communication and involvement with the children. The teacher play style statements came from definitions of play styles that range from 1) uninvolved, 2) caretaker -washing a child's hands, 3) safety/behavior monitorredirecting a child, 4) stage manager- getting materials for children, 5) play monitorwatching children play to 6) play enhancer- actively playing with children. The teacher verbalization statements were taken from a verbal interaction scale designed by WilcoxHerzog in 1998. These are on a 7-point scale and range from 1) not talking to a child, 3) talking with child about their behavior, 5) making simple statements or asking closeended questions, to 7) talking with children about fantasy play. Finally teachers' involvement statements came from the Howes' Adult Involvement Scale (1990), and 
teachers rank ordered statements about the importance of interacting with children. This scale ranges from 1) ignoring children, 3) minimal care giving to, 6) intense interactions. The self-report was used to relate the observed teacher practices to the teacher beliefs about sensitivity, play style, involvement and verbalization in their early childhood classroom.

The teachers in this study rated play at high-levels $(M=77.1 \%)$, and demonstrated in the observations a high-level of play and involvement $(M=75.6 \%)$ of the time. The teachers scored on average 44.38 out of a possible 48.00 points in their sensitivity to children in their interactions. The intercorrelation revealed that the high level of involvement and high level of verbalization were positively related to holding an early childhood teaching certification. Even with more specificity to measurement the intercorrelational results for this group of teachers showed no significant relation between their beliefs and behaviors. Wilcox-Herzog concluded that the sample size $(n=47)$ may have played a role in the lack of significance. The inconsistent results in the research about teacher beliefs and behaviors highlight the importance of identifying the variables in the population sampled and the selection of the measurement instrument.

The research implications of the cited studies suggest a need to study contextspecific effects of beliefs in order to understand the relation and the nature of their affect and connections to teacher knowledge, teacher instructional practices and student outcomes. But, the current literature is more focused on the debate between early childhood teacher beliefs and their demonstration of developmentally appropriate practices (DAP). The recommended DAP encompass a wide range of practices. The research tends to label teacher beliefs and practices as child-centered or teacher-directed. 
Then the developmentally appropriate classroom is depicted as more child-centered based on play and children's social- emotional experiences and interactions with language, literacy and early mathematics. In contrast the teacher-directed classroom is more likely to have a stronger academic focus or approach to language, literacy and early mathematical skills. This can often be portrayed as a less positive social-emotional climate where the teacher would be more directive in the approach to the key domains. The research discussed early in this review indicates that teachers' professed importance of developmentally appropriate practices was stronger than what was reported about their instructional practices. Agreement on what classroom models are "appropriate" versus "inappropriate" is still being debated (Harts, Burts and Charlesworth, 1997).

The Nespor (1987) study results suggest that if we, as teacher educators and researchers, are interested in why teachers organize, run their classrooms, and interpret classroom processes the way they do, we must understand the teachers' goals. The teachers' goals and classroom structures have sources in teachers' beliefs. The beliefs are far more influential on the teacher than the knowledge in determining how they define tasks and behaviors. A conclusion brought forth from study results posits that the influence of teacher beliefs on teaching perspectives may develop early and be difficult to alter. This is a consistent theme in research on teaching beliefs. The challenge for researchers in studying teacher beliefs is finding empirical work that examines teacher beliefs and instructional practices with a specific content area such as mathematics.

\section{Research on Young Children and Mathematics}

The debate about the Developmentally Appropriate Practices (DAP) movement has been an impetus for closer examination of dynamics of the early childhood classroom 
environment. Spodek and Brown (1993) acknowledge the Developmentally Appropriate Practices movement but suggest an alternative approach to curriculum research in early childhood education. They propose a research agenda that investigates the content of prekindergarten programs as to how they are related to elementary school subjects. For example, reading specialists stimulated by the Vygotsky Social Cultural Theory (1978) shifted away from promoting the concept of reading readiness to one of emerging literacy. This helped early childhood teachers see the process of learning oral and written language as a seamless process to more mature literacy skills. A shift in mathematics is also emerging. There is a renewed interest in doing research relating to fostering children's mathematical thinking (Baroody, 1993). The research about the issue of whether organized mathematics should be a part of the early childhood curriculum is incomplete.

The research on early mathematical development provides evidence that prekindergarten children do come to school with informal numerical competence. Several research studies (Clearfield and Mix, 1999; Starkey and Cooper, 1980; Starkey, Spelke and Gelman, 1990; and Wynn, 1992) have even interpreted infants' performance in experiments as the ability to discriminate small sets. Such a starting point has led researchers to examine toddlers and to conclude that children as young as 2-years 6months of age could identify pictures or small sets before they could use the counting words (Fuson, 1992; Huttenlocher, Jordan and Levine, 1994; Sophian, 1995; and Wynn, 1992). The results of the students' responses to the calculation tasks suggest that before the ages of 2-years 9-months to 2-years 11-months children are using approximation rather than exactly adding and subtracting (Huttenlocher et al., 1994). Children gradually 
develop basic number and arithmetic concepts as a result of the real experiences that they bump into that involve counting (Baroody, 1992). Young children see mathematics as meaningful, interesting and worth learning. The desire for young learners to quantify in their world is a natural. They have the disposition and the motivation to quantify the world around them (National Research Council, 2001). The challenge is to build on those initial fragile understandings to make them more reliable. Collecting evidence to look carefully at the relation of teachers' sense of efficacy and beliefs about mathematics may shed some light on their instructional practices.

Research on young children's understanding of mathematics has centered on whether infants and toddlers have the ability to quantify. Piagetian theory (Ginsburg, 1983; Kamii, 2000; and Piaget, 1952) defined the ability to conserve number as a defining attribute to quantitative competence. A review of the research by Mix, Huttenlocher, and Levine (2002) presents new ways of thinking about quantitative competence. "The basic assumption of most work on quantitative development is that early abilities serve as a meaningful precursor of later skills" (p. 7). This assumption supports the developmental pathway Piaget described in his 1945/1965 studies. Piaget defined three levels of performance related to the conservation-of-number task. At level one a child cannot make a set that has the same number; at level two the child can use one-to-one correspondence but cannot conserve the number. At the third level the child can conserve the quantity. For example, the child can identify that there are as many blue counters as red counters and demonstrate that the spacing or position does not change the quantity (Kamii, 2000). Current research is still looking at early mathematics as a developmental pathway or transition. The first stage of the developmental pathway 
centers on the importance of object-counting. This is also referred to in the literature, as stable order principle, or perceptual and figurative counting. Next, children begin to use counting to identify equivalent sets rather than physical appearance as they are ready to move to larger numbers and the third transition. The proposed third transition is when the child begins to write number words to connect to their object counting and quantities that they want to represent. At the end of these three transitions children should have a seriated, embedded, unitized, cardinalized sequence of number (Fuson, 1992).

A complete theory does not exist that proposes how counting and other arithmetic procedures link with children's existing knowledge to develop new levels of understanding (Baroody, 1992). Researchers continue to speculate on what areas of cognition are involved in the quantitative development of pre-kindergarteners and early primary children. In all of these studies there was variance in the age at which these concepts emerged.

Gelman and Gallistel (1986) looked at the field of cognitive development of prekindergarteners as their own entity. Earlier research had looked at pre-k childrens' mathematical abilities with a deficit model. The mathematical disposition of pre-k children was described in terms of the capabilities they lacked, instead what they were capable of doing. The researchers studied the relation between numerical abstraction and numerical reasoning to see if it would reveal the early presence of numerical concepts (origins and development of the logico-mathematical operations). They identified skeletal how-to-count principles as the initial steps to conceptual competence: 1) stable order principle: count tags in the same sequence on every count; 2) one-to-one principle: every item in a collection must be tagged with only one unique tag; and 3) cardinality principle: 
the tag used for the last item in a collection represents the total number of items in the collection. Gelman and Gallistel concluded from their studies that by the age of three years children have learned enough count words to be able to use the same sequence of tags reliably for as many as five items. The 3-and 4-year-olds follow the one-to-one principle for counting with small sets and show clear evidence of being able to apply the cardinal principle. The cardinal principle was present even in the 2-year 6-month-olds in the study but full competence had not emerged. The evidence of the children's work does suggest that the ability to apply the cardinal principle does lag behind the one-to-one and stable-order principles. The study supports the argument that young children have mathematical competence as early as 2-years-old and could benefit from mathematical literacy activities in the early childhood classroom.

The research in pre-kindergarteners' how-to-count principles provides a background to understand how these concrete principles evolve as the children get older to more abstract principles. Steffe and Kieren's (1994) research describes quantitative development in terms of principles. The researchers collected data on six first and second grade children. They believed that a child fuses sensorimotor signals that are happening in their environment into experiences with objects, for example food and toys. From this research the authors proposed learning stages. The proto-numerosity stage includes: 1) the perceptual counting scheme; and 2) the production of a perceptual collection of units to be counted. They found that 6-year-olds remained in this stage for at least six months. The next stage, the figurative counting scheme, means that the child can verbally produce a sequence of number words even if the objects are not in range of perception. They found that the 6-year-olds would hold up four fingers on one hand and three fingers on 
the other to represent the collection and make the transformation from a counting scheme into a figurative scheme. The third stage, initial number sequence, shows that the child is aware of the beginning and end of the count. The child counts the items within the boundaries, but does not see the counted items as a set of one thing. The fourth stage, tacitly-nested number sequence, indicates that the child knows that the number seven means from one up to and including seven, but still does not see that seven is part of nine. Understanding the part-whole numerical relation merges in the fifth stage, explicitlynested number sequence. Then children understand the seven means seven times a unit and also the number sequence one to and including seven. The research showed that the perceptual or interiorized records in 6 year-olds decay, for no other reason than interiorized records can decay and they may go back to an earlier scheme. The more experiences that a child has to re-present these schemes the sooner the internalization can happen.

The Three R's, Readiness, Reading, and Results, are recommendations for the pre-kindergarten environment made by the Carnegie Corporation Initiative (2002). Their publication What Kids Need (2002) presents a case for literacy development through phonological awareness, print awareness and word sense, but makes no mention of mathematical literacy. The research focus on reading literacy has influenced a narrow set of skills that have become the realm of early education. "American children often enter elementary school without a foundation of informal mathematical knowledge," (Klein, Starkey and Wakeley, 1999). The study conducted by Klein, Starkey and Wakeley (1999) examined pre-kindergarten children's informal mathematical knowledge and range of mathematics concepts. They studied 5 pre-kindergarten classrooms with 4-and 5-year-old 
children from middle-income families. The pre-test results of the number/arithmetic revealed that the children were successful in counting small sets but had less success with large sets. The children understood ordinal terms first and second, but not third and fourth. They could solve two-set addition problems with equal sets, but not unequal sets. On the spatial/geometric tasks the children named several of the simple shapes and could duplicate patterns and recognize triangle transformations. A math curriculum designed to promote development in the domains of numerical and spatial cognition was conducted with children designated as the intervention group. The posttest performance of the intervention group on the number/arithmetic tasks indicated that children's accuracy increased significantly and exceeded the control group on the two-set addition task. The intervention group also demonstrated greater accuracy than the control group on the spatial/geometric tasks. The Klein, Starkey and Wakeley (1999) study supports the National Research Council (2000) conclusions that pre-kindergarten children can develop skills while learning to increase their attention span and regulate their thinking (Bowman et al., 2000). The conclusions of the NRC and the research findings of Klein et al., (1999) bolster the reasoning behind this current study to investigate what role the teacher's efficacy and beliefs have on mathematics instructional practices in the early childhood classroom.

Few research studies have examined the various factors that influence and shape the development of mathematical understanding before formal schooling. Graham, Nash and Paul (1997) conducted a qualitative study to explore child care settings to examine the mathematical activities and dialogue in which teachers and children engage. They also wanted to investigate teacher attitudes and beliefs about education and mathematics. 
The study was conducted at two daycare centers serving 3-4- and 5-year-olds from professional and university-affiliated families. The teachers were observed six times over a period of three weeks and then interviewed about their beliefs about developmentally appropriate practice and attitudes about teaching mathematics. The researcher coded conversation as mathematical if either the child or the teacher formally or informally discussed numbers or mathematical operations. There were twelve instances of mathematical discussions over the course of twelve hours of observations. The four concepts were counting, numeral recognition, age and shapes. The contexts of these discussions were song/rhyme, direct teaching, opportunistic teaching and spontaneous conversations about mathematics. Three of the four pre-kindergarten teachers interviewed believed that mathematics should be taught informally. All teachers believed that concrete objects and games were part of this informal development. Even though the sample was small it was evident that the teachers thought mathematics was important, but this belief was not reflected in the observations of their practice. Even though the classrooms varied in teacher-student ratio, physical set-up, and age-grouping the amount of actual mathematics was minimal for all classrooms and teachers. The researchers concluded that the status of mathematics in early childhood classrooms warranted further study.

Supporting pre-kindergarten children's readiness for school mathematics is a collaboration between school and home. A survey project was designed to study the ecological context of young children's mathematical development in pre-kindergarten classrooms and at home (Klein, Starkey and Wakeley, 1998). The teacher questionnaires were sent to licensed pre-kindergarten programs in California encompassing private 
nonprofit, state pre-kindergarten, and University pre-kindergarten programs $(n=300)$. The parent questionnaires were administered to parents of pre-kindergarten children who had been involved with an earlier study of a pre-kindergarten mathematics curriculum ( $n$ $=47$ ). The questionnaire asked teachers and parents to respond about which mathematical abilities or skills do children typically develop by the end of prekindergarten? Some examples of the choices were, "show which doll in a row of 5 is second," "measure a pencil with a piece of string" and "use a calculator to solve singledigit addition or subtraction problems."

The survey findings showed that teachers and parents did believe that prekindergarten children possessed mathematical knowledge. The parents attributed more mathematical knowledge than the teachers did, for example $81 \%$ of the parents believed that by the end of pre-kindergarten a child should be able to solve addition and subtraction problems with objects. Only $75 \%$ of the teachers agreed with this statement. A small percentage (16\%) of the teachers believed that pre-kindergarten children have mathematical knowledge that has not been recognized in the developmental research for this age range. For example, the pre-kindergarten age child should be able to read arithmetic symbols and use numerals to make a pattern such as odd and even. The study found that most teachers believed that the pre-kindergarten environment contributed to mathematical readiness. Two-thirds of the parents and one-third of the teachers surveyed did not know what mathematics was taught in the pre-kindergarten curriculum. The survey data and developmental profiles of the children revealed the importance of a comprehensive pre-kindergarten mathematics curriculum in order to prepare children for school mathematics. 
Some studies have examined the relation between teachers' pedagogical content beliefs in mathematics and student achievement in mathematics. Peterson, Fennema, Carpenter and Loef (1989) studied 39 first-grade teachers in a Midwest school district to conceptualize the pedagogical content beliefs specifically about teaching addition and subtraction in first-grade. They wanted to provide a model to analyze pedagogical content beliefs and describe how the content beliefs influenced teacher thinking, decision making and ultimately student performance. The data on pedagogical content beliefs about addition and subtraction were collected in a 48 item, 5-point Likert scale, belief questionnaire. The four belief constructs that the research addressed were 1) children construct their own mathematical knowledge; 2) mathematics instruction should be organized to facilitate children's construction of knowledge; 3) children's development of mathematical ideas should provide a basis for sequencing topics for instruction, and 4) mathematical skills should be taught in relation to understanding and problem solving. The questionnaire was designed to assess teachers' beliefs on four subscales: 1) how children learn mathematics; 2) the relation between mathematical skills and understanding and problem solving; 3 ) teachers' beliefs about the basis for sequencing topics in addition and subtraction instruction; and 4) how addition and subtraction be taught. The questionnaire was followed by a structured protocol audio-taped belief interview that provided another method to obtain information on teacher beliefs. The interview questions were also based on the four fundamental assumptions (belief constructs). The researcher scored each teacher's belief with a 5-point Likert scale. The researcher judged where the teacher fell on the continuum for each of the four belief constructs. The results of the belief questionnaire indicated that teachers had the highest 
average agreement on the belief that mathematics should be taught in relation to/in isolation from problem solving. The examination of the interviews provided evidence of a causal relation with teachers' beliefs affecting their selection, organization and presentation of mathematics content and their pedagogical strategies. This study's results point out that teacher beliefs are linked to classroom action and may affect the quality of students' learning. One conclusion drawn from this study states, "teachers' pedagogical content beliefs in addition and subtraction show up in self-reports of their approaches to teaching addition and subtraction, their choices of mathematics content, their conceptions of the roles of teacher and learner, and their goals for instruction" (Peterson et al., 1989, p. 37).

Staub and Stern (2002) replicated the Peterson et al., (1989) study with 496 thirdgrade German elementary students in 27 classrooms. The teacher belief questionnaire and structured interviews utilized in the Peterson, Fennema, et al., study (1989) were found to be applicable in German speaking countries. The study used hierarchical linear modeling to examine the effects of classroom-level variables such as teachers' beliefs on individual student outcomes. They found that students in classrooms with teachers who had a stronger cognitive-constructivist orientation, identified from the belief questionnaire, had greater gains in achievement with demanding mathematical word problems than students whose teachers had a less constructivist view. The cognitive-constructivist viewpoint is defined as learning understood to be dependent on the individual's own constructive cognitive processes. In other words, how students construct learning is related to the environment but also how they make use or are constrained by the knowledge already available. Staub and Stern concluded that teachers with a stronger cognitive- 
constructivist orientation tended to select more structure-oriented tasks including more demanding mathematical word problems than teachers with less of a cognitive constructivist view. So from this work one could conclude that pre- kindergarten teachers with high efficacy and belief in the importance of mathematics provide more constructive mathematical experiences in their classroom.

The past research on early mathematical development and early childhood teachers' content beliefs about mathematics can provide a starting point for examining how early childhood teachers' beliefs and conceptions of teaching and learning mathematics are related or not related to their instructional practices. Liping Ma's 1999 study of teachers' practices in China and the United States found that Chinese teachers felt that the more significant the occasion when a concept was first introduced as the primary learning was for their students, the more support it contributed to the students' later learning. The observational data from the study showed that not a single teacher was observed who was promoting learning beyond their own (teacher's) mathematical knowledge. The beliefs that teachers hold influence the perceptions and judgments that can undermine the personal efficacy needed for continued self-development. This suggests that studying the relation among a teacher's sense of efficacy, teacher beliefs about early mathematics and actual instructional practices will help identify what direction change strategies should be addressing.

Conceptual Framework

The theory and research reviewed provides evidence that teachers' efficacy is related to student outcomes (Ashton and Webb, 1986; Bandura, 1997; Gibson and Dembo, 1984; Guskey and Passaro, 1994) and that teachers' beliefs about 
(developmentally appropriate) practices affect instruction in their classrooms (Cassidy et al., 1995; Charlesworth et al., 1993, Hollingsworth, 1989; Isenberg, 1990; Nespor, 1987). The research does not clearly represent the relation of teachers' efficacy to the teachers' beliefs about the importance of early mathematics with their instructional practices. The purpose of this study will be to examine the relation between the variables in an early childhood context in relation to mathematics instruction. Teacher general and personal efficacy, teacher mathematics beliefs, and teacher instructional practices in mathematics are the three major constructs of this study. The following figure (Figure 1) is a model for thinking about the relation.

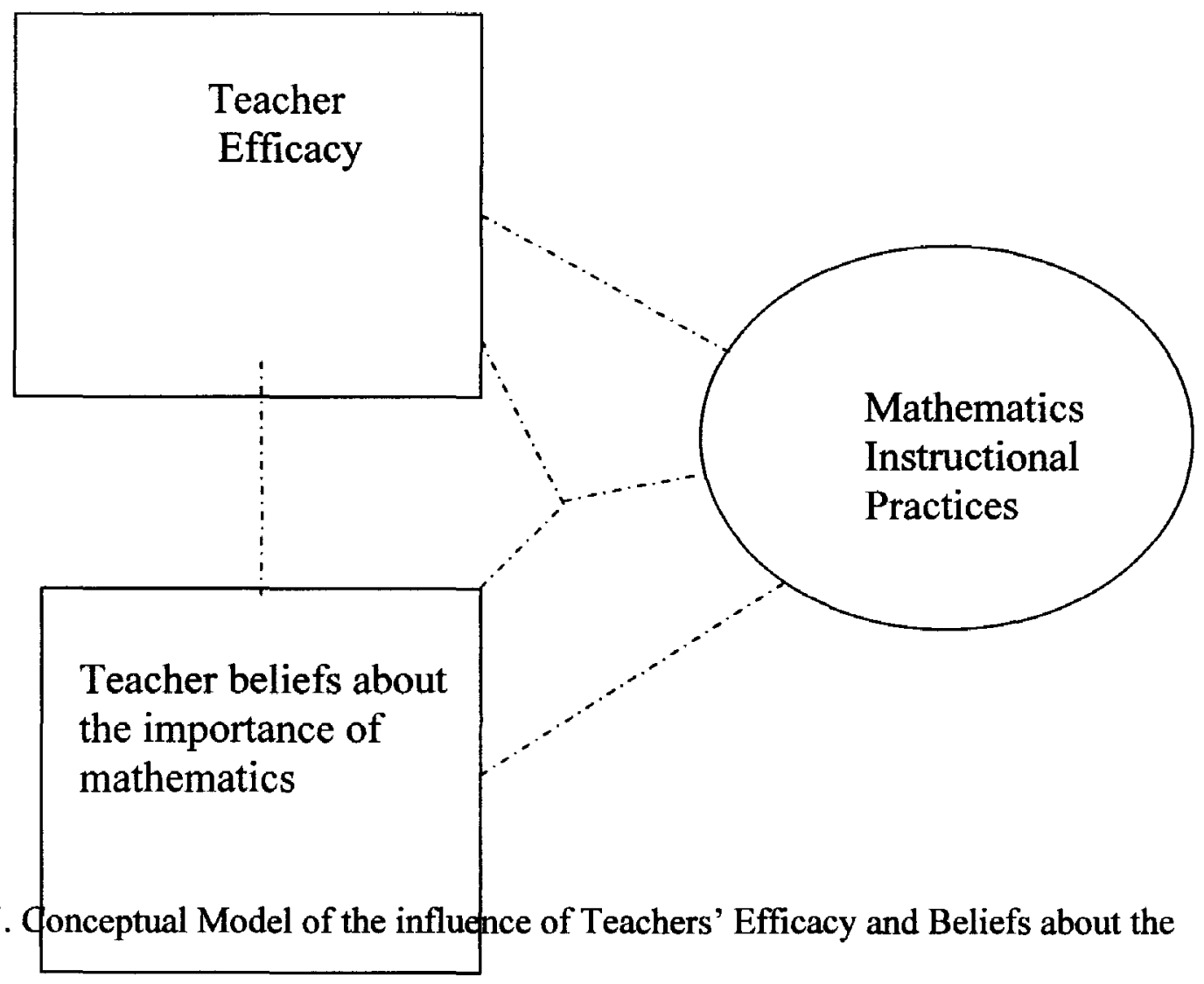

importance of mathematics has on the Mathematics Instructional Practices in the Early Childhood Classroom 


\section{Summary}

The research in the area of teacher efficacy has been on-going for three decades. The theoretical work of Rotter (1966) and Bandura (1977) provided a foundation for the research to measure efficacy. Efficacy measurements have been used to examine a range of teaching actions; reading to minority students (Armor et al., 1976); perception of classroom control (Rose and Medway,1981); relationship between teacher efficacy and classroom behaviors (Gibson and Dembo, 1984) and teacher responsibility for student outcome (Guskey, 1987). More recently Tschannen-Moran and Woolfolk Hoy (2001) designed an instrument to measure factors that facilitate and impeded teaching in a particular context. Selection of instrument and methodology were key findings important to this research study.

The research on teacher beliefs suggests that beliefs are the best indicators of the decisions individuals make (Bandura, 1986). The challenge in researching teacher beliefs is to find empirical work that examines the context-specific effects of beliefs in order to understand the relation and the nature of their effect and connections to teacher practice, teacher knowledge and student outcomes. The research in early childhood teacher beliefs has focused on developmentally appropriate practices (Charlesworth et al., 1993; Smith, 1997); teacher and principal beliefs regarding curriculum, and teaching strategies (Spidell-Rusher et al., 1992) and to explore relations among pre-k, kindergarten and primary teacher beliefs about school entry, testing and retention. One key finding for the current research was the limited number of empirical studies that examined the contextspecific beliefs of pre-k teachers about early mathematics. 
Few research studies have examined the various factors that influence and shape the development of mathematical understanding before formal schooling. In addition the research about the issue of whether organized mathematics should be a part of the early childhood curriculum is incomplete. The past research on early mathematical development and early childhood teachers' content beliefs about mathematics can provide a starting point for examining how early childhood teachers' beliefs and conceptions of teaching and learning mathematics are related or not related to their instructional practices. 


\section{CHAPTER III}

\section{METHODS AND PROCEDURES}

All young Americans must learn to think mathematically, and they must think mathematically to learn. National Research Council $(2001$, p. 1)

This chapter explains the general research context for the study and the sampling technique. It also includes a description of the methods and instruments used in data collection and analysis to answer these questions:

What is the relation between measures of teacher efficacy, and measures of teacher beliefs about the importance of mathematics?

What is the degree of relation among the measures of teacher efficacy, teacher beliefs about the importance of mathematics and observations of the mathematical instructional practices of teachers?

\section{The General Perspective}

America's programs for pre-kindergarteners vary greatly in quality and content. The growing consensus from empirical research is that early childhood environments must support the development of a full range of capacities to best serve as a solid foundation for school learning. Research from a variety of theoretical perspectives suggests that a defining feature of a supportive environment is the teacher (National Center for Family Literacy, 2003; No Child Left Behind, 2002). How a teacher creates the learning experiences that will extend and challenge the child are key to cognitive development (Bowman et al., 2001). This study examined the responsiveness of early childhood 
teachers to the developmental level of children in the mathematics domain. The joint position statement from the National Association of Education of Young Children (NAEYC) and the National Council of Teachers of Mathematics (NCTM) confirms..." a high-quality, challenging and accessible mathematics education for 3-to 6- year old children is a vital foundation for future mathematics learning" (2002, p. 24). Researchers who examined the professional standards thought that the foundation for mathematics learning include knowledge of number and operations, geometry, and measurement. In addition, a positive attitude toward mathematics and a strong foundation in mathematics should be established in the earliest years (PSSM, 2000). Each year more evidence reveals that a high-quality early education promotes later achievement. The effort to improve early childhood mathematics must be embraced by educators, administrators and policy makers as they have done with reading readiness programs.

One of the biggest challenges in implementing mathematical learning goals for very young children is the range of qualifications of the adults who teach them (Clements, 2000). Today, low standards and low rewards are the norm for early childhood teachers (Edwards, 1999). Many states do not require teacher certification in early childhood education. Many state funded pre-kindergarten programs, including Head Start, require a minimum Child Development Associate credential. Some states mandate inservice training for pre-kindergarten but requirements vary significantly (Carnegie Corporation Initiative, 2002). Turnover in the early childhood staff created by low incentives both economic and professional impedes the maintenance of quality staff over time. Qualified teachers, who are more likely to stay in programs, base their mathematics teaching largely on strong personal beliefs about how and what children should learn 
(Battista, 1994; Cohen, McLaughlin and Talbert, 1993). Teachers' beliefs about instructional practices are filtered through their beliefs and knowledge about key domains of early functioning: social emotional skills, literacy, and early mathematics learning.

Teachers seem inclined to base their beliefs upon their own experiences, rather than the results of research because of mistrust of the validity of the research (Richardson, 1996). Teachers' beliefs in their efficacy affects how they think, feel, behave and motivate themselves (Bandura, 1986). Bandura (1978) reported that efficacy beliefs, along with outcome expectations, influence behavior. Therefore, environmental effects created by teachers' actions often alter their expectations.

\section{Purpose}

The purpose of this study was to examine if a relation among early childhood teachers' sense of self efficacy, beliefs about early childhood mathematics and their mathematics instructional practices exist. It documented teaching efficacy and beliefs about the importance of mathematics and mathematics instructional practices of early childhood teachers in large metropolitan Midwestern school district. It also examined the effect of teacher efficacy and beliefs on mathematics with two self-report surveys and observations of a sample of teachers' mathematics instruction.

\section{The Research Context}

Examining teachers' efficacy and beliefs can inform educational practice in early childhood programs. Kagan (1992) reported that preexisting beliefs held by teachers appear to play important and pervasive roles in the nature of classroom instruction and reflect their fundamental thinking about teaching. This personal knowledge lies at the heart of teaching (Clandinin and Connelly, 1995). Eliciting teacher beliefs has been done 
through a variety of means: questionnaires with Likert type scales; teacher think-aloud procedures as they view videotapes of their instructional practices and semi-structured interviews. The methodologies have been both quantitative and qualitative in nature.

The design for this study was correlational. Goodwin and Goodwin (1996) noted that in correlational research one can examine "nature" as it is and address topics that may not be practical or possible to explore using experimental methods. In this study a number of constructs were examined at one time: teacher efficacy, teacher mathematics beliefs; and mathematics instructional practices. Teacher efficacy and beliefs were revealed using self-report surveys and mathematics instructional practices were described using an observational instrument. All instruments used have established reliability and validity support (Kowalski, Pretti-Frontczak and Johnson, 2001; Stonewater, 1996; Tschannen-Moran, Woolfolk Hoy 2001).

The Research Participants

Site and Sample

The study was conducted in a large Midwestern metropolitan school district that serves approximately 90,000 students. Currently, the district provides parents of early childhood children with a number of options. The Early Jump Start program is a collection of the metropolitan school district's early childhood programs serving fouryear-olds and younger. The options include Head Start/Early Head Start, prekindergarten, the 3-year-old Program, tuition-based pre-kindergarten and 4-year-old child care programs, and tuition-based classrooms for early childhood students. The programs differ in class schedules and funding; however but all share district-wide common 
curriculum and goals. The teachers and classrooms in this study are on staff in these early childhood district programs.

\section{Entrance}

A meeting was conducted in late February, 2003 with the district Assistant Superintendent of Research and Deputy Superintendent to propose the project. The researcher provided an overview of the proposed study and the estimated time and expectations regarding the obligations for the participating teachers and students. Preceding the meeting, a research application was submitted to the Deputy Superintendent and the researcher was given authorization to conduct the study on the condition that teachers knew that their participation was voluntary. Human Studies Committee of the University of Louisville approved the study following the meeting with district personnel.

\section{Instruments}

The research design of this study is correlational to determine if a relation among teacher efficacy, teacher beliefs about early mathematics and mathematics instructional practices exist. The investigation includes two questionnaires and an observational record of the teachers' mathematics instructional practices collected from two visits. Part one of the study is a quantitative data collection with the use of self-report questionnaires of teacher efficacy and teacher beliefs. The efficacy questionnaire gives a more comprehensive idea of the teacher's thinking about his/her ability to influence student engagement, instructional practices and classroom management. The belief questionnaire identifies the teachers' beliefs about the importance of social-emotional skills, language 
and literacy and early mathematical activities in the early childhood classroom. Only the mathematical beliefs subscale is used in the correlation analysis.

The instrument used to measure teacher efficacy was a self-report questionnaire designed to describe pre-kindergarten teachers' assessments of their beliefs about their own ability to execute specific teaching actions. The Teachers' Sense of Efficacy Scale, TSES (Tschannen-Moran and Woolfolk Hoy, 2001) was developed at Ohio State University and is sometimes referred to as the Ohio State Teacher Efficacy Scale (OSTES). The TSES measure was designed to assess competence across the wide range of activities and tasks teachers are asked to perform in terms of the resources and constraints in their particular teaching contexts (Appendix A). The instrument consists of 24 items assessed along a 9-point continuum with anchors from 1-nothing, 3-very little, 5-some influence, 7-quite a bit, to 9-a great deal. Factor analysis identified three 8-item subscales entitled efficacy for instructional strategies, efficacy for classroom management, and efficacy for student engagement. In previous research the TSES correlated positively with existing measures of teacher efficacy thus providing construct validity. The strongest correlation was between the TSES and the other measurement scales in assessing Personal Teaching Efficacy (PTE). A lower correlation was evident in capturing General Teaching Efficacy (GTE). Principal axis factoring with Varimax rotation yielded factor loadings ranging from 0.50 to 0.78 . The reliabilities for the efficacy subscales computed for each factor were 0.91 for instruction, 0.90 for management and 0.87 for engagement. Intercorrelation between the subscales on instruction, management and engagement were $0.60,0.70$, and 0.58 respectively. The 
TSES moves beyond previous measures of efficacy by capturing a wider range of teaching tasks.

The instrument used to measure teacher beliefs was a self-report questionnaire developed by Kowalski, Pretti-Frontczak and Johnson (2001) that investigated the prekindergarten teacher's beliefs about the importance of key domains in the prekindergarten environment. The 54 items were written to represent the three domains of early functioning: social-emotional skills, literacy, and mathematics. The three scales each contained 18 items, 5 distracters and 13 assessment items. Teachers used a 5-point Likert scale (1-not at all important, 2-somewhat important, 3-important, 4-very important and 5-critically important) to rate the importance of the skills and abilities early childhood children should learn (see Appendix B). Factor analysis supported the three domains. Scale reliability was reasonably high as demonstrated by the calculation of Cronbach's alpha. The coefficients were $0.81,0.85$, and 0.88 respectively for socialemotional, literacy and early mathematics scales. The Post Hoc comparisons of the Kowalski et al., (2001) revealed that teachers rated the social-emotional items $(M=3.8)$ significantly higher than language and literacy $(M=2.9)$ and early mathematics items $(M=2.9)$. Correlational analysis revealed a low, but positive correlation between level of teacher education and mean score on the social-emotional scale.

\section{Sample}

The sample for this study represents early childhood teachers responsible for making the selections and decisions regarding the daily curriculum plan and assessing and reporting progress to parents. The sample was a population of pre-k educators who work with the Jump Start and pre-k programs in the Midwestern metropolitan school 
district. The observations were conducted with pre-kindergarten educators who were a subset of the Jump Start/Pre-K teachers from the district pre-school lead teachers who completed the teacher efficacy and teacher belief questionnaires for the researcher. The researcher coded the self-report questionnaires so participating teachers' names were not on the questionnaires.

The teacher efficacy and teacher beliefs in mathematics scales were scored by the researcher. The composite scale scores for teacher efficacy and teacher beliefs in mathematics were displayed on a scatterplot. The scatterplot was further divided into four quadrants using the median scores for teacher efficacy and teacher mathematics beliefs. Individual scale scores and scatterplot of composite scores were given to an independent referee to identify twenty teachers to be observed. The referee selected a purposeful sample of teachers from four quadrants delineated as high efficacy/high beliefs, high efficacy/low beliefs, low efficacy/high beliefs, low efficacy/low beliefs based on teachers' individual efficacy and belief mean scores. The points on the scatterplot were matched with the participants' scale scores from the Teacher Efficacy and Teacher Beliefs in mathematics, and subsequently five early childhood teachers in each of the four categories were identified to be observed. Therefore, the researcher was not to be involved in sample selection and had no knowledge of the teachers' level of efficacy or beliefs. This sampling design was used to reduce bias and pre-conceived expectations that the researcher might have had prior to observing the teachers' mathematical instructional practices.

Teacher identified by the independent referee were contacted by phone to solicit their cooperation in two observation sessions. Teachers were informed that the researcher 
wanted to observe during mathematics instruction. The teacher identified the times that would be appropriate for the researcher to observe in the classroom.

\section{Data collection}

The administration of the two questionnaires containing took place during a late January mandatory district professional development meeting for early childhood teachers. The study was described and the researcher reviewed the purpose and gave an overview of the scales for the belief and efficacy questionnaires. Participants were told that the purpose of the questionnaires was to investigate teacher beliefs about teaching and learning in the early childhood environment. They were assured of anonymity and confidentiality and that information would not be reported about any identified individual. The information would be compiled and shared with the district and the schools as well as with others who are interested. The teachers were asked to answer each question and to rate their beliefs on each item to the best of their ability, even if they did not hold beliefs in every situation. The importance of ensuring the independence of the participants' responses was stressed.

The procedures for data collection are displayed in the tables following this chapter. Table 1 represents the data collection procedures including information sought, how it was collected and sources of the data. Table 2 represents the time schedule of the collection, analysis and reporting.

The second component of the study was an observation protocol of teacher mathematics instructional practices. A review of research revealed few instruments for observing mathematics in the pre-kindergarten setting. For the instruments that exist established reliability and validity was limited. Therefore the Standards Observation 
Form (Stonewater, 1993) was chosen as the measure of teacher mathematics instructional practices. The instrument was developed based on the NCTM's Professional Standards for Teaching Mathematics (1991) and the criteria are consistent with the Principles and Standards for School Mathematics (2000) and the NCTM and NAEYC joint position statement on mathematics in the early childhood environment (2002). The data collection instrument was designed to be used in projects where specific examples about classroom teaching were needed. This instrument was not designed is not to evaluate teachers, but to document the extent to which teaching meets the criteria of the standards. The items in the observation address six professional teaching standards. Worthwhile mathematical tasks require the teacher to pose tasks that are based on sound and significant mathematics that address the knowledge of the students' understandings in a range of ways so that diverse groups of students learn mathematics. Teacher's role in discourse means that the teacher poses questions to elicit and challenge students' thinking along with listening and deciding when to provide information, what to pursue in depth and when to let students struggle. Student's role in discourse means that the teacher encourages students to listen and learn mathematics from each other and initiate questions, make conjectures and communicate their solutions to make connections. How the teacher enhances the discourse with tools means the teacher encourages students to use calculators, computers, concrete materials such as cubes, counters, and tangrams along with oral or written presentations to learn mathematical content. The learning environment is a mathematics classroom where the development of students' mathematical power is fostered through the use of physical space and materials. The teacher demonstrates respect and values the students' thinking. The teacher promotes 
independent and collaborative tasks. Mathematics teacher's analysis of the teaching and learning means the teacher assesses to ensure that students are learning sound and significant mathematics (NCTM, 1991). The psychometric properties of the Standards Observation Form are not published, but the instrument was used in two projects (Johnson, 1992; Walters, 1991). The development of the instrument inter-rater reliability for previous results came from pairs of expert observers rating eight teachers on each of the six standards. The 48 pairings were identical on 0.50 of the items and the remaining 39.6 had a difference of one unit. The overall average difference between ratings was 0.625 units. This instrument would require inter-observer training for reliable use of this scale.

The Standards Observation Instrument was designed (Stonewater, 1993) with three forms to provide for collection of quantitative or qualitative data. The form adopted for this study identified the evidence for each criterion with a check or a blank if no evidence of the criterion was observed. The researcher modified the recording by using a one if the criterion was exhibited during the observation and a zero if not exhibited during the time of the visit. Interrater reliability for the instrument was established prior to beginning the teacher observations. The researcher and a mathematics teacher educator observed two early childhood classrooms during a time when children were engaged in mathematics with the teacher. The purpose of the two observations was to analyze the effectiveness of the instrument to capture mathematics instructional practices in the early childhood classroom and to establish inter-rater reliability. The observers were in agreement on the criteria for the six standards $93 \%$ and $90 \%$ of the time. The differences in the two observers' ratings were in regards to the teacher's role in discourse. The items 
that were dissimilar were whether the teacher had created an environment in which mathematical thinking and reasoning were the norm and whether the teacher sorted ideas out in the open in order to decide what to pursue. The researcher and mathematics educator discussed the items and clarified the criterion that would be used in future observations. The researcher and mathematics educators adapted the wording from the Stonewater form on items 1.2, 2.3, 2.6, and 4.6 (Appendix C). The modifications considered the skills and knowledge that would be more representative of the early childhood classroom. It was also agreed that item 6.5 related to teacher describing and commenting on student learning to students and parents would rarely be observed.

\section{Observation}

Research on teacher beliefs and efficacy indicates that it is important to observe teachers in their classrooms to note how reported beliefs relate to actual teaching behaviors and practices (Pajares, 1992). The classroom observation measure can be an instrument in assessing the validity of the perceived efficacy and beliefs in practices obtained from the self-report questionnaires. It is important to identify factors that affect practices that can be explained by a set of predictor variables (Maxwell, McWilliam, Hemmeter, Jones Ault and Schuster, 2001). Observations were scheduled and dictated by teachers' daily plans for a time period when children were actively engaged in large or small group mathematical activities with the teacher. The researcher used a modification of the Standard Observation Form (Stonewater, 1993) to document classroom instruction in mathematics content.

By selecting the sample from a single school district the respondents may not reflect the larger population of pre-kindergarten educators. The distribution sampled the 
teachers who attended the professional development session when the self-report questionnaires were distributed. The questionnaires were designed for early childhood lead teachers. Other personnel (e.g., teaching assistants, resource teachers and district administrators) who completed the questionnaires were excluded from the sample. Including personnel other than teachers could impact the correlational design. A correlational study sample requires a minimum number of cases. The rule of thumb used for this study to determine sample size that could detect a difference at $p<.05$ (one tail) was under thirty subjects (Shavelson, 1996). This represented six times as many cases as independent variables (Stevens, 2002). A demographic section in the questionnaire was used to examine characteristics and qualifications of the participants included in the sample. See results in Table 3.

\section{Table 3}

Characteristics of Sample Population Full Data Set and Sub Group Observation Sample

Characteristics

Large data set

$(N=94)$
Observation sample

$$
(n=20)
$$

Years teaching

Four or fewer

40

6

Five to ten

26

7

Eleven or more

28

7

Student population

Urban

Rural

Suburban 
Table 3 (continued)

Characteristics

Large data set

$(N=94)$
Observed sample

$(n=20)$

Highest level of education

GED

6

1

High school diploma

13

2

One year of college

17

5

Two years of college

19

5

Three years of college

17

0

Bachelors' degree

10

4

Highest accreditation

CDA

56

12

$\mathrm{AS}$ in ECE

5

2

AAS in ECE

17

1

Bachelors in ECE

7

1

Certificate in IECE

4

2

No response

5

2

The use of triangulation (Merriam, 1998) and multiple sources of data strengthened the documentation of the early childhood teachers' efficacy and beliefs about the importance of mathematics. The data from three measurements helped to examine if what teachers reported was evident in their classroom mathematics 
instructional practices. The relation of efficacy and beliefs to teachers' mathematics instructional practices were not documented, perhaps a result of sample selection or instrument sensitivity. The use of quantitative measures underscored the teachers' efficacy about student engagement, instructional practices, classroom management and the level of importance teachers placed on early mathematics. The observation measurement provided evidence of teachers' mathematics instructional practices.

\section{Data Analysis}

The three-instrument model of this design required multiple methods of analysis. The first step in analyzing the questionnaires and observation responses was to examine the descriptive data (e.g., frequencies, means, standard deviations) from the three scales for patterns or trends. The descriptive data provided a way of organizing and depicting and describing the initial information (Shavelson, 1996).

A reliability analysis was conducted to determine internal consistency reliability coefficients. The goal was to obtain Cronbach's alpha coefficients of 0.70 or higher. The twenty-four item teacher efficacy scale (subscales; efficacy in student engagement, instructional strategies and classroom management) had a reliability coefficient of Alpha $=0.83$ for $n=94$. The reliability coefficient for the fifty-four item teacher belief scale (subscales; social emotional skills, language and literacy and early mathematics) was Alpha $=0.91$ for $n=94$. The observational instrument had a reliability coefficient of Alpha $=0.85$ for $n=20$. The reliability coefficients were all higher than 0.70 . The composite scores for Teacher Efficacy and Mathematics Instructional Practices and the subscale score for Teacher Beliefs in mathematics were used in subsequent analysis. The scores were used to calculate correlational coefficients. Scatterplots were then used to 
inspect for the assumptions of normality, linearity and homoscedasticity of the correlation. The conceptual goal of the analyses was to determine if teacher efficacy and teacher beliefs in the importance of mathematics were significantly related to the mathematics instructional practices of early childhood teachers.

The scale scores for teacher efficacy and beliefs in mathematics were used by an independent referee to identify a sample of teachers for the observational phase of the study. The observations in strategically selected classrooms with high and low ratings on the teacher efficacy and teacher beliefs scale were used to confirm if the composite scores on the efficacy and belief factors could be used to identify teachers who believe and demonstrate standards-based early mathematics teacher instructional practices based on the recommendations of a high-quality mathematics education for 3-to 6-year olds (NAEYC, NCTM, 2002; NCTM, 2000).

A series of correlations were computed to examine the hypothesis that early childhood teachers' efficacy and beliefs about the importance of mathematics were related to the mathematics instructional practices. The results of computed correlation coefficients were also used to analyze for a relation between teacher efficacy and teacher beliefs about mathematics. The correlation coefficients between teacher efficacy, and teacher beliefs were statistically significant but not related to mathematics instructional practices. Tests of statistical significance were calculated to address whether the portion of variance in $r$ emerged by chance when its true value in the population is zero, or whether it represented a systematic relation among teacher efficacy, teacher beliefs and mathematics instructional practices. The lack of significance and small sample size eliminated the need for further regression analysis. The conceptual goal was to determine 
if teacher efficacy and teacher beliefs in the importance of early mathematics are indicators of teacher mathematics instructional practices. The variables used in the analysis are shown in Table 4.

\section{Table 4}

Variables used in Correlational Analysis

Predictor:

Variable

Teacher efficacy

Teacher beliefs
Criterion:

$$
\text { Variable }
$$

Teacher mathematics instructional practices

Teacher mathematics instructional practices

\section{Summary of the Methodology}

The purpose of this study was to investigate whether teachers' efficacy and beliefs about mathematics education for early childhood students were related to their teacher mathematics instructional practices. The correlational design incorporated data from a teacher efficacy self report survey TSES (Tschannen-Moran and Woolfolk Hoy, 2001) with and a self report questionnaire (Kowalski, Pretti-Frontczak and Johnson, 2001) that rates teacher beliefs about the importance of various development skills and abilities. The self-report instruments were administered to early childhood lead teachers while attending a district-wide professional development sessions. The results of the teacher efficacy and teacher beliefs about mathematics scores were placed on a scatterplot used by an independent referee to select a sample of teachers who were solicited to participate 
in the observational phase of the study. The observations were conducted with the Standards Observation Form protocol (Stonewater, 1993). The results presented in Chapter IV strengthen the documentation of whether teacher efficacy or teacher mathematics beliefs relate to teacher mathematics instructional practices in the early childhood environment. In addition the observational data on mathematics instructional practices will inform the direction change strategies should address. 


\section{CHAPTER IV}

\section{RESULTS}

"Not a single teacher was observed who would promote learning beyond his or her own mathematical knowledge". Liping Ma (1999, p. 54)

The answers to the two research questions of this dissertation are addressed in this chapter. The results of the statistical analysis are reported as are the following analyses. The data used in analysis are: overall score for Teacher Efficacy (Tschannen-Moran and Woolfolk Hoy, 2001); the overall score on Teachers' Beliefs about the importance of mathematics in the early childhood classroom (Kowalski et al., 2001); observation scores on of teachers' Mathematics Instructional Practices (Stonewater, 1993) along with field notes from the observations of the selected sample of the full data set.

\section{Research Question 1}

The first research question asked: What is the relation between measures of teacher efficacy, and measures of teacher mathematics beliefs? It was hypothesized that teachers higher in efficacy will rate the importance of mathematics higher on the Teacher Belief Scale than the teachers with lower efficacy.

The instrument used to measure teacher efficacy was a survey (TSES, 2001), designed to describe pre-kindergarten teachers' assessments of their beliefs about their own ability to execute specific teaching actions. The instrument consists of 24 items assessed along a 9 point continuum with anchors from 1-nothing, 3-very little, 5-some influence, 7-quite a 
bit, to 9-a great deal. The instrument used to measure Teacher Beliefs about the importance of Mathematics, The Child Development Project -Early Childhood Research Consortium, (Kowalski, Pretti-Frontczak and Johnson 2001) was a self-report survey that describes the pre-kindergarten teacher's beliefs about the importance of key domains in the pre-kindergarten environment. Ninety-four questionnaires were distributed and 94 completed questionnaires were returned resulting in a (100\%) return rate. The descriptive data from the Teacher Efficacy and Teacher Mathematics Beliefs about mathematics questionnaires are presented in Table 5.

Descriptive Statistics

\section{Table 5}

Means, Standard Deviations, and Ranges for Teacher Efficacy and Beliefs about Mathematics

\begin{tabular}{lcccc} 
Variable & Mean & Standard deviation & Possible Range Actual Range \\
\hline Teacher Efficacy & & & & \\
\hline Student engagement & 7.78 & 0.93 & $1.00-9.00$ & $4.38-9.00$ \\
Instructional strategies & 7.87 & 0.93 & $1.00-9.00$ & $5.50-9.00$ \\
Classroom management & 7.96 & 0.91 & $1.00-9.00$ & $4.88-9.00$ \\
Total score & 7.87 & 0.86 & $1.00-9.00$ & $5.13-9.00$ \\
\hline
\end{tabular}


Table 5 (continued)

Means, Standard Deviations, and Ranges for Teacher Efficacy and Beliefs about Mathematics

Variable Mean Standard deviation Possible Range Actual Range

Teacher Beliefs

$\begin{array}{lcccc}\begin{array}{l}\text { Social emotional } \\ \text { skills }\end{array} & 3.53 & 0.81 & 1.00-5.00 & 1.00-4.83 \\ \begin{array}{l}\text { Literacy and } \\ \text { language }\end{array} & 2.55 & 0.88 & 1.00-5.00 & 1.00-3.94 \\ & & & & \\ \text { Early mathematics } & 3.05 & 0.65 & 1.00-5.00 & 1.78-5.00 \\ & 3.04 & 0.58 & 1.00-5.00 & 1.24-4.43\end{array}$

A Vacha-Hasse meta-analysis (1998) pointed out that considerable variability was observed in instruments measuring efficacy. In an effort to see if the early childhood sample of this study was comparable to earlier research a $t$ test was conducted with the teacher efficacy means for both studies. The Teacher Efficacy scale means are significantly different from the means reported by Tschannen-Moran and Woolfolk Hoy (2001). The overall Teacher Efficacy mean was 7.87 for this study was compared to a mean of 7.10 from the previous research (Tschannen-Moran and Woolfolk Hoy, 2001). The level of significance was set at $p<.05$. There is a significant difference between the two groups of Teacher Efficacy means, with the mean of the current study, higher than the previously reported Tschannen-Moran and Woolfolk Hoy mean, $t(2,106)=2.98, p<$ .05. The efficacy subscale for Student Engagement included items on how much a teacher felt capable of motivating students who show low interest in schoolwork. On a 9- 
point scale the mean 7.78 score for this study was compared to the mean 7.11 reported for preschool teachers in the earlier study. Again, a significant difference was found between the two groups with the mean, $t(2,106)=2.6, p<.05$ for this study higher than the Tschannen-Moran and Woolfolk Hoy (2001) study. The efficacy subscale for Instructional Strategies explored the extent the teacher can provide alternative explanations or examples when students are confused. The mean 7.87 for this sample was compared to a mean of 7.10 reported in the earlier study. The $t(2,106)=3.0, p<.05$. Indicating a significant difference with the mean for the present study higher than the mean reported in the earlier study. The third efficacy subscale, Classroom Management, indicated how much a teacher felt her/she could control disruptive behavior in the classroom. The 7.96 mean was compared to the 7.11 mean of the earlier study. The $t(2$, $106)=3.2, p<.05$ indicating a significant difference with the mean for the present study higher than the reported Tschannen-Moran and Woolfolk Hoy (2001) study. The early childhood teachers participating in the present study were positive about their efficacy in activities in a teacher's work life. In terms of the rating scale anchors, their efficacy ranged from quite a bit to a great deal.

In an effort to see if the early childhood sample of this study was comparable to earlier research a $t$ test was conducted with the teacher belief means for both studies. The items on the teacher beliefs instrument (Kowalski et al., 2001) represent three domains of early functioning: social emotional skills, literacy and language and early mathematics. The instrument consists of 54 items assessed along a 5-point continuum with anchors from 1-not at all important, 2-somewhat important, 3-important, 4- very important to 5critically important. A $t$ test for significance of means between the results of this study 
and prior research were calculated to determine whether the two studies resulted in comparable findings. The level of significance was set at $p<.05$. The 3.52 mean for Social Emotional Skills in this study compared to the 3.86 mean previously reported by Kowalski, Pretti-Frontczak and Johnson (2001) were significantly different with the mean, $t(2,150)=3.2, p<.05$. in the present study higher. The 2.55 mean for Literacy and Language compared to the 2.97 mean reported in the previous study was significantly different with the mean of the present study higher $t(2,150)=4.0, p<.05$. The Early Mathematics mean for 3.05 for this study compared to a 2.92 mean reported in earlier research, $t(2,150)=0.13, p<.05$ was not significantly different. There is a similarity between means for the two groups in Early Mathematics. Early childhood teachers in this sample viewed social emotional skills as important to very important, language and literacy skills as somewhat important to important and mathematics behaviors and skills as important to very important. The purpose of this dissertation was to study mathematics behaviors. Therefore, in further analyses reported below only the early mathematics subscale was used.

\section{Correlations}

Pearson correlation coefficients were calculated to explore the relation among the subscales on the Teacher Efficacy scale and Teacher Mathematics Beliefs. An alpha level $\mathrm{p}<.05$ was set as the significance value for statistical tests. The correlations are displayed in Table 6. 


\section{Table 6}

Correlations Among Subscales for Teacher Efficacy and Beliefs about Mathematics

\begin{tabular}{lcc} 
Subscale & 1 & 2 \\
\hline & Teachers $(N=94)$
\end{tabular}

$\begin{array}{lllll}\text { 1. Beliefs in mathematics } & .247^{*} & .269^{*} & .226^{*} & .198^{*} \\ \begin{array}{l}\text { 2. Teacher efficacy (overall) } \\ \text { 3. Efficacy in student engagement }\end{array} & .949^{*} & .934^{*} & .915^{*} \\ \text { 4. Efficacy in instructional strategies } & - & .851^{*} & .803^{*} \\ \text { 5. Efficacy in classroom management } & - & - & .762^{*} \\ \text { * Correlation is significant at the } p<.05 \text { level (1-tailed) } & & - & -\end{array}$

Teacher Mathematics Beliefs are correlated with overall Teacher Efficacy and with the efficacy subscales of student engagement, instructional strategies and classroom management. The Teacher Efficacy subscales are strongly intercorrelated: $0.85,0.80$, and 0.76. This warrants the use of the overall Teacher Efficacy scores rather than individual subscale scores because the scales are related within the questionnaire. The scatterplot below (Figure 2) illustrates the relation between overall Teacher Efficacy scores and Teacher Mathematics Beliefs scores. The relation is positive but the dispersion of the points reflects the weak correlation $r=.247$. Further the $r^{2}=.0611$ indicates that $6 \%$ of the total variance can be accounted for by knowing the scores on teacher efficacy and teacher mathematics beliefs. 


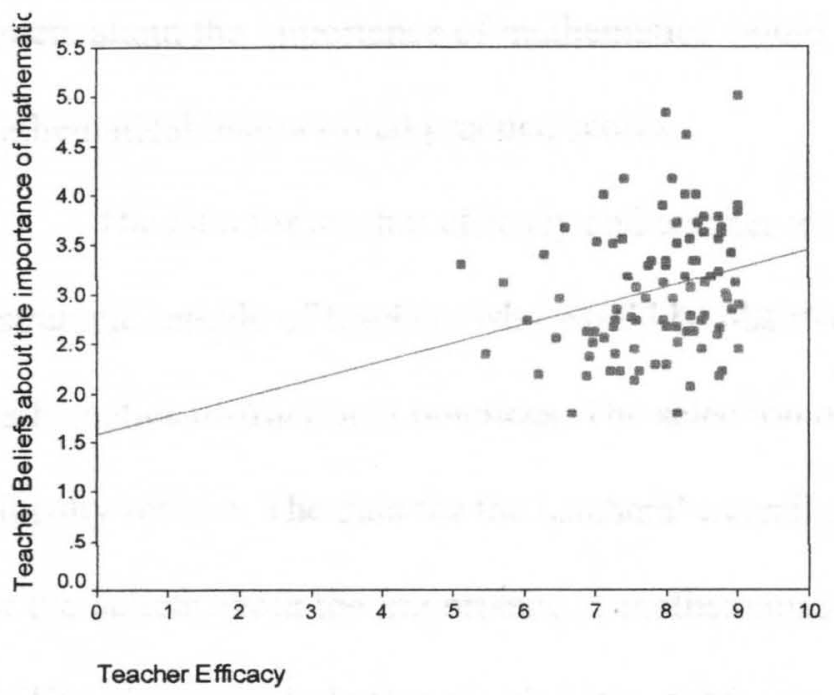

Figure 2. Scatterplot of Overall Teacher Efficacy Scores and Teacher Mathematics Beliefs Scores

Summary research question 1

The hypothesis was based on Bandura's Social Cognitive theory $(1986,1997)$ that individuals construct personal standards and these standards guide, motivate and regulate the person's behavior. The hypothesis that the teachers higher in efficacy will consider the importance of mathematics higher on the Teacher Belief Scale than the teachers with lower efficacy was found to be true with this sample, but the correlation is weak. The Pearson correlation coefficients confirm that teacher efficacy is related to teacher mathematics beliefs.

\section{Research Question 2}

The second research question addressed the relation among the measures of teacher efficacy and teacher beliefs about the importance of mathematics and observations of the mathematics instructional practices of teachers. It is hypothesized that teacher efficacy and teacher mathematics beliefs relate to mathematics instructional practices. Specifically, it was hypothesized that scores on teacher efficacy and teacher 
beliefs about the importance of mathematics would be significant predictors of mathematical instructional practice scores.

The data for teacher efficacy and teacher mathematics beliefs were used to select a strategic sample of teachers who would be observed to obtain information about their mathematics instructional practices. The selection of the observation sample was done by a faculty referee. The data for the teachers' overall score on teacher efficacy and the score for the beliefs about the importance of mathematics are displayed in a scatterplot (Figure 3). The scatterplot is further divided into quadrants using the median scores for teacher efficacy and teacher mathematics beliefs. The four quadrants delineated high efficacy/high beliefs, high efficacy/low beliefs, low efficacy/high beliefs, low efficacy/low beliefs. The points on the scatterplot are matched with the participants' scores from the teacher efficacy and teacher mathematics beliefs. Five early childhood teachers were identified in each quadrant to be observed. These twenty teachers were contacted by the researcher to solicit their cooperation in two observation sessions of their mathematics instructional practices and all agreed to participate. The descriptive statistics for the 20 identified teachers are in Table 7. 


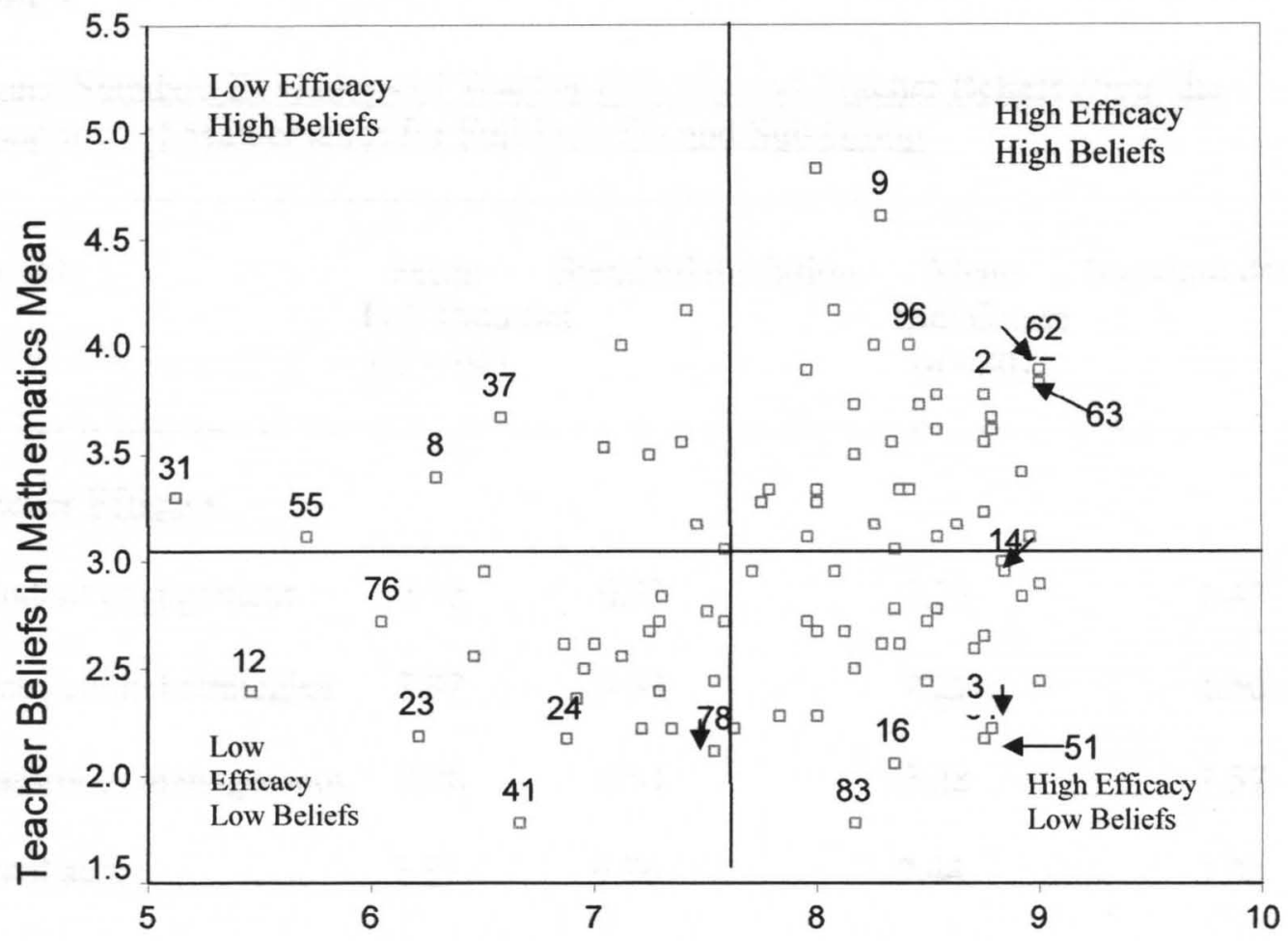

Teacher Overall Efficacy Mean

Figure 3. Scatterplot of Quadrants of High and Low Teacher Efficacy and Teacher Belief Scores of Individual Teachers; Numbers Identify Sub Group of Teachers Observed. 
Table 7

Means, Standard Deviations of Teacher Efficacy and Teacher Beliefs about the importance of Mathematics for Full Data Set and Sub Group

Variable

Mean Standard deviation Mean Standard deviation Full Data Set

$$
(N=94)
$$
Sub Group

$(n=20)$

Teacher Efficacy

$\begin{array}{lcccc}\text { Student engagement } & 7.78 & 0.93 & 7.25 & 1.43 \\ \text { Instructional strategies } & 7.87 & 0.93 & 7.25 & 1.60 \\ \text { Classroom management } & 7.96 & 0.91 & 7.28 & 1.57 \\ \text { Total score } & 7.87 & 0.86 & 7.44 & 1.33\end{array}$

Teacher Beliefs

$\begin{array}{lcccc}\begin{array}{l}\text { Social emotional } \\ \text { skills }\end{array} & 3.53 & 0.81 & 3.26 & 0.96 \\ \begin{array}{l}\text { Literacy and } \\ \text { language }\end{array} & 2.55 & 0.88 & 2.33 & 0.96 \\ \begin{array}{l}\text { Early mathematics } \\ \text { Total score }\end{array} & 3.05 & 0.65 & 2.91 & 0.86 \\ & 3.04 & 0.58 & 2.83 & 0.70\end{array}$

Descriptive statistics for the 20 teachers on the Standards Observation Form (Stonewater, 1993) are displayed in Table 8. 


\section{Table 8}

Means, Standard Deviations, and Ranges for Standards Observation Form

Variable Mean Standard deviation Possible range Actual range

Standards Observation Form

Categories

\begin{tabular}{|c|c|c|c|c|}
\hline Mathematical tasks & 8.70 & 1.87 & $0.00-12.00$ & $5.00-12.00$ \\
\hline $\begin{array}{l}\text { Teacher's role in } \\
\text { discourse }\end{array}$ & 12.30 & 2.89 & $0.00-20.00$ & $8.00-19.00$ \\
\hline Student discourse & 2.70 & 1.98 & $0.00-10.00$ & $0.00-6.00$ \\
\hline $\begin{array}{l}\text { Tools for } \\
\text { discourse }\end{array}$ & 7.70 & 1.78 & $0.00-14.00$ & $4.00-12.00$ \\
\hline $\begin{array}{l}\text { Learning } \\
\text { environment }\end{array}$ & 5.20 & 1.51 & $0.00-10.00$ & $2.00-8.00$ \\
\hline $\begin{array}{l}\text { Analysis of } \\
\text { teaching and learning }\end{array}$ & 4.85 & 1.98 & $0.00-10.00$ & $0.00-8.00$ \\
\hline Total Score & 39.20 & 8.84 & $0.00-76.00$ & $23.00-56.00$ \\
\hline
\end{tabular}

Out of a possible 76.00 points on the six mathematical standards, teachers in this sample had a mean of 39.20 . Since there was limited reliability data on the Standard Observations Form (Stonewater, 1993) it was important to explore whether the categories in the scale were measuring separate in combined components. Therefore, Pearson correlation coefficients were calculated to measure relation among categories of the Standards Observation Form. Results are displayed in Table 9. 
Table 9

Intercorrelations Among the Standards Observation Form Categories of Teacher Mathematics Instructional Practices

Subscale

1

2

3

4

5

6
1. Mathematics tasks
$\begin{array}{lllll}.721^{*} & .431^{*} & .621^{*} & .752^{*} & .685^{*}\end{array}$
2. Teacher discourse

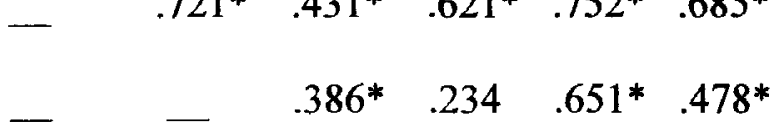
3. Student discourse

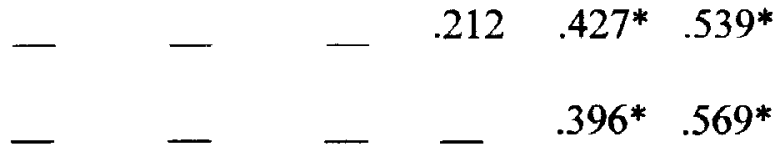
4. Tools
$-$
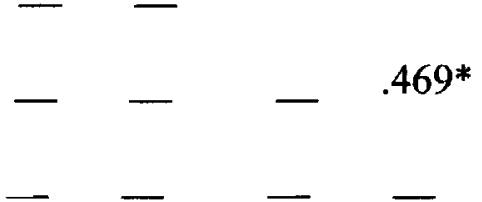
6. Analysis of teaching
* Correlation is significant at $p<.05$ level (1-tailed)

The scores on the Standards Observation Form categories are moderately and significantly intercorrelated with the exception of Teacher discourse and Tools and Student discourse and Tools. The categories are related within the questionnaire and warrant the use of the overall Mathematics Instructional Practices score.

The selection of the sample was strategic in that it captured individuals from the edges of the quadrants (Figure 3). To prove that the selected sample represented the extremes a correlation was calculated. Pearson correlation coefficients among Teacher Overall Efficacy and Teacher Mathematics Beliefs and Mathematics Instructional Practices scores are displayed in Table 10. 


\section{Table 10}

Correlations Among Teacher Beliefs about the importance of Mathematics, Teacher Efficacy and Mathematics Instructional Practices

Subscale

12

3

Teachers $(n=20)$

1. Teacher beliefs

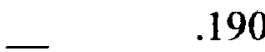

.295

2. Teacher efficacy

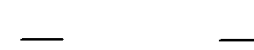

.242

3. Mathematics instructional practices

The selected sample did reflect the extremes of the scatterplot as teachers' efficacy and beliefs about the importance of mathematics are weakly correlated and none is statistically significant at $p<.05$. The hypothesis that beliefs ratings and efficacy ratings would be related was supported for the full sample, but not the selected High/High, High/Low, Low/Low and Low/High subgroups. Another premise of the study was that high or low levels of teacher efficacy and teacher mathematics beliefs are related to teacher Mathematics Instructional Practices. The results of the correlation coefficients show that teacher efficacy and teacher mathematics beliefs are not reliably related to early childhood teachers' mathematics instructional practices as measured by the instruments used in this study.

The correlation between teacher mathematics beliefs and mathematics instructional practices was $r=.295$, low weak positive. A scatterplot of scores on Teacher Beliefs about the importance of mathematics and Mathematics Instructional Practices shows a relatively flat regression line. See Figure 4. 


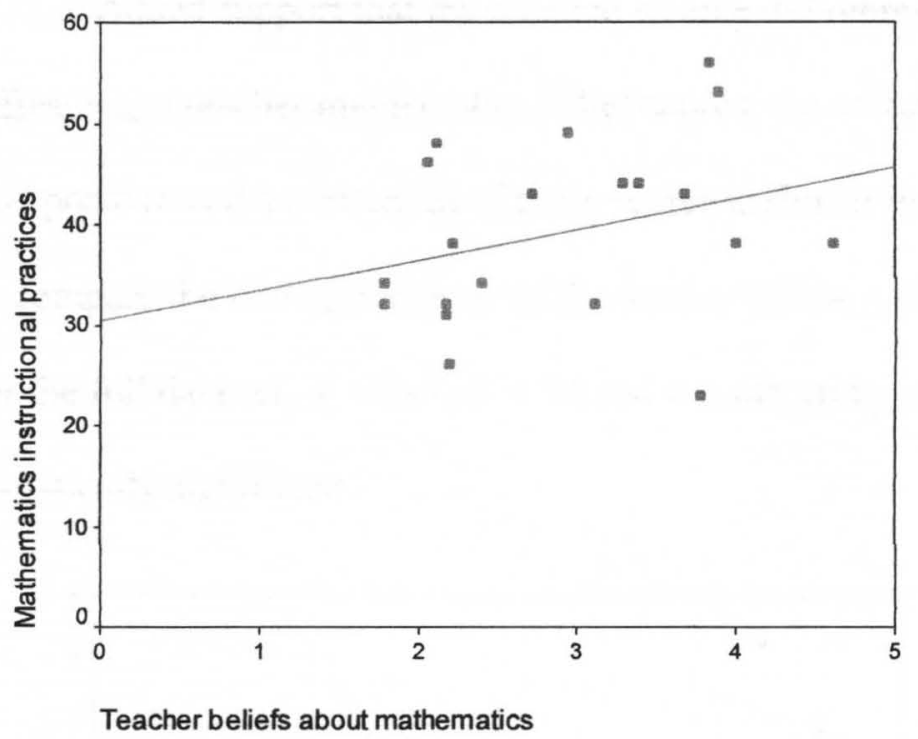

Figure 4. Scatterplot of Teacher Belief Scores and Mathematics Instructional Practices Scores of a Sub Group of Early Childhood Teachers

The correlation between Teacher Efficacy and Mathematics Instructional Practices was $r=.242$, low positive. Figure 5 illustrates the relatively flat regression line.

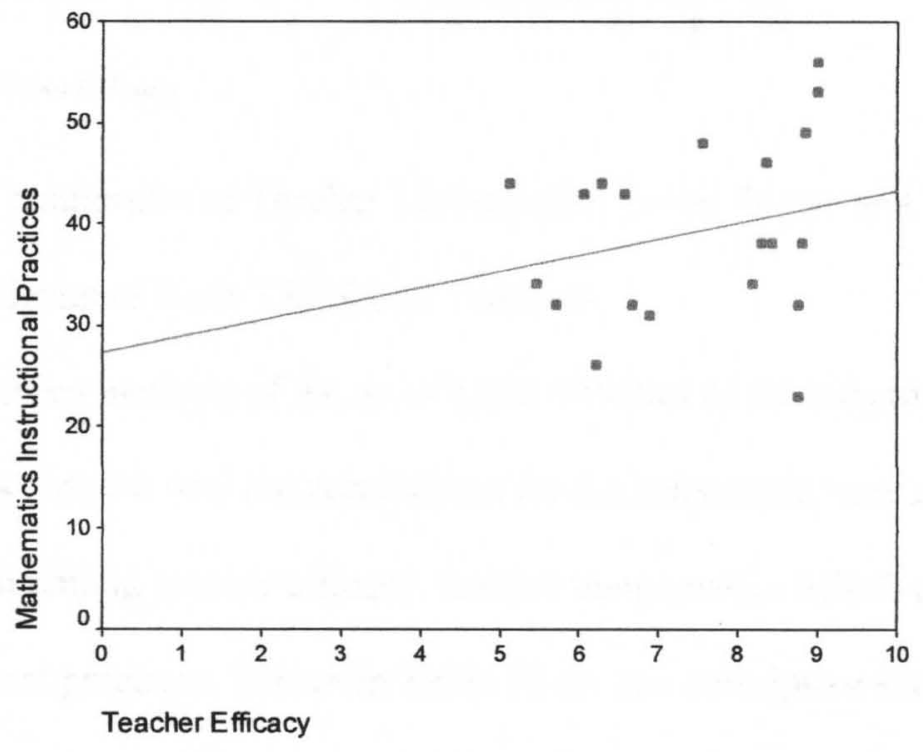

Figure 5. Scatterplot of Teacher Efficacy Scores and Mathematics Instructional Practices Scores of a Sub Group of Early Childhood Teachers 
Added support that the selected sample did represent the extremes of the teacher efficacy and teacher mathematics belief scores, the correlation coefficient was $r=.190$, low positive and a scatterplot of these scores is shown in Figure 6. A z test of proportions to compare the two correlations of the teacher efficacy and teacher mathematics beliefs for the full data set, $r=.247, N=94$ and the sub group, $r=.190, n=20$ was not statistically significant.

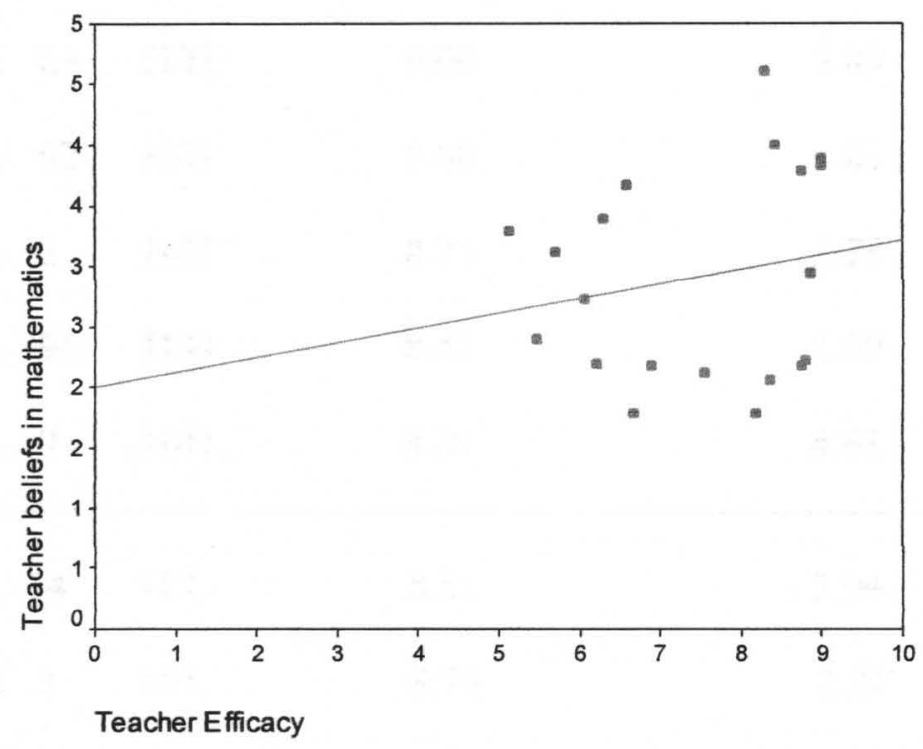

Figure 6. Scatterplot of Teacher Mathematics Belief Scores and Teacher Efficacy Scores of a Sub Group of Early Childhood Teachers

Further analysis of the descriptive statistics of the subgroup was conducted in order to determine why the correlations for the subsample were not statistically significant among teacher efficacy, teacher mathematics beliefs and mathematics instructional practices. Shown in Table 11 are the descriptive statistics for teacher efficacy, teacher mathematics beliefs and mathematics instructional practices for the selected twenty participants in the sample. 


\section{Table 11}

Means for Sub Group Observed in Teacher Efficacy and Beliefs about the importance of Mathematics and Mathematics Instructional Practices

Teacher Efficacy Teacher Beliefs Mathematics Instructional

Participant

Number
Mean Score Mean Score Mean Score

Range (5.13-9.00)* Range (1.78-4.83)* Range (23.00-56.00)*
3.04

39.20
3.89
3.83
3.78
4.00
4.61
1. $63 \mathrm{H} / \mathrm{H}$
9.00
8.75
8.42
8.29
53.00
2. $62 \mathrm{H} / \mathrm{H}$

4.61

8.29

6. $14 \mathrm{H} / \mathrm{L}$

8.85

2.94

49.00

7. $3 \mathrm{H} / \mathrm{L}$

8.79

2.22

38.00

8. $51 \mathrm{H} / \mathrm{L}$

8.75

2.17

32.00

9. $16 \mathrm{H} / \mathrm{L}$

8.35

2.06

46.00

10. $83 \mathrm{H} / \mathrm{L}$

8.17

1.78

34.00

11. $37 \mathrm{~L} / \mathrm{H}$

6.58

3.67

43.00

12. $8 \mathrm{~L} / \mathrm{H}$

6.29

3.39

44.00

13. $76 \mathrm{~L} / \mathrm{H}$

6.05

2.72

43.00

14. $55 \mathrm{~L} / \mathrm{H}$

5.71

3.11

37.00

15. $31 \mathrm{~L} / \mathrm{H}$

6.29

3.39

44.00 
Teacher Efficacy Teacher Beliefs Mathematics Instructional Practices

Participant

Number
Mean Score

Range (5.13-9.00)* 7.44
Mean Score Mean Score

Range (1.78-4.83)* Range (23.00-56.00)*

39.20

\begin{tabular}{|c|c|c|c|c|}
\hline 16. 78 & $\mathrm{~L} / \mathrm{L}$ & 7.54 & 2.12 & 48.00 \\
\hline 17. 24 & $\mathrm{~L} / \mathrm{L}$ & 6.88 & 2.17 & 31.00 \\
\hline 18. 41 & $\mathrm{~L} / \mathrm{L}$ & 6.67 & 1.78 & 32.00 \\
\hline 19. 23 & $\mathrm{~L} / \mathrm{L}$ & 6.21 & 2.19 & 26.00 \\
\hline 20. 12 & $\mathrm{~L} / \mathrm{L}$ & 5.46 & 2.39 & 34.00 \\
\hline
\end{tabular}

* Subscale Range

The category designated High/ High includes teachers who reported high efficacy and high beliefs about the importance of mathematics. All but one of the teachers in the category scored above the subgroup mean of 39.20 on the Mathematics Instructional Practices. Participant \#2 evidenced minimal standards-based mathematics during two observations of instructional practices. The mean score of 23.00 was the lowest for all participants observed. Similarly the category Low/Low included teachers who reported low efficacy and low beliefs about the importance of mathematics. Teachers in the category subgroup scored below the mean 39.20 on mathematics instructional practices with one exception, participant \#78. Participant \#78's score of 48.00 was higher than scores received by other teachers in the category and the third highest in the sub sample. Both of these participants may have had an impact on the correlation coefficient for the sub sample. Pearson correlation coefficients were calculated for the High/High and 
Low/Low categories without participants \#2 and \# 78. A statistically moderate correlation was found for Teacher Beliefs about the importance of Mathematics and Mathematics Instructional Practices with an $r=.660$ and $r^{2}=.435, p<0.05$. The Teacher Efficacy and Mathematics Instructional Practices was strong and statistically significant with an $r=$ .817 and $r^{2}=.667, p<0.05$

In an effort to explore the polar ends of teacher efficacy, teacher beliefs continuum (High/High and Low/Low), the scores with the group of five High/High and five Low/Low participants were examined with independent $t$ - tests. The High/High or Low/Low category was the independent variable and separate $t$-tests used Teacher Efficacy, Teacher Mathematics Beliefs or Mathematics Instructional Practices as the dependent variable. The $t$-test with Teacher Efficacy was statistically significant, $t(2,8)=$ $5.7, p<.05$. The $t$-test with Teacher Mathematics Beliefs was not statistically significant, $t(2,8)=10.3, p>.05$. The $t$-test with Mathematics Instructional Practices was not statistically significant, $t(2,8)=1.056, p<.05$. Pearson correlation coefficients calculated for the High/High and Low/Low groups are in Table 12. 


\section{Table 12}

Correlations Among the High/High and Low/Low groups for Teacher Efficacy, Beliefs About Mathematics and Mathematics Instructional Practices with and without Outliers

$\begin{array}{lllllll}\text { Subscale } & 1 & 2 & 3 & 1 & 2 & 3\end{array}$

$$
\text { Teachers }(n=10) \quad \text { Teachers }(n=8)
$$

1. Teacher beliefs

2. Teacher efficacy (overall) .508

3. Mathematics practices

* Correlation is significant at $p<.05$ level (1-tailed)

Note. Each set of correlations was based on those teachers' classification High/High and Low/ Low

Even though the sample size is small for the number of variables (Steven, 2002), the results provide more information about the High/High and Low/Low groups in the sample. The correlation for teacher mathematics beliefs $r=.812, r^{2}=.659 p<.05$ and $r$ $=.837, r^{2}=.700 p<.05$ supports the hypothesis that beliefs about the importance of mathematics are related to Teacher Efficacy for the groups designated as High/High and Low/Low, both with and without the outlier scores. The correlation of $r=.817, r^{2}=.667$ $p<.05$ between teacher efficacy and mathematics instructional practices for the High/High and Low/Low groups without the outlier scores reflects how the outlier impacted the findings. The analysis of the High/High and Low/Low teachers in the study points out the need for more in-depth research with the mathematics instructional practices instrument. A larger, less extreme sample may provide a more accurate picture of the mathematics instructional practices in the early childhood classroom. Perhaps future research could study the mathematics instructional practices first, which could 
explore the reverse of the conceptual model. By measuring mathematics instructional practices initially and then mapping backwards to determine the teacher characteristics (e.g., efficacy and beliefs) of the teachers that fall into the highest category would help identify the appropriate model for how to change teacher practices.

\section{Summary of research question 2}

The second research question addressed the relationships among the measures of teacher efficacy, teacher mathematics beliefs and observations of the mathematical instructional practices of teachers. The hypothesis was based on Bandura's Social Cognitive theory $(1986,1997)$ that teachers who have confidence in their own teaching abilities and believe that student learning can be influenced by their effective teaching exhibit different types of teaching behaviors. It was hypothesized that the combination of high teacher efficacy and high teacher mathematics beliefs would show alignment with observations of standards-based mathematics instructional practices. The results show that the relation among the measures of Teacher Efficacy and Teacher Mathematics Beliefs and the Mathematics Instructional Practices of teachers are not statistically significant. The results of teacher observations in this study did not show evidence that the teachers with higher efficacy and higher beliefs in mathematics had instructional practices that were more in line with the nationally defined standards than the teachers with lower efficacy and beliefs. A correlation of the High/High and Low/Low groups showed a statistical relation in this small sample between Teacher Efficacy and Teacher Mathematics Beliefs. But, Teacher Efficacy and Teacher Mathematics Beliefs were not related to the Mathematics Instructional Practices. Further examination of the scores from the observation instrument showed that they High/High and Low/Low categories each 
had one outlier with scores 33 points lower or 22 points higher than the other members of the category. Elimination of these two individuals resulted in the expected relation between Teacher Efficacy and Teacher mathematics beliefs and observed Mathematics Instructional Practices.

\section{Observational Data}

Although not part of the original study, field notes on the classroom demographics were collected on a cover sheet along with the Standards Observation Form (Appendix C). The cover sheet provided documentation of the mathematical concepts and context during the two observations of the teachers. Items on the cover sheet were tallied for counts of types of mathematic concepts, types of student groupings and whether the activity was teacher or student chosen. These quasi statistics as referred by Becker (1958) are used when counting recurrent, straightforward behaviors from field notes. Although not appropriate for tests of significance they can be used to add to the description of the classroom events and provide indicators about early childhood teachers' mathematics instructional practices. The data from the cover sheet notes are presented in Table 13. 
Table 13

Classroom Demographic Frequencies

\begin{tabular}{lcc}
\hline Mathematical Classroom Opportunities & $\begin{array}{c}\text { Percentage } \\
\text { Evident }\end{array}$ & $\begin{array}{c}\text { Percentage } \\
\text { Not evident }\end{array}$ \\
\hline Enumeration & $92 \%$ & $8 \%$ \\
Classification & $55 \%$ & $45 \%$ \\
Patterns & $36 \%$ & $64 \%$ \\
Relations & $27 \%$ & $73 \%$ \\
Data & $8 \%$ & $92 \%$ \\
Dynamics & $2 \%$ & $98 \%$ \\
\end{tabular}

Mathematical Context

Evident Not Evident

Group lesson

$35 \%$

$65 \%$

Play activity

$5 \%$

$95 \%$

Game

$5 \%$

$95 \%$

Center activity

$78 \%$

$22 \%$

Teacher Chosen

$93 \%$

$7 \%$

Student Chosen

$10 \%$

$90 \%$

Along with the field notes, the data from the Standards Observation Form (Stonewater, 1993) categories can also provide more information about the characteristics of mathematics classroom practices in an early childhood classroom. The categories are shown in Table 14. 


\section{Table 14}

\section{$\underline{\text { Standards Observation Form Categories }}$}

\begin{tabular}{lcc}
\hline Standards & $\begin{array}{c}\text { Percentage } \\
\text { Evident }\end{array}$ & Percentage \\
& & Not Evident \\
\hline
\end{tabular}

1. Worthwhile Mathematical Tasks

$77 \%$

$23 \%$

2. Teacher's Role in Discourse

$62 \%$

$39 \%$

3. Student Discourse

$27 \%$

$73 \%$

4. Tools for Discourse

$34 \%$

$66 \%$

5. The Learning Environment

$60 \%$

$40 \%$

6. Analysis of Teaching and Learning

$48 \%$

$52 \%$

\section{Summary}

The relation of efficacy and beliefs to teachers' mathematics instructional practices were not documented, perhaps a result of sample selection or instrument sensitivity. The use of quantitative measures did underscore the teachers' efficacy about student engagement, instructional practices, classroom management and the level of importance early childhood teachers placed on mathematics. The observation measurement provided evidence that early childhood teachers' are instructing mathematics. The results of the correlation coefficients show that teacher efficacy and teacher mathematics beliefs are not reliably related to early childhood teachers' mathematics instructional practices as measured by the instruments used in this study. 
These findings do not align with the conceptual model (Figure 1) and the revision of the model will be proposed in Chapter V. The implications of the correlational results and future research agendas will be also be presented. 


\section{CHAPTER V}

\section{DISCUSSION, LIMITATIONS AND IMPLICATIONS}

The beauty and joy of math is all around us. Mathematics is a language that needs to be spoken, a music that needs to be heard, and art that needs to be seen, and a dance that needs to be performed. And like reading it is a precious gift that will last a lifetime.

Rachel R. McAnallen (1999, p. 2)

\section{Discussion of Theories}

The purpose of this study was to explore two key variables that may influence the mathematical teaching practices of the early childhood teacher. By measuring the relation among teacher efficacy, teacher mathematics beliefs and mathematics instructional practices the results were expected to reflect that teacher efficacy and teacher mathematics beliefs both influence mathematics instructional practices. The basis of the hypotheses is grounded in Social Cognitive Theory (Bandura, 1986, 1997) that proposes that behavior, cognition, other personal factors and the environment influence one another in a process of reciprocal determinism. The relations among the determinants as sources of influence do not all have equal strength (Bandura, 1986). The schema used for this analysis was a model with efficacy, beliefs and practices equally weighted. It was hypothesized that teacher efficacy and teacher beliefs influence mathematics instructional practices. In addition, teachers higher in efficacy were expected to rate their beliefs about the importance of mathematics higher than the teachers with lower efficacy. The results 
showed that teachers higher in efficacy did rate the importance of mathematics higher than the teachers with lower efficacy but the correlation was weak.

\section{Discussion of Teacher Efficacy}

The teacher efficacy results revealed that early childhood teachers in this study developed a positive efficacy about their capabilities to motivate and engage students who were less interested in schoolwork, control disruptive behaviors in the classroom and provide alternative explanations for students. The mean scores for all the subscales of teacher efficacy were significantly higher than those reported in previous findings (Woolfolk and Hoy, 2002). The higher means may reflect the fact that the participants were attending a required district professional development session and responded to the questionnaire in more socially acceptable ways. Some teachers' scores in the present study hit the maximum possible score which may have reduced variance. Future research may need to explore if and how the range of responses for teacher efficacy need to be expanded.

The teacher efficacy results in this study also supported Bandura's (1997) theory that teachers who believe that they are competent to teach their students were considered to have strong self-efficacy beliefs. The discussion about the most effective way to measure teacher efficacy and the reference to teachers efficacy as a "messy" construct (Pajares, 1992) may have materialized in the significant differences between the means of this study and past results. Instruments that measure teacher efficacy may only offer a glimpse into a much broader beliefs system. Pajares suggested that items on self-report inventories fall prey to 'it depends' thinking, and responses fail to provide either accurate or useful inferences of behaviors" (p. 327). A self-report inventory for teacher efficacy 
may result in responses that represent what the teacher believes that he/she can do in a broader or more global perspective. Recommendations of additional qualitative data included with the questionnaires could provide more depth of understanding into the possible interactions of teacher efficacy and a teacher's planning and instructional decisions. Overall, the results of this study of teacher efficacy demonstrated that the early childhood teacher participants were optimistic about what they could do in their classrooms to promote student engagement, had a well managed class and used effective instructional strategies.

\section{Discussion of Teacher Mathematics Beliefs}

The results for teacher beliefs provided information about three key domains of the early childhood environment. The purpose of the study was to examine beliefs about early mathematics. Although the teacher beliefs instrument revealed beliefs about social emotional skills and literacy and language, only the teacher beliefs about the importance of mathematics are the focus of this study.

Although the comparison of means within this study for teacher efficacy with means in prior research (Tschannen- Moran and Woolfolk Hoy, 2001) found significant differences, the means for teacher mathematics beliefs were not significantly different from those reported in Kowalski et al., (2001). The design of the teacher efficacy and teacher belief scales may have been a reason for the differences. The teacher efficacy scale was designed to measure efficacy of teachers in varied educational contexts. The teacher belief scale was specifically designed to measure beliefs about mathematics with an early childhood teacher population. The difference between efficacy and belief means suggests that early childhood teachers would have perhaps responded to the efficacy scale 
using a global perspective than was possible on the teacher beliefs scale. The teachers could respond to the efficacy scale without the situational influences of the district guidelines and recommended early childhood mathematics curriculum influencing their responses. Since the efficacy means were at the upper end of the range, the items may not have reflected important differences in teacher efficacy nor could the results reflect teacher efficacy that might pertain to early childhood contexts. The teacher beliefs about mathematics were more similar to those found with other early childhood teacher populations because they were responding to items that were specific to early childhood contexts.

Teacher efficacy was found to be related to teacher mathematics beliefs. The scarcity of studies on teacher beliefs and more specifically those looking at early mathematics made it challenging to find corroborating evidence for these results. The findings of Kagan (1992), Spidell-Rusher, McGrevin and Lambiotte (1992) and Nespor (1985) support findings that teachers' beliefs tend to align with what researchers consider are essential child-centered practices for young children. The characteristics of teachers' beliefs however, are based on the uncertainties of the classroom and the orchestration of children and activities in a highly unpredictable and complex environment. These uncertainties may have been a factor in the weak correlation between teacher efficacy and teacher beliefs about mathematics. Alternatively, it could be that there is a lack of consensus among early childhood teachers that mathematics is important for preschool children. The research on early childhood mathematics recommends research-based curriculum and teaching practices (Baroody, 2000; Bowman et al., 2001; Clements and Sarama, 2003; Fuson, 1992). Identifying a common core of professional thought about 
the pedagogical mathematical content knowledge of early childhood teachers has not been as widely studied (Shulman, 1986; Klein, Starkey and Wakeley, 1999; WilcoxHerzog, 1998). The large range of teacher belief scores from the present study might reflect the lack of consensus on what and how mathematics should be taught in an early childhood classroom. Thus, although teachers are reporting a strong sense of efficacy in their teaching capabilities, their beliefs about mathematics as an important content for preschoolers has not yet become a consensus.

The second hypothesis sought to investigate how the combination of teacher efficacy and teacher mathematics beliefs is aligned with standards-based mathematics instructional practices. A lack of relation was found among teacher efficacy, beliefs and observed classroom practices. The hypothesis was not supported with the results from this sample and the results suggest teacher efficacy and teacher mathematics beliefs were not significantly related to observations of early childhood teachers' mathematics instructional practices. The findings might provide additional support for the possible differences between teachers' sense of efficacy and their beliefs about mathematics in the early childhood education. Earlier research on the relation between teacher beliefs and teacher actions (Charlesworth, Burts, Mosely and Fleege, 1993; Graham, Nash and Paul, 1997; Hyson, Hirsch-Pasek and Rescorla, 1990) found no relation between teacher beliefs and instructional practices related to the teachers' orientation to a basic skills academics or child-centered approach. The lack of relation was linked to the lack of measurement specificity and inclusion of participants with less extreme beliefs. Another correlational study that assessed teacher beliefs and practices (Wilcox-Herzog, 2002) found no relation between teachers' beliefs and practices in the classroom. The Wilcox- 
Herzog study defined lack of measurement specificity as researchers asking teachers about the importance of academic experiences and their beliefs about children's developmental abilities but then using a rating scale to examine the global quality of the child care setting versus the prevalence of academic experiences. The study results indicated the congruence between beliefs and practices may have been stronger if teachers had been asked to comment specifically about the items directly related to the observational measure. This study (Wilcox-Herzog, 2002) found that a cross-section of participants who were exposed to differing amounts of child development and/or early childhood education held different beliefs and result in lack of relation between beliefs and actions. Wilcox-Herzog concluded that measurement specificity, teachers' perceived ability to practice beliefs and depth of training created rifts between beliefs and practices.

Other studies reported that teachers stated mathematics as important but it did not translate into practice. Results from Stipek and Byler study (1997) show that teacher beliefs correlated with instructional practices; however, they concluded that researchers needed to be mindful of how the goals of early childhood educators vary regarding their beliefs about whether basic skills and knowledge are appropriate curriculum content in the pre-k classroom.

\section{Discussion of Mathematics Instructional Practices}

The Standards Observation Form used in this study only published results using only a 5-point Likert scale so limited comparisons can be made between the previous study (Kowalski et. al, 2001) and the present study results with the Standards Observation Form. Research (Cassidy et al., 1995; Charlesworth et al., 1993; Hollingsworth, 1989; Isenberg, 1990; Nespor, 1987; Spodek, 1988; Vartulli, 1999; 
Wilcox-Herzog, 1998) on the relation between teacher beliefs and teacher instructional practices found a lack of relation may be due to a variety of factors. For example teachers' mathematics instructional practices are not only governed by their own values and beliefs, but by external mandates and policies, such as those of a school district, or school administrator that impacts the decisions teachers can make. The influence of external mandates may not be detectable in the observational results with the Standards Observation Form but may need to be pursued using a separate instrument in which personal versus external influences are specifically measured about the early childhood teacher.

The correlations of teacher efficacy and teacher mathematics beliefs in the present study were not surprising. The subgroup of teachers was not representative of the full data set in regards to teacher efficacy and teacher beliefs since they were selected for being on the edges of the quadrant. A more in-depth look at the individual participants in the four quadrants (High/High, High/ Low, Low/High, Low/Low) was conducted to see if a sampling error may have affected the mathematics instructional practice scores. The mathematics instructional practice mean scores were based on two observations when the teacher participant was engaged in mathematics instruction. One subgroup participant rated him/herself as very highly efficacious and having high mathematics beliefs but had the lowest mean score for the whole subgroup in mathematics instructional practices. In addition, one participant who rated him/herself as very low in teacher efficacy and had low mathematics beliefs had a very high mean score in mathematics instructional practices. Pearson correlation coefficients between, teacher efficacy, beliefs and mathematics instructional practices, excluding the two outliers was statistically 
significant. It raises the question of whether early childhood teacher efficacy was measured too broadly. Perhaps the instrument administration was flawed in recognizing teachers' sense of efficacy and would be different in different subject matters. The researcher should have defined the instrumentation as relating to mathematics to narrow the teachers focus prior to completing the teacher efficacy measurement. The research did not instruct the participants to relate their teacher efficacy to mathematics instruction.

The literature for early childhood mathematics instructional practices is primarily focused on developmentally appropriate practices. The National Association of the Education of Young Children (Bredekamp and Copple, 1997) does not endorse a specific curriculum, but the guidelines recommend a challenging, interesting and developmentally age-appropriate curriculum. The caveat is to have a curriculum that is not too narrow focusing only on basic skills, or a curriculum that expects the next-grade mastery of basic skills rather than mathematical knowledge appropriate to the child's developmental stage. It is stated in the NAEYC curriculum content (Bredekamp and Copple, 1997) that young children 3 though 8 should directly participate in solving mathematical problems and in the collection and analysis of data. A joint position statement from the National Association of the Education of Young Children (NAEYC) and the National Council of Teachers of Mathematics (NCTM, 2002) identifies what teachers and key professionals need to do to build the foundation for mathematics learning. They recommend deep and sustained interaction with key mathematical ideas by actively introducing mathematical concepts, methods and language. Teachers should support the children in play or in contexts that provide the opportunity for them to explore and manipulate mathematical ideas. Hyson, the Associate Director for Professional Development at NAEYC, reports 
that excellent pre-kindergarten programs put academics as essential but not as isolated components of the curriculum (2003). Therefore, we could conclude that teachers must believe that they have the ability to successfully implement a challenging, interesting and developmentally age-appropriate curriculum in mathematics. Perhaps the lack of appropriate knowledge and preparation could cause pre-service and inservice teachers to fail to see mathematics as a priority for young children and have less confidence in their ability to teacher mathematics effectively (NAEYC, 2002).

The data from the observations of mathematics instructional practices from the current study presents a contrast to what NAEYC/NCTM guidelines recommend in context and type of mathematics content. For example the recommendations encourage pre-k teachers to use teaching practices that strengthen children's ability to problem-solve and reason as well as represent, communicate and connect mathematical ideas. The Standards Observation Form category frequency results (Table 14) indicate that teachers observed for the current study are presenting worthwhile mathematical tasks in a favorable learning environment. The joint position guidelines recommend that teachers integrate mathematics with other activities as well as other activities with mathematics. It was documented from the classroom demographics results (Table 13) that the mathematics observed was usually found in center related activities, for example puzzles, sand play, songs and movement. Therefore, the activity time, material and support is in a context which children can engage in play, exploration and manipulation of mathematical ideas.

The teacher will actively introduce mathematical concepts, methods and language. The NAEYC/NCTM recommends a range of appropriate experiences and 
teaching strategies. Standard 2- Teacher's Role in Discourse in the Standards Observation Form (Appendix C) has two items 2.1 and 2.3 that relate to teacher's level of questioning. To what extent does the teacher pose questions to engage students' thinking and does the teacher ask students to orally justify with 'why framed' questions? Vygotsky's Social Cultural Theory (1978) also relates to NAEYC and NCTM recommendations by noting that if a child cannot do something alone, he or she may be successful with a more cognitively aware person who facilitates through modeling and assistance (Boehm \& Weinberg, 1997). The researcher recorded field notes about the types of questions that the teachers in the current study used. The most frequently asked questions were: (a) what is more, 7 or 9 ? (b) how many Billy goats are in the water? (c) which has more, the green or the yellow? (d) do you need letters or numbers to count? and (e) can you find the number 10 ? All of these questions are categorized as low-level questions requesting basic recall of information. The students' responses to this type of question were usually one or two words; yes or no, more or less, identification of the number or shape or mimicking a teacher response. The researcher recorded only two instances where students were asked questions requiring them to justify their thinking: (a) why do we measure? (b) did he find a red circle? Both instances of these questions occurred during observations in High/High teachers' classrooms. The types of questions teachers generate influence the level of student discourse. As documented on the Standards Observation Form category frequency results (Table 14) the teacher-student interactions emphasized more teacher talk over student talk. Therefore, the observations of the teachers' mathematics instructional practices indicated that a context was in place for students to talk about the mathematics but teacher talk more often dominated the small group or center activity. 
Another item relating to teacher talk was 2.7 on Standard 2- Teacher's Role in Discourse (Appendix C). It stated that the teacher appropriately sorted out ideas in open discussion. The teachers observed showed minimal evidence of mentally sorting ideas out loud in front of the students in an effort to encourage in their students' similar thinking and reasoning processes. For example, in several of the observed classrooms, a center activity would involve matching numerals to pictorial representations of the numbers. The teacher facilitated the children guessing with encouraging words, but did not model a strategy to help them move beyond a hunt and find strategy of guessing. The selection of the mathematical activities offered could promote student conversation but this was a missed opportunity. Even with the evidence of mathematical tools and materials that do invite students to converse with the teacher and each other, in all cases the teacher monopolized the discourse. Pianta and La Paro (2003) conducted a qualitative study of Early Childcare for the National Institute of Health and Human Development. They characterized the early education environments as socially positive but instructionally passive. The results of this study support the findings in the Pianta and La Paro, 2003 research. The classrooms were busy and well-organized but limited evidence of teacher intentionality to direct and design interactions between children where the teacher purposefully challenges and scaffolds the students' skills. Thus, although NAEYC and NCTM (2002) urge a classroom context that provides exploration of mathematical ideas, and Vygotsky's Social Cultural Theory (1978) proposes facilitation of learning through supportive teacher modeling and assistance, these recommendations were rarely observed in practice. 


\section{Discussion of observational field notes}

The field notes taken during the observations also add to the information about the mathematics instructional practices. Bogdan and Bilken (1992) suggest that the field notes can provide descriptions of the physical setting and accounts of the activities and events. A cover sheet developed by the researcher and independent referee provided a systematic method of collecting data about the classroom demographics. For example the type of mathematical concepts occurring during the visit, the context of the lesson and how students were grouped. Table 13 shows the frequencies. The key findings from the field notes are that early childhood teachers are placing more emphasis on number and enumeration than other concepts combined. Teaching to small groups is more evident than play, games and group lessons combined. Examining the demographic field notes along with the Standards Observation Form category frequencies (Table 14) a snapshot of mathematical practices emerged. The early childhood teacher concentrates on numeracy, but does that along with classification and pattern activities. The teacher uses center and group activities to teach mathematics rather than through games and play. The teacher makes the choice of what center and activity for each child in most cases.

Field notes show mathematical tasks in the High/High classrooms had more evidence of variation and integration into students' daily center activities than the Low/Low classrooms. As noted before the overall mathematics content focused on enumeration and classifications (Table 13). The enumeration and classification activities required more mimicking by the student than organized thinking or problem solving. The tasks in these classrooms were connected to the weekly theme but often the lesson was founded on numeral or shape recognition or a rhyme or song to reinforce enumeration. In 
contrast the High/High classroom tasks went beyond numeral recognition and enumeration. For example, during a one week focus on zoos, one participant constructed a paper model of the leg of a giraffe. The students were using non-standard measurement tools, such as pencils and plastic figures to estimate and find the length of the leg. This prompted the students to explore examples and non-examples. For example the students' thinking moved beyond the objects the teacher had provided and they began to estimate how many large cardboard bricks it would take to cover the model of the giraffe leg. This experience with estimating length prompted a student to ask if he could measure his own height in pencils. The teacher's role in this particular activity moved beyond telling and directing to one of facilitating that led to the student's exchange of thinking and exploration of the concept of estimation. In contrast, students in another classroom were given a numeral card or a dot card and instructed to come find the matching card on the floor without encouraging any communication or discussion from the students. Opportunities to use the language of mathematics were embedded in both the High/ High and Low/Low learning environments, but the mathematics instructional practices differed in how the High/ High teacher capitalized on the event with the level of conversation with the students and how the Low/Low teacher missed the learning opportunity.

The format for the mathematics instruction for both High/High and Low/Low groups consisted of small group tasks such as counting and sorting various objects and shapes into groups and center activities that included puzzles, artwork and blocks. During the course of all the observations, mathematics instruction was rarely supported during play activities (Table 13). In an issue of Parent and Child (2003), Douglas Clements states, "Research shows that half of children's natural play includes some form of 
mathematics" (p. 39). The students in the classrooms in this study were engaged in activities that included mathematical materials for manipulation and visualization like geometric blocks, counters and puzzles. However, the observations of the teaching practices in this study did not show an integration of the mathematical ideas students were exploring in play through guided student-teacher conversation.

In summary, the results of the analysis of the descriptive statistics and field notes for the identified High/High and Low/Low groups would indicate that the most distinct difference in the mathematics instructional practices were the teachers' selection of mathematical content and support of student discourse to strengthen children's ability to represent, communicate and connect mathematical ideas. The mutual interaction model (Bandura, 1997) proposed that efficacy has a powerful influence on behavior when borne out of research when beliefs are measured on specific tasks. The mutual interaction among internal personal factors, teacher efficacy and teacher beliefs did appear in the results of the full sample. The relation was not present in the subgroup among teacher efficacy, teacher mathematics beliefs and mathematics instructional practices.

\section{Summary}

The key findings in this study relate to efficacy, beliefs and instruction. Although the teacher efficacy measurement may not have correlated with mathematics instructional practices it did relate to teacher beliefs. The level of efficacy of the early childhood teachers in this sample confirmed that in assessing their capabilities, skills and knowledge they rate themselves high in instructional strategies, classroom management and student engagement. The early childhood teachers did not rate their belief in the importance of mathematics beliefs as high as they rated their efficacy. The belief rating 
may reflect the lack of consensus among early childhood teachers that mathematics is important for preschool children. No correlation between beliefs and mathematics instructional practices may also suggest the teachers are following district policies in regards to curriculum and that their instruction of mathematics may not be aligned with recent NAEYC and NCTM standards-based recommendations. Finally, no correlation among teacher efficacy, teacher mathematic beliefs and mathematics instructional practices signals a need for more research. Finding out what personal or external factors relate to mathematics instructional practices will guide the development of instructional strategies and knowledge to provide pre-k teachers with the tools to launch their students on a developmentally appropriate pathway to mathematical literacy.

\section{Limitations}

Research as focused on measuring teacher efficacy and teacher beliefs supports that these variables are important in understanding and informing educational practice (Henson, 2002; Pajares, 1992; Soodak and Podell, 1996; Tschannen- Moran and Woolfolk Hoy, 1998; and Vartuli, 1999). There are difficulties in studying these constructs due to definitional problems and availability of valid and reliable instruments for measuring them. For this study, the selection of instruments to measure teacher beliefs in the importance of early mathematics and their mathematics instructional practices was limited to few options. The limited options may reflect that much of the early childhood research has focused on measuring teachers' beliefs and practices related to NAEYC Developmentally Appropriate Practice in Early Childhood Programs (1997). The Teacher Beliefs about the Early Childhood Classroom (Appendix B) and the Standards Observation Form (Appendix C) were used in a limited number of previous 
studies and had few scores against which to compare results of the present study. The Teacher Sense of Efficacy Scale (Appendix A) had scores from early childhood teacher populations and published psychometric properties. The multiple methods approach may also have been confounded by the limited previous research using the teacher beliefs and mathematics instructional practices instruments with early childhood populations. The lack of data about early childhood teacher beliefs about mathematics may reflect their knowledge of the 1997 NAEYC position or their beliefs that it was not developmentally appropriate practice to teach mathematics in isolation with 3 to 6-year olds. The NAEYC and NCTM joint position statement about appropriate mathematics in early childhood (2002) is only recently beginning to appear in the literature and will probably take longer to surface as part of teachers' practice. The knowledge of the 2002 position statement would have informed teachers and early childhood administrators of the importance and appropriateness of mathematics for the pre-k curriculum.

One limitation of the study is that the efficacy and belief instruments required individuals to interpret personal and external factors in responding to these items. Items reflecting multiple influences tend to be poorly measured by Likert-type questionnaires (Henson, 2002). A self-report questionnaire may also be subject to individuals who are unable or unwilling to accurately represent their beliefs, but may respond instead in socially acceptable ways. Since the questionnaires were distributed during a mandatory professional development session, the participants may have been influenced by the setting to provide responses that might have differed if another setting was used. The early childhood teachers may have responded differently because of their awareness of being part of a research project that seemed to be associated with a required district 
meeting. The responses may have been attuned to what the district would want to hear rather than what they truly believed.

The availability of observational instruments to reliably measure mathematics instructional practices in the early childhood classroom is very limited. A specific instrument for measuring the targeted early childhood teacher behaviors that aligns with the mathematics joint position statement released by NAEYC and NCTM has not been developed. The selection of the Standards Observation Form was based on the promising nature of this measure to investigate characteristics of mathematics in the early childhood environment that were aligned with NCTM's principles and standards. The wide range of scores indicates that the Standards Observation Form is sensitive to differences in teaching and instructional practices even though the initial instrument was aimed at $\mathrm{K}-12$ mathematics teaching. What the instrument did not clearly measure was how the teacher determined what resources to use that would guide the development of mathematics skills and concepts that were most significant for the early childhood audience.

This study was conducted in a school district that provides early childhood teachers with a student profile that outlines appropriate skills for three-and four-year olds. For example, on the three year old profile there are three items related to enumeration, rote counts to 5 , rote counts to 10 , touch- counts numbers of objects up to 5 . The content of mathematical tasks and skill reinforcement observed in the course of the observations for the present study suggests that teachers might be using the student profile as a curriculum rather than a guide to assessing skill development. Perhaps with limited pedagogical mathematical knowledge and mathematical experiences the pre-k teacher utilizes the checklist as the suggested curriculum. For example, on the checklist for 3- 
year olds it only requires the child be able to count to five. The pre-k teacher may not scaffold the children beyond this level of understanding even if they are capable of enumerating higher.

Young children do not have to be protected from the study of mathematics or made ready to learn. Children are positively disposed to do and understand mathematics when they first encounter it (Baroody, 1992; Fuson, 1992; Gelman and Gallistel, 1978; Ginsburg, 1983; Greenes, 1999; Huttenlocher, Jordan and Levine, 1994; Mix, Huttenlocher and Levine, 1997; Sophian, 1992; Starkey and Cooper, 1980; and Wynn, 1992). The Standards Observation Form instrument does not easily allow for the identification the teachers' philosophy of mathematics instruction. Information is not gathered about teachers' use of mathematics instruction as skill-based, procedural, rote, identification process or a child-centered activity. Skill-based and child-centered approaches both guide young learners in strengthening number sense, but child-centered activities go beyond this to support the development of thinking, reasoning and an understanding mathematics. Tschannen-Moran, Woolfolk Hoy and Hoy (1998) recommend the development of instruments that could measure factors that facilitate and impede teaching in a particular context. What may be warranted is the use of a structured interview before classroom observations to establish some of the teachers' personal content knowledge in early childhood mathematics instruction before reviewing their practices.

The use of an observational instrument brings possible sources of error. Such sources of error include the teachers' knowledge about what was being observed. The teachers were contacted by phone to solicit their cooperation in two observation sessions 
of their mathematics instructional time. The teacher determined the time and knew that the researcher wanted to see children engaged in mathematics. All of the teachers observed were using district recommended topics, such as Zoo Week, Ocean Week, Garden Week etc. and variations of district-suggested activities that related to the weekly topic. Ten of the 20 teachers had higher scores on their first observation than their second and the opposite was true of the other ten. It did not appear from the scored data that the teachers were changing or modifying activities from the knowledge of being observed. That was an indication that the researcher was observing what actually occurred in their daily routines. Attempts were made to be inconspicuous, but in seven classrooms the researcher was introduced to the children and the children were told of the purpose of the visit. The children were naturally curious and some engaged the researcher in conversation. From past experience of observing teachers, the researcher knew it was important to connect with the teacher and the children to make sure they were comfortable. This is also a suggested step (Boehm and Weinberg, 1997) to use to reduce reactivity in the observation target. The limitations of classroom observations are by far outweighed by the valuable insights researchers can gather about the cognitive processes of teachers and students. In summary, the two observations only provided a snapshot of a portion of mathematics instruction in the early childhood classroom and may or may not represent a typical sequence of events. The district recommended topics could not be changed by the teacher and it appeared that this may have had an influence on the content of mathematics activities occurring in the classroom. Future studies of this nature should include a qualitative component to the observation rating in order to clarify and the role of the teacher in the plan and design of their mathematics activities and centers. 
Three fourths of young children in the United States participate in preschool programs (Barnett and Hustedt, 2003). The No Child Left Behind (USDE, 2002) educational reform act requires highly qualified teachers for all children but pre-k teachers are not included in this legislation. The focus of this study was to explore teacher efficacy and teacher beliefs about mathematics for early childhood students and the relation these may have on the mathematics instructional practices of the early childhood teacher. Given the findings of this investigation, there are several implications for teacher self-efficacy theory, research and teacher education.

\section{Implications}

\section{Conceptual Model}

The lack of statistical significance among teacher efficacy, teacher mathematics beliefs and mathematics instructional practices suggest that the conceptual framework explored in this study needed revision. The model (Figure 1) did not address other factors that may inform mathematics instructional practices in the early childhood classroom. The measures of teacher efficacy and teacher mathematics beliefs accounted for only small amounts of variance in how these constructs relate to each other and in how the constructs relate to teacher practices in the classroom. The revised model (Figure 7) addresses the other factors that may inform mathematical instructional practices. 
Revised Conceptual Model

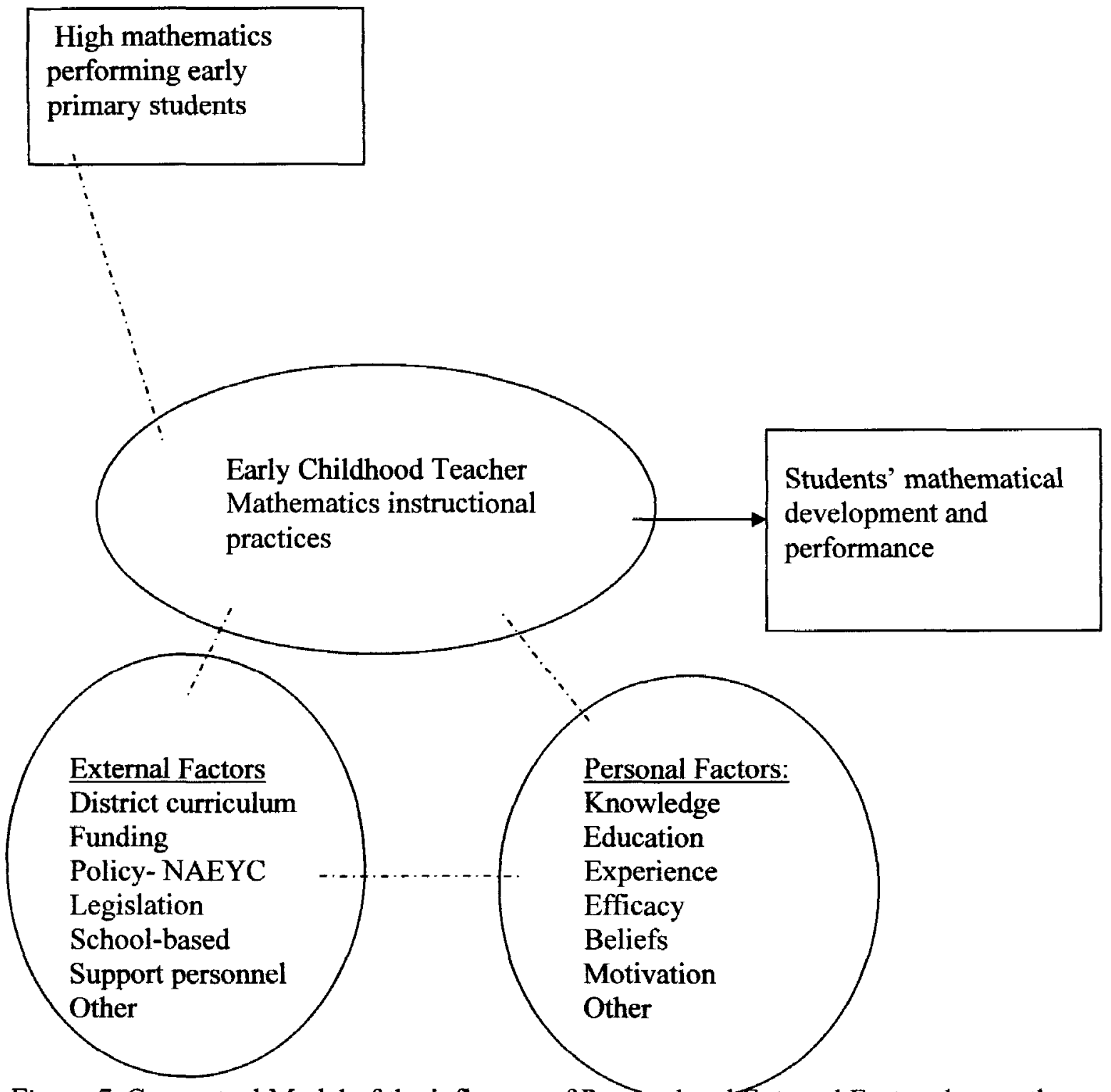

Figure 7. Conceptual Model of the influence of Persomat and External Factors has on the Mathematics Instructional Practices in the Early Childhood Classroom 
The retrospective model suggests that the teachers to be observed would be obtained by identifying students who are high performing in mathematics in early primary. The researcher would identify the pre-k teachers of those students. The research would begin with measuring mathematics instructional practices and then work backward to identify the factors that influenced the teachers' mathematics instructional decisions and teaching. These would include personal factors such as teacher mathematics knowledge, pedagogical knowledge, education, experience, motivation, as well as efficacy and beliefs. Also the study would assess the external factors such as district curriculum, resources and support, funding, policy and legislation that could impact the quality of the instructional experience. The data would be collected through self-report as well observations and interviews with the teachers.

Two strategies for improving the research on efficacy and beliefs were recommended by Pajares (1997). First, researchers should assess the sources and effects of self-efficacy through direct long-term observation rather than rely on self-reports. The use of the teacher efficacy and teacher beliefs quantitative measures provided important information, but these instruments do not have the richness of data, that might come from interviews and observations. An extension of research approaches to teacher efficacy, teacher belief and mathematics instructional practices research might include a study of the sources early childhood teachers draw on to make decisions and judgments about their mathematics instruction. The revised conceptual model encompasses these recommendations and combines the collection of quantitative data and qualitative data for a more comprehensive study of the factors that characterize early childhood mathematics instruction. 
Since a correlation was found between teacher efficacy and teacher mathematics beliefs, but not with mathematics instructional practices, the assumption could be made that teacher efficacy and beliefs do not affect instructional practices. Not finding a relation underscored the need to reflect about the methodological design. Pajares (1992) recommends the increased of the use of experimental techniques in order to manipulate sources and effects. The use of an experimental study would include an experimental and control group and could provide more depth of understanding into the possible interactions of teacher efficacy and beliefs when teachers plan and make instructional decisions. The Vygotskian Social Cultural Theory (1978) espouses that the teachers' pedagogy promotes learning processes that lead to cognitive development. The early childhood teacher's ability to recognize the child's mathematical development is directly related to the teacher's beliefs and effectiveness to perform these behaviors (Carlton, 1999). Teacher efficacy and beliefs can be influenced by meaningful, active interventions (Henson, 2001; Ross, 1994). The use of experimental techniques would tell whether teacher efficacy and teacher beliefs are a cause or a consequence of the adoption of more structured teaching techniques such as those present in the Klein, Starkey and Wakeley, (1999) research studies. An example of an intervention study done by Stipek, Givvin, Salmon and MacGyvers, 1998 provides a model for an experimental technique. The purpose of the Stipek (1998) study was to measure an intervention's effect on teacher practices and student motivation in reform-minded mathematics. The design included one experimental group of teachers $(n=9)$ who received a one week summer mathematics workshop as professional development, collegial support and collaboration through bi- 
weekly evening meetings in implementing the two reform mathematics curriculum units. A control group $(n=7)$ did not receive professional development and used schoolapproved textbooks. The data were collected with videotapes and field notes. The data provided clear and consistent evidence that teachers who experienced the training related to reform-minded mathematics were more consistent in their practices being promoted by reform mathematics experts. The application of this type of intervention design would promote NAEYC and NCTM (2002) recommendation for institutional structures and policies that support teachers' mathematics learning, teamwork and planning.

The early childhood classroom is a complex environment with many interactions among children, adults, materials and tasks. In this study the twenty classroom populations observed included children identified as autistic, Down's Syndrome, language delayed and physically challenged. The researcher was impressed with how the teachers had developed skills in differentiating instruction, managing additional personnel, equipment and paperwork to provide a learning environment for children in their classrooms with special needs. Tschannen-Moran and Woolfolk Hoy (2002) suggest that more research into the sources of efficacy and beliefs would provide knowledge on how to better equip teachers for the complexity of their jobs. The employment of a randomized experimental approach could broaden teacher knowledge about instructional practices that are responsive to the mathematics development of different students, including those with special needs. In turn assessing what relation between efficacy and beliefs support the implementation of the instructional practices that meet the mathematical needs of the pre-k child. Experimental designs could explore how 
professional development opportunities and teacher-based research interventions facilitate change in teachers' thought and practice.

\section{Expanding Teacher Knowledge of the NAEYC/NCTM standards-based position}

The results of this study confirm that early childhood teachers have varying beliefs about what mathematics concepts young children should learn. The early childhood teachers did not rate their belief in the importance of mathematics beliefs as high as they rated their efficacy. The large-scale research of Pianta and LaParo (2003) found that early childhood teachers have a consensus about providing a warm, caring and sensitive social environment for their pre-k population. What is still in question is what academic content about which these teachers can form a consensus. Kowalski et al., (2001) hypothesized that teachers likely select goals that are related to what they believe is important and to what they believe they can accomplish. The national organizations are just beginning to discuss the importance of targeting emergent mathematics in the preschool years. Communicating this crucial information and providing curriculum guidance and professional development to the pre-k teaching population may not be occurring in a systematic, programmatic, long-term way. Reports on educating pre-k children from the National Research Council (Bowman et al., 2001) recommends the critical need for well-prepared teachers who know the "big ideas" in academic domains such as mathematics, literacy, and science, who know about early development, teaching and learning, and who are well prepared to implement challenging yet child-friendly academic content. The change in early childhood teachers' mathematics instructional practices is not likely to result from presenting a national position statement and research. But ultimately research will have to provide more evidence that early childhood teacher 
efficacy and beliefs about mathematics and instructional practices are related to student outcomes (Kagan, 1990). Dialogue among the stakeholders, teachers, teacher educators, parents, and early childhood specialists, needs to move expediently to generate a consensus about how to implement appropriate mathematics educational practices to inform legislative, state and local school district policy makers. The National Research Council (Bowman, 2001) recommended that every teacher of 3- to 5-year olds hold a bachelors degree with specialization in early childhood education. Teacher educators need to provide pre-k pre-service and experienced teachers with the knowledge of teaching and learning mathematics, insights into the children's conception of mathematics, and how the context of the pre-k environment is important to this development (Graham, Nash and Paul, 1997).

\section{Instrumentation}

The level of efficacy of the early childhood teachers in this sample confirmed that in assessing their capabilities, skills and knowledge they rate themselves high in instructional strategies, classroom management and student engagement. The results also indicated the congruence between beliefs and practices may have been stronger if teachers had been asked to comment specifically about the items directly related to the standards-based observational measure. The lack of correlation among efficacy, beliefs and practices is the basis for reflecting on the effectiveness of the instruments and methodology used in this study.

Potential future research in this area of study should include a qualitative component to the self-report data to inquire about the differences in the pre-k teacher philosophies about mathematics in the early childhood curriculum. An interview could 
provide more data about the role of the contextual dynamics, such as school policies, collective efficacy and district mandates have on individual teacher efficacy and beliefs in their own competence, and persistence to teach pre-k children. Measurement instruments are needed that will allow for deeper examinations of personal factors including teacher efficacy and teacher beliefs that are specific to the early childhood context. "More careful and fine-grained assessment of the factors that both facilitate and impede teaching in a particular teaching context is likely to produce more powerful instruments" (Tschannen-Moran et al., 1998. p. 240). More research is necessary with instruments that will define if teacher efficacy and teacher beliefs have any affect on teachers' instructional practices. A better understanding of relation among teacher efficacy, teacher beliefs and mathematics instructional practices will broaden our knowledge about how these factors can improve the teaching of mathematics and affect future student achievement in mathematics.

Supervision of Early Childhood Mathematics practices

The lack of a relation between teacher mathematics beliefs and their mathematics instructional practices may suggest teachers are adhering to district curriculum guidelines regardless of their personal knowledge. This can be both beneficial and detrimental for students. Teacher educators, supervisors and administrators of early childhood teachers need to be current with the latest standards. The practices that the researcher observed were not modeled after the standards-based NAEYC and NCTM (2002) classroom context that provides exploration of mathematical ideas. The observational data (Table $13,14)$ show evidence of classrooms where discourse and decision making are teacherbased and students are not making the choices. Another example is the facilitation of 
learning (Vygotsky, 1978) through supportive teacher modeling and assistance. The teachers provided worthwhile mathematical activities but missed opportunities to scaffold the students thinking and connecting to mathematical concepts. The mathematics concept focus was primarily enumeration. Further research in observing mathematics practices in the pre-k classroom is needed to provide early childhood educators, district resource personnel and principals with a NAEYC/NCTM standards-based framework of what developmentally appropriate mathematics instruction looks like in an early childhood classroom. The observational data of the current study embarked on identifying some of the teacher practices, but the framework should also include what students are doing. Through this documentation of the learning a clearer picture will emerge of the most effective mathematics practices that will maximize developmental growth for pre-k children.

Early childhood teachers are being mandated to promote higher level achievement for all children. The professional knowledge and education of the early childhood teachers in the United States is diverse. Successful reform in the early childhood environment will require profound teacher and learning. Teachers are practicing in an era of mathematics curriculum reform and face pedagogical issues such as implementing new technologies effectively in their instruction. The results of this study reveal the need for refining tools that will help identify effective, appropriate, standards-based early childhood mathematics practices. Research will need to provide evidence to effect change for teachers' mathematics instruction, administrators' assessment and support of early childhood mathematics and district policies and guidelines that are in-line with current research. Most importantly, the student outcome will be mathematical literacy. 


\section{Summary}

The premise of this research study was to provide a process of change if a mismatch between early childhood teachers' efficacy, mathematics beliefs and their mathematics instructional practices was discovered. The implications of the findings suggest a conceptual model that encompasses teacher efficacy, teacher mathematics beliefs along with personal and external factors are also part of the early childhood teachers' mathematics instructional practices. The lack of correlation found among teacher efficacy, teacher mathematics beliefs and instructional practices suggests that an experimental study with an experimental and control group could provide more depth of understanding into the possible interactions of teacher efficacy and beliefs when teachers plan and make instructional decisions. The early childhood teachers in this study had varying beliefs about mathematics in the pre-k classroom. The crucial information about the importance the early development of children's mathematical foundations presented in the NAEYC and NCTM (2002) standards-based recommendations need to communicated in a systematic, programmatic, long-term way. This would include providing curriculum guidance and professional development to the pre- $\mathrm{k}$ teaching population. The observations in this study revealed that the pre-k teachers are adhering to district guidelines that are not in line with the latest standard recommendations. Teacher educators, supervisors and administrators of early childhood teachers need to be current with the latest standards and have tools that will help identify effective, appropriate, standards-based early childhood mathematics practices. Only through evaluation and reflection on practices can teacher educators, supervisors, administrators and early childhood teachers address the diversity of student cognition and have a deeper 
understanding of how children learn mathematics. The research and observations of what early childhood teachers know and believe they are able to has a profound effect on the way they teacher and on ultimately their students mathematical literacy development. 


\section{REFERENCES}

Armor, D., Conroy-Oseguera, P., Cox, M., King, N., McDonnell, L., \& Pascal, A., et al. (1976). Analysis of the school preferred reading programs in selected Los Angeles minority school (Rep. No. R-2007-LAUSD). Santa Monica, CA: RAND. (ERIC Document Reproduction Services No. ED130243)

Arnett, J. (1989). Caregivers in day-care centers: Does training matter? Journal of Applied Developmental Psychology, 10, 541-552.

Ashton, P. T., Buhr, D., \& Crocker, L. (1984). Teachers' sense of efficacy: A selfor norm-referenced construct? Florida Journal of Educational Research, 26(1), 29-41.

Ashton, P.T., \& Webb, R.B. (1986). Making a difference: Teachers sense of efficacy and student achievement. New York: Longman.

Balfanz, R. (1999). Why do we teach young children so little mathematics? Some historical considerations. In J. Copely (Ed.), Mathematics in the early years (p. 3-10). Reston, VA: National Council of Teachers of Mathematics

Ball, D. L. (1988). Knowledge and Reasoning in Mathematical Pedagogy: Examining What Prospective Teachers Bring To Teacher Education. Unpublished doctoral dissertation, Michigan State University. 
Ball, D. L., \& Bass, H. (2000). Interweaving content and pedagogy in teaching and learning to teach: Knowing and using mathematics. In J. Boaler (Ed.), Multiple Perspectives on the teaching and learning of mathematics (pp. 83-104). Westport, CT: Ablex.

Barnett, S. W., \& Hustedt, J. (2003). Preschool: The most important grade. Educational Leadership, 60(7), 54-57.

Bandura, A. (1977). Self efficacy: Toward a unifying theory of behavioral change. Psychological Review, 84, 191-215.

Bandura, A. (1978). The self-system in reciprocal determinism. American Psychologist, 344-358.

Bandura, A. (1982). Self-efficacy mechanism in human agency. Psychological Review, 37, 122-147.

Bandura, A. (1986). Social foundations of thought and action: A social cognitive theory. Englewoods Cliff, NJ: Prentice Hall.

Bandura, A. (1997). Self-efficacy: The exercise of control. New York: W.H. Freeman.

Bandura, A. \& Walters, R.H. (1963). Social learning and personality development. New York: Holt, Rinehart and Winston.

Baroody, A. (1987). Children's mathematical thinking: a developmental framework for pre-school, primary and special education teachers. New York: Teachers College Press.

Baroody, A. (1992). The development of preschoolers' counting skills and principles. In J. Bideaud, C. Meljac, \& J. P. Fischer. (Eds.), Pathways to number: 
Children's developing numerical abilities (pp. 99-323). Hillsboro, NJ: Lawrence Erlbaum.

Baroody, A. (1993). Fostering the mathematical learning of young children. In B. Spodek (Ed.), Handbook of research on the education of young children (pp. 151-175). New York: Macmillan.

Baroody, A. (2000, July). Does mathematics instruction for three- to five-yearolds really make sense? Young Children, 61-67.

Battista, M. (1994, June). Teacher beliefs and the reform movement in mathematics education. Phi Delta Kappan, 75, 462-468.

Beck, L. E., \& Winsler, A. (1995). Scaffolding children's learning. Washington, DC: National Association for the Education of Young Children.

Becker, H. (1958). Problems of proof and inference in participant observation. American Sociological Review, 23, 652-660.

Berman, P., McLaughlin, M., Bass, G., Pauly, E., \& Zellman, G. (1977). Federal programs supporting educational change: Vol. VII. Factors affecting implementation and continuation. (Rep. No. R-1589/7-HEW). Santa Monica, CA: RAND. (ERIC Document Reproduction Service No. ED140 432)

Bideaud, J., Meljac, C., \& Fischer, J.P. (Eds.). (1992). Pathways to numbers; children's developing numerical abilities. Hillsdale, NJ: Erlbaum.

Boehm, A. E., \& Weinberg, R.A. (1997). The classroom observer. New York: Teachers College Press.

Bogdan, R.C. \& Bilken, S.K. (1992). Qualitative research for education ( $2^{\text {nd }}$ ed.). Boston: Allyn and Bacon. 
Bowman, B., Donovan, S., \& Burns, M.S. (Eds.). (2001). Eager to learn. Washington, DC: National Academy Press.

Bredekamp, S., \& Copple, C. (1997). Developmentally appropriate practice in early childhood programs. Washington DC: National Association for the Education of Young Children.

Brouwers, A., \& Tomic, W. (2001). The factorial validity of scores on the teacher interpersonal self-efficacy scale. Educational and Psychological Measurement, 61, 433445 .

Carlton, M. P. (1999). School readiness: The need for a paradigm shift. School Psychology Review, 28, 338-353.

Carnegie Corporation of New York. (2002). What kids need: Today's best ideas for nurturing, teaching, and protecting young children. Boston: Beacon Press.

Cassidy, D.J., Buell, M.J., Pugh-Hoese, S., \& Russel, S. (1995). The effect of education on child care teachers' beliefs and classroom quality: Year one evaluation of the TEACH early childhood Associate degree scholarship. Early Childhood Research Quarterly, 10, 171-183.

Clandinin, D.J., Connelly, M. (1995). Teachers' professional knowledge landscape. New York: Teacher College Press.

Charlesworth, R., Hart, C., Burts, D., Mosely, J., \& Fleege, P. (1993). Measuring the developmental appropriateness of kindergarten teachers' beliefs and practices. Early Childhood Research Quarterly, 8, 255-276. 
Clark, C., \& Peterson, P. (1986). Teachers' thought processes. In M. C. Wittrock (Ed.), Handbook of research on teaching (pp. 255-296). New York: Macmillan Publishing Company.

Clearfield, M., \& Mix, K.S. (1999). Number versus contour length in infants' discrimination of small visual sets. Psychological Science, 10, 408-411.

Clements, D. \& Sarama, J. (2000). Standards for preschoolers. Teaching Children Mathematics, 7, 38-41.

Clements, D., \& Sarama, J. (2003, February/March). Creative pathways to math: How to nurture your child's mathematical mind. Parent and Child, 10, 34-40.

Clements, D., Sarama, J., \& DiBiase, A-M. (2002). NCTM position statement. Teaching Children Mathematics, 9, 24.

Copley, J. (Ed.). (1999). Mathematics in the early years. Reston, VA: National Council of Teachers of Mathematics.

Darling-Hammond, L. (2000). Teacher quality and student achievement: A review of state policy evidence. Retrieved July 7, 2003 from Education Policy Analysis Archives: http://epaa.asu.edu/epaa/v8n1/index.tml

Duttweiler, P. (1984). The internal control index: A newly developed measure of locus of control. Educational and Psychological Measurement, 44, 209-221.

Edwards, D. (1999). Public Factors That Contribute to School Readiness. Early Childhood Research \& Practice I, 2.

Friedman, S., \& Haywood, H.C. (Eds.). (1994). Child care and child development: The NICHD study of early child care. New York: Academy Press. 
Fuson, K. C. (1992). Relationship between counting and cardinality from age 2 to age 8. In J. Bideaud, C. Meljac, \& J. P. Fischer. (Eds.), Pathways to number: Children's developing numerical abilities (pp. 127-149). Hillsboro, NJ: Lawrence Erlbaum.

Gelman, G. \& Gallistel, C.R. (1986). Child's understanding of number. Cambridge, MA: Harvard University Press.

Gibson, S., \& Dembo, M. (1984). Teacher efficacy: A construct validation. Journal of Educational Psychology, 76, 569-582.

Ginsburg, H. P. (Ed.). (1983). The development of mathematical thinking. New York: Academic Press.

Goodwin, W. L., \& Goodwin. L. (1996). Understanding quantitative and qualitative research in early childhood. New York: Teachers College Press.

Graham, T., Nash, C. Paul, K. (1997). Young children's exposure to mathematics: The child care context. Early Childhood Educational Journal, 25, 31-38.

Greenes, C. (1999). Ready to learn: Developing young children's mathematical learning. In J. Copley (Ed.), Mathematics in the Early Years (pp. 39-47). Reston, VA: National Council of Teachers of Mathematics.

Guskey, T. (1987). Teacher efficacy, self concept, and attitudes toward the implementation of mastery learning. (Report No. SP028793). Washington, DC: American Educational Research Association. (ERIC Document Reproduction Services No. ED281838)

Guskey, T., \& Passaro. P. (1994). Teacher efficacy: A study of construct dimensions. American Educational Research Journal, 31, 627-643. 
Harms, T., Clifford, R., \& Cryer, D. (1998). Early childhood environment rating scale-revised edition. New York: Teachers College Press.

Hart, C. H., Burts, D.C., \& Charlesworth, R. (Eds.). (1997). Integrated curriculum and developmentally appropriate practice: Birth to age eight. Albany, NY: State University of New York Press.

Henson, R., Kogan, L., \& Vacha-Haase, T. (2001). A reliability generalization study of the teacher efficacy scale and related instruments. Educational and Psychological Measurement, 61, 404-415.

Henson, R. (2002). From adolescent angst to adulthood: Substantive implications and measurement dilemmas in the development of teacher efficacy research. Educational Psychologist, 37, 137-150.

Hinkle, D., Wiersma, W., \& Jurs, S. (1988). Applied statistics for the behavioral sciences. Boston: Houghton Mifflin Company.

Hofferth, S., Shauman, K., West, J., \& Henke, R. (1998). Characteristics of children's early care and education programs: Data from the 1995 National Household Education Survey. National Institute on Early Childhood Development and Education. Retrieved, from the World Wide Web:

Hollingsworth, S. (1989). Prior beliefs and cognitive change in learning to teach. American Educational Research Journal, 26, 160-189.

Howes, C. (1990). Social play scale, social pretend play scale, and adult play scale: Training tape script. Los Angeles: University of California, Los Angeles Graduate School of Education. 
Howes, C., Smith, E., \& Galinsky, E. (1995). The Florida child care quality improvement study: Interim report families \& work institute. Retrieved November 28, 2002, from http://ecrp.uicu.edu

Hoy, W. K, \& Woolfolk, A.E. (1990). Socialization of student teachers. American Educational Research Journal, 27, 279-300.

Huttenlocher, J., Jordan, N., \& Levine, S.C. (1994). A mental model for early arithmetic. Journal of Educational Psychology: General, 123, 284-296.

Hyson, M. C., Hirsh-Pasek, K., \& Rescorla, L. (1990). The classroom practices inventory: An observation instrument based on NAEYC's guidelines for developmentally appropriate practices for 4-and 5-year-old children. Early Childhood Research Quarterly, $5,475-594$.

Isenberg, J.P., (1990). Reviews of research. Teachers' thinking and beliefs and classroom practices. Childhood Education, 66, 322, 324-327.

Jackson, P. and Haroutunian, S. (Eds.). (1989). From Socrates to software: The teacher as text and text as teacher. Chicago: University of Chicago Press.

Johnson, I.D. (1992). Miami Preble County middle grades mathematics project. Ohio Board of Regents. (Grant no. 2-56)

Kagan, D. (1992). Implications of research on teacher beliefs. Educational Psychologist, 27, 65-90.

Kamii, C. (2000). Young children reinvent arithmetic. $\left(2^{\text {nd }}\right.$ ed.) New York: College Press.

Kentucky Department of Education (2002, March). Preschool program summary report. Retrieved February 6, 2003 from http://www.kde.state.ky.us 
Kessel, C., Epstein, J., \& Keynes, M. (Eds.). (2002). The mathematical education of teachers. Washington DC: Conference Board of Mathematical Sciences.

Klein, A., Starkey, P., \& Wakeley, A. (1998, June). Supporting Pre-Kindergarten Children's Readiness for School Mathematics. Paper presented at the NIECDE Project Director's Meeting, Washington, DC.

Klein, A., Starkey, P., Wakeley, A. (1999, April). Enhancing Pre-Kindergarten Children's Readiness for School Mathematics. Paper presented at the annual meeting of the American Educational Research Association, Montreal, Quebec, Canada.

Kowalski, K., Pretti-Frontczak, K., \& Johnson, L. (2001). Importance of various developmental skills and abilities. Journal of Research in Childhood Education, 16, 5-14. Krajac, V.D., Bloom, P.J., Talan, T., \& Clark, D. (2001). Who's caring for the kids: The status of the early childhood workforce in Illinois. Wheeling. IL: The Center for Early Childhood Leadership, National-Louis University.

Lortie, D.C., (1975). Schoolteacher: A sociological study of teaching. Chicago: University of Chicago Press.

Ma, L. (1999). Knowing and teaching elementary mathematics: Teachers' understanding the fundamental mathematics in China and the United States. Mahwah, New Jersey: Lawrence Erlbaum Associates, Inc.

Marcon, R. (1999). Differential impact of preschool models on development and early learning of inner-city children: A three-cohort study. Developmental Psychology, $35,358-375$. 
Maxwell, K., McWilliam, R.A., Hemmeter, M., Ault, M., \& Schuster, J. (2001). Predictors of developmentally appropriate classroom practices in kindergarten through third grade. Early Childhood Research Quarterly, 16, 431-452.

McAnnallen, R. (1999, November/December). Math, too, is fundamental. Wonderful Ideas, XI, 2.

McDill, E. L., \& Natriello, G. (1999). The sociology of day care. In J. Copley (Ed.), Mathematics in the early years (pp. 21-29). Reston, VA: National Council of Teachers of Mathematics.

Merriam, S. B. (1998). Qualitative Research and Case Study Applications in Education. San Francisco: Jossey-Bass.

Miller, N., \& Dollard, J. (1941). Social Learning and Imitation. New Haven, CT: Yale University Press.

Mix, K., Huttenlocher, J., \& Levine, S. (2002). Quantitative development in infancy and early childhood. New York: Oxford University Press.

Moll, L. (1994). Vygotsky and education: Instructional implications and applications of sociohistorical psychology. New York: Cambridge University Press.

National Association of the Education of Young Children. (1996). NAEYC position statement: Responding to linguistic and cultural diversity- Recommendations for effective early childhood education. Young Children, 51, 4-12.

National Association of Education of Young Children \& National Council of Teachers of Mathematics. (2002, April). Early childhood mathematics: Promoting good beginnings. Retrieved June 18, 2003, from http://www.naeyc.org.resources/position_statements/psmath.htm 
National Center for Family Literacy, (2003, June). Preschool education research highlights. Retrieved July 7, 2003 from http://www.famlit.org

National Council of Teachers of Mathematics. (2000). Principles and standards for school mathematics. Reston, VA: National Council of Teachers of Mathematics.

National Council of Teachers of Mathematics. (1989). Curriculum and evaluation standards for school mathematics. Reston, VA: National Council of Teachers of Mathematics.

National Council of Teachers of Mathematics. (1991). Professional standards for teaching mathematics. Reston, VA: National Council of Teachers of Mathematics.

National Research Council. (2001). Adding it up: Helping children learn mathematics. Washington, DC: National Academy Press.

National Research Council. (1989). Everybody counts: A report to the nation on the future of mathematics education. Washington, DC: National Academy Press.

Nespor, J. (1987). The role of beliefs in the practice of teaching. J. Curriculum Studies, 19, 317-328.

Pajares, M. F. (1992). Teacher's beliefs and educational research: Cleaning up a messy construct. Review of Educational Research, 62, 307-332.

Peterson, P.L., Fennema, E., Carpenter, T.P. and Loef, M. (1989). Teachers pedagogical content beliefs in mathematics. Cognition and Instruction, 6, 1-40.

Piaget, J. (1952). The child's concept of number. London: Routledge \& Kegan Paul LTD.

Pianta, R. C., \& La Paro, K. (2003). Improving early school success. Educational Leadership, 60, 24-29. 
Pontius, R. (1998, April). Correlational analysis and comparison of two selfefficacy instruments. Paper presented at the National Association for Research in Science Teaching, San Diego, CA.

Posner, G. J., \& Gertzog, W.A. (1982). The clinical interview and the measurement of conceptual change. Science Education, 66, 195-209.

Rand Mathematics Study Panel. (2002, September). Mathematical proficiency for all students: Toward a strategic research and development program in mathematics education. Santa Monica, CA: Author.

Richardson, V. (1996). The role of attitudes and beliefs in learning to teach. In J. Sikula, T. Buttery, \& E.Guyton, (Eds.), Handbook of research on teacher education (pp. 102-119). New York: Macmillan Publishing Company.

Riggs, I., \& Enochs, L. (1990). Toward the development of an elementary teacher's science teaching efficacy belief instrument. Science Education, 74, 625-637.

Rose, J. S., \& Medway, F.J. (1981). Measurement of teachers' beliefs in their control over student outcome. Journal of Educational Research, 74, 185-190.

Ross, J. A. (1994). The impact of an inservice to promote cooperative learning on the stability of teacher efficacy. Teaching and Teacher Education, 10, 381-394.

Rotter, J.B. (1966). Generalized expectancies for internal versus external control reinforcement. Psychological Monographs, 80, 1-28.

Sanders, W.L., \& Rivers, J.C. (1996). Cumulative and residual effects of teachers on future students. Knoxville, TN: University of Tennessee Value-Added Research and Assessment Center. 
Shavelson. (1996). Statistical Reasoning for the Behavioral Sciences (3rd ed.). Needham Heights, MA: Allyn \& Bacon.

Sheridan, S., \& Schuster, KM. (2001). Evaluation of Pedagogical Quality in Early Childhood Education: A Cross-National Perspective. Journal of Research in Childhood Education, 16, 109-124.

Shulman, L. S. (1987). Knowledge and teaching: Foundations of the new reform. Harvard Educational Review, 57, 1-21.

Shulman, L. S. (1990). Reconnecting foundations to the substance of teacher education. Retrieved July 7, 2003, from Teachers College Record http://search.epnet.com

Smith, K. (1997). Student teachers' beliefs about developmentally appropriate practice: Pattern, stability, and the influence of locus of control. Early Childhood Research Quarterly, 12, 221-243.

Smith, S. S. (2001). Early childhood mathematics (2nd ed.). Needham Heights, MA: Allyn \& Bacon.

Soodak, L., \& Podell, D. (1996). Teacher efficacy: Toward the understanding of a multi-faceted construct. Teaching and Teacher Education, 12, 401-411.

Sophian, C. (1995). Representation and reasoning in early numerical development: Counting, conservation, and comparisons between sets. Child Development, 66, 559-577.

Spidell Rusher, A., McGrevin, C.Z., \& Lambiotte, J.G., (1992). Belief systems of early childhood teachers and their principals regarding early childhood education. Early Childhood Research Quarterly, 7, 277-296. 
Spodek, B. (1987). Thought processes underlying preschool teachers' classroom decisions. Early Childhood Development and Care, 29, 197-208.

Spodek, B. (1988). Implicit theories of early childhood teachers. Early Childhood Development and Care, 38, 13-31.

Spodek, B. \& Brown, P.C. (1993). Curriculum alternative in early childhood education: A historical perspective. In Spodek, B. (Ed.), Handbook of research on the education of young children. New York: Macmillan

Starkey, P., Spelke, E.S., \& Gelman, R. (1990). Numerical abstraction by human infants. Cognition, 36, 97-127.

Staub, F., \& Stern, E. (2002). The nature of teachers' pedagogical content beliefs matters for student's achievement gains: Quasi-experimental evidence for elementary mathematics. Journal of Educational Psychology, 94, 344-355.

Steffe, L., \& Kieren, T. (1994). Radical constructivism and mathematics education. Journal of Research in Mathematics Education, 25, 711-733.

Stevens, J. P. (2002). Applied multivariate statistics for the social sciences (Vol. 4). Mahwah, NJ: Lawrence Erlbaum Associates.

Stipek, D., \& Byler, P. (1997). Early childhood education teachers: Do they practice what they preach. Early Childhood Research Quarterly, 12, 305-325.

Stipek, D., Givvin, K.B., Salon, J.M., MacGyvers, V.L., (1998). Can a teacher's intervention improve classroom practices and student motivation in mathematics? The Journal of Experimental Education, 66, 319-337.

Stonewater, J. (1993). Standards Observation Instrument. Unpublished manuscript. 
Thompson, A. G. (1984). The relationship of teachers' conceptions of mathematics teaching to instructional practices. Educational Studies in Mathematics, 15, 105-127.

Tschannen-Moran, M., Woolfolk, A., Hoy, W. (1998). Teacher efficacy: Its meaning and measure. Review of Educational Research, 68, 202-248.

Tschannen-Moran, M., Woolfolk Hoy, A. (2001). Teacher efficacy: capturing an elusive construct. Teaching and Teacher Education, 17, 783-805.

Tschannen-Moran, M., Woolfolk Hoy, A. (2002, April). The Influence of Resources and Support on Teachers' Efficacy Beliefs. Paper presented at the annual meeting of the American Educational Research Association, New Orleans, LA.

United States Department of Education, (2002). No child left behind: A desktop reference. Retrieved February 16, 2003, from http://www.ed.gov/offices/OESE

United States Department of Education, (2002). Introduction: No child left behind. Retrieved November 11, 2002, from http:/www.nochildleftbehind.gov United States Department of Education, (1998). Even start: Evidence from the past and a look to the future. Retrieved July 7, 2003 from http://www.ed.gov/pubs/EvenStart/highlights/html

United States Department of Education, National Center for Education Statistics. Children's reading and mathematics achievement in kindergarten and first grade. Washington, DC: NCES

Vacha-Haase, T., Nilsson, J. (1998). Statistical hypothesis testing. Measurement \& Evaluation in Counseling \& Development, 31, 46-58. 
Vartuli, S. (1999). How early childhood teacher beliefs vary across grade level. Early Childhood Research and Practice, 14, 489-514.

Vygotsky, L.S. (1978). Mind in society. Cambridge, MA: Harvard University Press.

Walters, E.G. (1991). The Ohio mathematics/science discovery project. National Science Foundation grant: Washington, DC.

Wheatley, K. (2001). The potential benefits of teacher efficacy doubts for educational reform. Teaching and Teacher Education, 18, 5-22.

Wilcox-Herzog, A. (2002). Is there a link between teachers' beliefs and behaviors? Early Education and Development, 13, 81-106.

Woolfolk, A., Hoy, W. (1990). Prospective Teachers' Sense of Efficacy and Beliefs About Control. Journal of Educational Psychology, 82, 81-91.

Woolfolk, A. (1998). Educational Psychology Seventh Edition.

Wynn, K. (1992). Children's acquisition of the number words and the counting system. Cognitive Psychology, 24, 220-251.

Zeichner, K., Tabachnick, B. Robert. (1981). Are the effects of university teacher education 'washed out' by school experience? Journal of Teacher Education, 32, 7-11. 


\section{Teachers' Sense of Efficacy Scale}

Teacher Beliefs

This questionnaire is designed to help us gain a better understanding of the kinds of situations that create challenges for teachers in their school activities. Please indicate your opinion about each of the statements below. Use the scale below to CIRCLE the number that best identifies HOW MUCH YOU CAN DO?

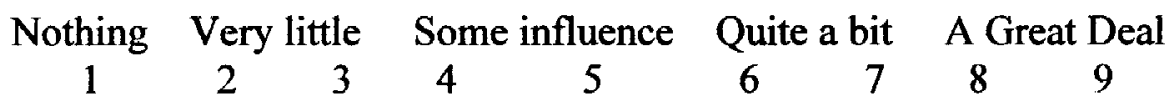

\begin{tabular}{|c|c|c|c|c|c|c|c|c|c|}
\hline $\begin{array}{l}\text { 1. How much can you do to get through to your most difficult } \\
\text { students? }\end{array}$ & $\overline{11}$ & 2 & $\overline{3}$ & 4 & 5 & $\overline{6}$ & 7 & 8 & $\overline{9}$ \\
\hline 2. How much can you do to help students think critically? & 1 & 2 & 3 & 4 & 5 & 6 & 7 & 8 & 9 \\
\hline $\begin{array}{l}\text { 3. How much can you do to control disruptive behavior in the } \\
\text { classroom? }\end{array}$ & 1 & 2 & 3 & 4 & 5 & 6 & 7 & 8 & 9 \\
\hline $\begin{array}{l}\text { 4. How much can you do to motivate students who show low } \\
\text { interest in school work? }\end{array}$ & 1 & 2 & 3 & 4 & 5 & 6 & 7 & 8 & 9 \\
\hline $\begin{array}{l}\text { 5. To what extent can you make your expectations clear about } \\
\text { school behavior? }\end{array}$ & 1 & 2 & 3 & 4 & 5 & 6 & 7 & 8 & 9 \\
\hline $\begin{array}{l}\text { 6. How much can you do to get students to believe they can do } \\
\text { well in school work? }\end{array}$ & 1 & 2 & 3 & 4 & 5 & 6 & 7 & 8 & 9 \\
\hline $\begin{array}{l}\text { 7. How well can you respond to difficult questions from your } \\
\text { students? }\end{array}$ & 1 & 2 & 3 & 4 & 5 & 6 & 7 & 8 & 9 \\
\hline $\begin{array}{l}\text { 8. How well can you establish routines to keep activities running } \\
\text { smoothly? }\end{array}$ & 1 & 2 & 3 & 4 & 5 & 6 & 7 & 8 & 9 \\
\hline 9. How much can you do to help your students' value learning? & 1 & 2 & 3 & 4 & 5 & 6 & 7 & 8 & 9 \\
\hline $\begin{array}{l}\text { 10. How much can you gauge student comprehension of what you } \\
\text { have taught? }\end{array}$ & 1 & 2 & 3 & 4 & 5 & 6 & 7 & 8 & 9 \\
\hline 11. To what extent can you craft good questions for your students? & 1 & 2 & 3 & 4 & 5 & 6 & 7 & 8 & 9 \\
\hline 12. How much can you do to foster student creativity? & 1 & 2 & 3 & 4 & 5 & 6 & 7 & 8 & 9 \\
\hline $\begin{array}{l}\text { 13. How much can you do to get children to follow classroom } \\
\text { rules? }\end{array}$ & 1 & 2 & 3 & 4 & 5 & 6 & 7 & 8 & 9 \\
\hline $\begin{array}{l}\text { 14. How much can you do to improve the understanding of a } \\
\text { student who is failing? }\end{array}$ & 1 & 2 & 3 & 4 & 5 & 6 & 7 & 8 & 9 \\
\hline $\begin{array}{l}\text { 15. How much can you do to calm a student who is disruptive or } \\
\text { noisy? }\end{array}$ & 1 & 2 & 3 & 4 & 5 & 6 & 7 & 8 & 9 \\
\hline $\begin{array}{l}\text { stablish a classroom management system } \\
; ?\end{array}$ & 1 & 2 & 3 & 4 & 5 & 6 & 7 & 8 & 9 \\
\hline $\begin{array}{l}\text { o to adjust your lessons } \\
\text { nts? }\end{array}$ & 1 & 2 & 3 & 4 & 5 & 6 & 7 & 8 & 9 \\
\hline 18. How much can you use a variety of assessment strategies? & 1 & 2 & 3 & 4 & 5 & 6 & 7 & 8 & 9 \\
\hline $\begin{array}{l}\text { 19. How well can you keep a few problem students from ruining } \\
\text { an entire lesson? }\end{array}$ & 1 & 2 & 3 & 4 & 5 & 6 & 7 & 8 & 9 \\
\hline $\begin{array}{l}\text { 20. To what extent can y } \\
\text { example when students a }\end{array}$ & 1 & 2 & 3 & 4 & 5 & 6 & 7 & 8 & 9 \\
\hline 21. How well can you respond to defiant students? & 1 & 2 & 3 & 4 & 5 & 6 & $\overline{7}$ & 8 & 9 \\
\hline $\begin{array}{l}\text { 22. How much can you assist families in helping their children to } \\
\text { do well in school? }\end{array}$ & 1 & 2 & 3 & 4 & 5 & 6 & 7 & 8 & 9 \\
\hline $\begin{array}{l}\text { 23. How well can you implement alternative strategies in your } \\
\text { classroom? }\end{array}$ & 1 & 2 & 3 & 4 & 5 & 6 & 7 & 8 & 9 \\
\hline $\begin{array}{l}\text { 24. How well can you provide appropriate challenges for very } \\
\text { capable students? }\end{array}$ & 1 & 2 & 3 & 4 & 5 & 6 & 7 & 8 & 9 \\
\hline
\end{tabular}


Appendix B

\section{Teacher Beliefs about the Early Childhood Classroom.}

Please carefully read and answer all the questions on this survey by filling in or circling the appropriate answer.

Your Name

Center/School Name

List the title of your position(s) at the center Age Level of

Students

Do you teach (circle all that apply): Head Start Jump Start Pre-K Preschool Special Ed

The number of years you have worked as a lead teacher

Which category best describes the population you work with: Urban Rural Suburban

Give the total number of children on your roster(s) for which you are the lead teacher

Approximately how many of these children have Local Education Agency IEPs

Do you currently use any of the following child assessment instruments in your classroom (circle all that apply): Brigance Galileo Denver MAPS Dial-R Peabody Acuscreen COR Battelle Portage Other

Are you the person who does the child assessments in your classroom? yes no

Circle the highest level of education you completed:

GED High School 1 year college 2 years college 3 years college Bachelors'
Degree

Some graduate school Masters' Degree Other

Circle the highest accreditation you have:

CDA AS in ECE AAS in ECE Bachelors in ECE Certificate in IECE

Have you taken college courses in child development or early education: yes no If yes, approximately how many? 


\section{Teacher Ratings}

Listed below are a number of possible behaviors and skills that young children may or may not display. You may think that some of these behaviors are very important for preschool age children to learn and that some are not important at all. Rate the importance of each of the behaviors or skills listed below using the following rating scale:

$1=$ not at all important $2=$ somewhat important $3=$ important $4=$ very important $5=$ critically important

\section{How important do you think it is for preschoolers to learn to:}

1. Understand the perspectives of other children

2. Help adults with simple tasks, without being asked

3. Share their personal possessions with other children if asked to

4. Say positive things about themselves

5. Identify and talk about their feelings

6. Play cooperatively with another child on a regular basis

7. Follow all adult commands without question

8. Share toys with a group of children on a regular basis

9. Solve conflicts with other children on their own without adult intervention

10. Ask permission before borrowing something

11. Use physical force to defend themselves if bothered by another child

12. Participate in activities when invited

13. Make choices and take responsibility for their own behavior

14. Say why they like something they have done

15. Be a class leader and boss other children around

16. Give sympathy to other children when they have been hurt

17. Learn to accept and express their anger in appropriate ways

18. Criticize other children's work if they don't like it

$\begin{array}{lllll}1 & 2 & 3 & 4 & 5 \\ 1 & 2 & 3 & 4 & 5 \\ 1 & 2 & 3 & 4 & 5 \\ 1 & 2 & 3 & 4 & 5 \\ 1 & 2 & 3 & 4 & 5 \\ 1 & 2 & 3 & 4 & 5 \\ 1 & 2 & 3 & 4 & 5 \\ 1 & 2 & 3 & 4 & 5 \\ 1 & 2 & 3 & 4 & 5 \\ 1 & 2 & 3 & 4 & 5 \\ 1 & 2 & 3 & 4 & 5 \\ 1 & 2 & 3 & 4 & 5\end{array}$

$\begin{array}{lllll}1 & 2 & 3 & 4 & 5\end{array}$

$\begin{array}{lllll}1 & 2 & 3 & 4 & 5\end{array}$

$\begin{array}{lllll}1 & 2 & 3 & 4 & 5\end{array}$

$\begin{array}{lllll}1 & 2 & 3 & 4 & 5\end{array}$

$\begin{array}{lllll}1 & 2 & 3 & 4 & 5\end{array}$

$\begin{array}{lllll}1 & 2 & 3 & 4 & 5\end{array}$

Write the numbers of two most important items listed above in the blank spaces provided: 


\section{Teacher Ratings Continued}

Rate the importance of each of the behaviors or skills listed below using the following scale:

$1=$ not at all important $2=$ somewhat important $3=$ important $4=$ very important $5=$ critically important

\section{How important do you think it is for preschoolers to learn to:}

19. Listen attentively to books that teachers read to the class

20. Use compound sentences

21. Talk louder than adults and other children so they can have their say

22. Retell a familiar story

23. Rhyme one spoken word with another (e.g., $\log$, dog, frog)

24. Write a $\log$, list, or story with some letters in it

25. Use language to tease other children in order to make their friends laugh

26. Recognize where sentences begin and end

27. Identify some of the letters of the alphabet, especially those from their own names

28. Predict that a story character who is hungry will seek food

29. Spell their names backward

30. Introduce a friend to another person

31. Chose books to read on their own by leafing through the pages and looking at the pictures

32. Read a printed label or sign on a familiar object

33. Tune out other children and adults when they don't want to listen

34. Tell a chronological story from beginning, to middle, to end, without assistance

35. Call other children bad names in order to defend themselves

36. Dictate a story for an adult to write down

$\begin{array}{lllll}1 & 2 & 3 & 4 & 5\end{array}$

$\begin{array}{lllll}1 & 2 & 3 & 4 & 5\end{array}$

$\begin{array}{lllll}1 & 2 & 3 & 4 & 5\end{array}$

$\begin{array}{lllll}1 & 2 & 3 & 4 & 5\end{array}$

$\begin{array}{lllll}1 & 2 & 3 & 4 & 5\end{array}$

$\begin{array}{lllll}1 & 2 & 3 & 4 & 5\end{array}$

$\begin{array}{lllll}1 & 2 & 3 & 4 & 5\end{array}$

$\begin{array}{lllll}1 & 2 & 3 & 4 & 5\end{array}$

$\begin{array}{lllll}1 & 2 & 3 & 4 & 5\end{array}$

$\begin{array}{lllll}1 & 2 & 3 & 4 & 5\end{array}$

$\begin{array}{lllll}1 & 2 & 3 & 4 & 5\end{array}$

$\begin{array}{lllll}1 & 2 & 3 & 4 & 5\end{array}$

$\begin{array}{lllll}1 & 2 & 3 & 4 & 5\end{array}$

$\begin{array}{lllll}1 & 2 & 3 & 4 & 5\end{array}$

$\begin{array}{lllll}1 & 2 & 3 & 4 & 5\end{array}$

$\begin{array}{lllll}1 & 2 & 3 & 4 & 5\end{array}$

$\begin{array}{lllll}1 & 2 & 3 & 4 & 5\end{array}$

$\begin{array}{lllll}1 & 2 & 3 & 4 & 5\end{array}$

Write the numbers of two most important items listed above in the blank spaces provided: 


\section{Appendix B}

\section{Teacher Ratings Continued}

Rate the importance of each of the behaviors or skills listed below using the following scale:

$1=$ not at all important $2=$ somewhat important $3=$ important $4=$ very important $5=$ critically important

\section{How important do you think it is for preschoolers to learn to:}

37. Sort objects into different groups by size, shape and color

38. Count by threes up to 99

39. Performs simple addition of two small groups by combining the groups and counting all the objects

40. Indicate how many objects are left after taking one from a small group

41. Identify and talk about patterns in the environment

42. Divide a group of objects in half

43. Tell time to the hour using a clock with roman numerals(e.g., I, II, III, IV)

44. Refer to familiar shapes (e.g., circle, square, triangle) by name

45. Explore part to whole relationships by fitting together simple puzzles

46. Arrange objects in order by size

47. Spell number words (e.g., one, two, three, four, etc.)

48. Identify a morning, afternoon, or evening activity

49. Compare the number of objects in two groups

50. Count forward from a number 1 to find out how many there are in a group

51. Count combinations of coins (e.g, pennies, nickels, dimes, quarters, etc.)

52. Put numerals in order to indicate 10 or less objects

53. Understand the concept of voting (e.g., the most votes wins)

54. Cut a pie into seven equal pieces

$\begin{array}{lllll}1 & 2 & 3 & 4 & 5 \\ 1 & 2 & 3 & 4 & 5 \\ 1 & 2 & 3 & 4 & 5\end{array}$

$\begin{array}{lllll}1 & 2 & 3 & 4 & 5\end{array}$

$\begin{array}{lllll}1 & 2 & 3 & 4 & 5\end{array}$

$\begin{array}{lllll}1 & 2 & 3 & 4 & 5\end{array}$

$\begin{array}{lllll}1 & 2 & 3 & 4 & 5\end{array}$

$\begin{array}{lllll}1 & 2 & 3 & 4 & 5\end{array}$

$\begin{array}{lllll}1 & 2 & 3 & 4 & 5\end{array}$

$\begin{array}{lllll}1 & 2 & 3 & 4 & 5\end{array}$

$\begin{array}{lllll}1 & 2 & 3 & 4 & 5\end{array}$

$\begin{array}{lllll}1 & 2 & 3 & 4 & 5\end{array}$

$\begin{array}{lllll}1 & 2 & 3 & 4 & 5\end{array}$

$\begin{array}{lllll}1 & 2 & 3 & 4 & 5\end{array}$

$\begin{array}{lllll}1 & 2 & 3 & 4 & 5\end{array}$

$\begin{array}{lllll}1 & 2 & 3 & 4 & 5\end{array}$

$\begin{array}{lllll}1 & 2 & 3 & 4 & 5\end{array}$

$\begin{array}{lllll}1 & 2 & 3 & 4 & 5\end{array}$

Write the numbers of two most important items listed above in the blank spaces provided: 


\section{Program Site}

umber \& age of children

Teacher/s

Paraprofessionals

Parents Nol.

tart Time of visit

End Time of visit

\section{bservable Mathematical Classroom Opportunities}

- Classification- putting things in groups /sorting

- Relations- magnitude comparisons

- Enumeration- Making numerical judgments or quantifying

- Dynamics- exploring the process of change or transformation

- Patterns and shapes- predicting or creating patterns

- Other

\section{Bontext of Mathematical Classroom Opportunity}

- Large Group

- Small group- 4 of fewer children

- Individual
Central Integrated

Teacher responsible Child resp.

Teacher present No Yes

\section{Context of Interaction and mathematical discourse}

- Group lesson

- Play activity

- Game

- Center activity
Central Integrated

Teacher chosen Child chosen

Teacher present No Yes Duration

Teacher talk Student talk $\%$ time

\section{Checklist:}

- Mathematical language in songs, verse, conversation, literature, movement

- Mathematical symbols: numbers, relations $<>=$, operations $+-X$

\section{Observable Mathematical tools: Circle}

calculators, counters, unfix cubes, money, abacus, number chart, calendar, number line, base-ten blocks, computer/math software, magnetic numbers, mathematics on :bulletin boards, walls, blackboard

balance scale, spring scale, Judy clocks, rulers, meter/yard sticks, geoboards, stopwatch, thermometer, grid paper, blackboard, worksheets

blocks, geometric shapes games with mathematical concepts, math focused literature , sand, water, plants, pegboards, puzzles 


\section{STANDARDS OBSERVATION FORM}

c Dr. Jerry K. Stonewater

Miami University, Oxford, OH 45056

\section{STANDARD 1 - WORTHWHILE MATHEMATICAL TASKS}

Were the tasks likely to promote the development of students' understanding of concepts/procedures in a way to enhance problem solving, reasoning, and mathematical communication or were they routine and algorithmic tasks?

\section{CRITERIA}

1.1 Promote student understanding; foster reasoning and communication.

01

1.2 Task based on sound and significant mathematical concepts.

01

1.3 Tasks convey "doing" mathematics.

01

1.4 Skill developed in context of problem solving/reasoning.

01

1.5 Based on information about students, especially how they learn math.

01

1.6 Considers student prerequisite knowledge.

01

\section{STANDARD 2 - TEACHER'S ROLE IN DISCOURSE}

Was the teacher discourse primarily teacher-centered or did the teacher establish an environment in which the students reasoned and thought about mathematics in a collaborative atmosphere?

\section{CRITERIA}

2.1. Teacher posed questions and tasks to engage students' thinking.

01

2.2 Teacher listened carefully.

01

2.3. Teacher asked students to justify ideas orally and (in writing) "why?"

01

2.4. Teacher intervened with students appropriately.

01

2.5. Teacher monitored student participation in discussions.

01

2.6 Student ideas were translated into mathematical language (or notation).

01

2.7 Teacher appropriately sorted out ideas in open discussion to decide which to pursue.

01

2.8 Student ideas were respected in the environment created.

01

2.9 Teacher created an environment in which mathematical reasoning and thinking were the norm.

01

2.10 Teacher effectively guided and encouraged student participation in discussions.

01 


\section{STANDARD 3 - STUDENT DISCOURSE}

Do students engage in making conjectures, proposing approaches and solutions, and arguing about the validity of claims? Do they speak to one another and attempt to make sense out of the mathematical ideas?

\section{CRITERIA}

3.1 Students listened to, responded to, and questioned the teacher and one another.

3.2 Students used a variety of tools to reason, make connections, solve problems and communicate.

01

3.3 Students initiated problems and questions, make conjectures, and present solutions.

01

3.4 Students explored examples and non-examples to explore conjectures.

01

3.5 Students tried to validate arguments and relied on mathematical evidence and argument to determine validity.

01

\section{STANDARD 4 - TOOLS FOR DISCOURSE}

Are the means to mathematical communication and approaches to mathematical reasoning broad and varied? Are students encouraged to use a variety of means?

\section{CRITERIA}

4.1 Computers, calculators, other technology.

4.2 Concrete materials as models.

4.3 Pictures, diagrams, tables, graphs.

4.4 Invented and conventional terms and symbols.

4.5 Metaphors, analogy and stories.

4.6 (Written) Oral hypotheses, explanations and arguments.

4.7 Oral presentations and dramatizations.
01

D 1

01

01

01

01

01

\section{STANDARD 5 - THE LEARNING ENVIRONMENT}

Do you observe genuine respect for others' ideas, a valuing of reason and sense-making, pacing and timing that allow students to think, and a forging of a social and intellectual community? Are students encouraged to think of themselves as successful mathematical thinkers?

\section{CRITERIA}

5.1 Necessary time provided and structured so students could explore and grapple with significant ideas and problems.

01

5.2 Context provided that encouraged the development of mathematical skill and proficiency.

01

5.3 Students' ideas, ways of thinking and dispositions were respected.

01

5.4 Students expected to work individually and collaboratively to make sense of mathematics. 
5.5 Students encouraged to take intellectual risks by raising questions and formulating conjectures.

01

\section{STANDARD 6 - ANALYSIS OF TEACHING AND LEARNING}

Does the teacher monitor students' learning on an ongoing basis to assess and adjust his or her teaching?

\section{CRITERIA}

6.1 Teacher observed, listened to, and gathered information about students to assess their learning.

01

6.2 Teacher examined effects of tasks, discourse, and environment on students' mathematical knowledge, skill, disposition.

01

6.3 Teacher ensured every student was learning significant math and developing positive disposition.

01

6.4 Teacher challenged and extended student ideas .

01

6.5 Teacher described and commented on student learning to students, parents, etc.

01

Suggested key

0 no evidence in the observational time

1 evidence during the observational time

-9 no answer or skipped item 


\section{CURRICULUM VITAE}

NAME: $\quad$ Elizabeth Todd Brown

ADDRESS: 522 Evergreen Place Court

Louisville, KY 40223

DOB: $\quad$ Rochester, Minnesota- June 6, 1948

EDUCATION

\& TRAINING:
B.S., Elementary Education with concentration in language arts Drake University 1966-1970

M.S., Elementary Education with concentration in literacy University of Louisville 1991-1995

Ph.D., Curriculum and Instruction University of Louisville 2000-2003

AWARDS: $\quad$ 2000/2001/2002 William Samuels Fellowship Award 1999 Fulbright Memorial Fund Teacher Program, alternate 1998 ExCEL (Excellence in Classroom and Educational Leadership) 1998 Golden Apple Achiever Award, Ashland, Inc.

1998 Helen Cunningham Educator Award for Excellence in Teaching Mathematics, GLCTM

1998 Presidential Award For Excellence in Teaching Mathematics and Science

\section{PROFESSIONAL SOCIETIES:}

American Educational Research Association- member

Association of Math Teacher Educators- member

Avenues to Certification for the Teaching Program- University of Louisville, 1992-1994

Board member

Center for the Advancement of the Teaching Profession- University of Louisville 1995-1999

Board member

Chair of Extended Sessions, NCTM Regional Conference, 1998

Delta Kappa Gamma- Xi Chapter- member 
Greater Louisville Council of Teachers of Math - member

Jefferson County Teachers Association -member, 1991-2000

National Council of Teachers of Mathematics - member

Site Based Decision Making Council- Wheeler Elementary School, 1992-1995 1997-1999

Greater Louisville Council of Teachers of Math - member

PUBLICATIONS:

\section{BOOKS}

Brown, E. Todd, Allen, C., Allen, L.,\& Karp, K. (1997) Feisty Females: Inspiring Girls

to Think Mathematically. Portsmouth, NH: Heinemann Books

\section{REFEREED JOURNALS}

Brown, E. Todd, Karp, K., Petrosko, J., Jones, J., Beswick, G., Howe, C., Zwanzig, K., (2002) Crutch of Catalyst: Teachers' Beliefs and Practices Regarding Calculator Use in Mathematics Instruction, Journal of Research in Mathematics Education, manuscript in process

Karp, K., Allen, C., Allen, L., \& Brown, E. T. (2002) Feisty females: Using children's literature with strong female characters to create mathematical lessons. Forthcoming in Theissen, D. (Ed.) Readings on Children's Literature in NCTM.

\section{PEER REVIEWED ARTICLES}

Brown, E. Todd, Karp, K. (2001) Geo Dolls, Traveling in a Mathematical World, Teaching Children Mathematics , 132-138, November.

Brown, E. Todd, Thomas, J. (1999) Expecting the Best, Producing Success, Peabody Journal of Education Vol.74, 224-235, Mahwah, NJ: Lawrence Erlbaum Associates, Publishers

Brown, E. (1998) How to make mathematics meaningful, Kentucky Teacher, P. 9, October.

Allen, C. Allen, L., Brown, E.T. \& Karp, K. (1998) Feisty Females: Using Children's Literature with Strong Female Characters to Create Mathematics Lessons. Teaching Children Mathematics, 88-94, October.

\section{NATIONAL MEETING PRESENTATIONS:}

Peer Reviewed

Pathways to Mathematical Knowledge for Preschool Children. Presentation with (with K. Karp and V. Molfese) at the American Educational Research Association, April 2003, Chicago, IL

Spreadsheets in Kindergarten, Why Not? Presentation (with L. Thomas) at the Annual Conference of the Teachers of Mathematics, April 2002, Las Vegas, NV 
Pushing buttons or Pushing the envelope. Presentation (with K. Karp, J. Jones, G. Beswick) National Council of Supervisors of Mathematics, April 2002, Las Vegas, NV

Crutch or Catalyst: Teachers Beliefs and Practices Regarding Calculator Use in Mathematics Instruction, Paper presented (with K. Karp, J. Jones, G. Beswick) American Educational Research Association, April 2002, New Orleans, LA

Exploring Numbers and Stories with the Emerging Mathematician. Presentation given (with K. Karp) at the Annual Conference of the National Council of the Teachers of Mathematics, April 2001, Orlando, Fl

The Hardy Girls Teach Math. Presentation given at the Annual Conference of the National Council of Teachers of Mathematics, April 2000, Chicago, IL

Feisty Females: Integrating Mathematics with Literature with Female Characters. Presentation given at the Regional Conference of the National Council of Teachers of Mathematics, October 1999, Pittsburgh, PA

Feisty Females: Integrating Mathematics with Literature with Female Characters. Presentation given (with K.Karp, L. Allen) at the Annual Conference of the National Council of Teachers of Mathematics, April 1998, Washington, D.C.

Feisty Females: Integrating Mathematics with Literature with Female Characters. Presentation given (with K.Karp) at the Regional Conference of the National Council of Teachers of Mathematics, January 1998, St. Louis, Missouri

We Pulled Together: An Interpersonal, Problem Solving Approach to Bring the Internet into the Classroom. Presentation with (C. Billows, B. Firquin, C. Rainey, A. Vogt) at the Kentucky Education Technology Conference, March, 1998, Louisville, KY

\section{INVITED PRESENTATIONS}

Mathematical Proficiency for All Students: Understanding the Mathematics We Teach: Middletown Elementary, Jefferson County Public School, May 2002

Patterns, Stories and Number Sense: St. Lukes' Preschool Parent Orientation, October, 2002

Patterns, Stories and Number Sense: Jefferson County Public Schools, Jump Start, January, 2002, Louisville, KY

Developing Mathematies Literacy and Language in Young Children: 
Jefferson County Public Schools, First Learnings Institiute, June, 2001, Louisville, KY

Assessment: University of Louisville, guest speaker for Dr. Chuck Thompson, September, 2000, Louisville, KY

Early Childhood Mathematics: JCPS Jump Start/Head Start, November, 2000, Louisville, KY

Geo Dolls: University of Louisville, guest speaker for Dr. Karen Karp, March 1999, Louisville, KY

Feisty Females: Keynote given (with Dr. K. Karp) at the lowa Council of Mathematics Annual Conference, February 1998, Des Moines, Iowa

Hands On, Minds On, Hearts On: Diversifying Instruction. OVEC/PRISM Summer Institute for Mathematics, Science and Technology, June, 1997 Oldham County, KY

Math Talk: Incorporating Literature with NCTM Standards. Wheeler Elementary Retreat, Jefferson County Public Schools, 1996, Louisville, KY

Kentucky Math Portfolio Scoring: Jefferson County Public Schools, Gheens Professional Development Center, 1994, Louisville, KY 